\title{
A RAPIDLY-DISSOLVING SILICA-SILVER BIOACTIVE GLASS FOR CARIOSTATIC APPLICATIONS
}

\author{
by \\ Saad Arshad, B.Eng (Ryerson University, 2014) \\ A thesis \\ presented to Ryerson University \\ in partial fulfillment of the requirements for the degree of \\ Master of Applied Science \\ in the program of \\ Mechanical and Industrial Engineering
}

Toronto, Ontario, Canada, 2017

(C) Saad Arshad, 2017 
A Rapidly-Dissolving Silica-Silver Bioactive Glass For Cariostatic Applications, Saad Arshad, MASc, Ryerson University, 2017

\section{Declaration}

\section{AUTHOR'S DECLARATION FOR ELECTRONIC SUBMISSION OF A THESIS}

I hereby declare that I am the sole author of this thesis. This is a true copy of the thesis, including any required final revisions, as accepted by my examiners.

I authorize Ryerson University to lend this thesis to other institutions or individuals for the purpose of scholarly research.

I further authorize Ryerson University to reproduce this thesis by photocopying or by other means, in total or in part, at the request of other institutions or individuals for the purpose of scholarly research.

I understand that my thesis may be made electronically available to the public 
A Rapidly-Dissolving Silica-Silver Bioactive Glass For Cariostatic Applications, Saad Arshad, MASc, Ryerson University, 2017

\section{Abstract}

In this study, bioactive glasses were designed for the purposes of reducing the incidence of dental caries and lesion formation by supplying the teeth with therapeutic ions which may support remineralization and provide an antibacterial effect against oral cavity bacteria. Three glasses were synthesised through the melt quench method: Si-Control $\left(\mathrm{SiO}_{2}-\mathrm{CaO}-\mathrm{P}_{2} \mathrm{O}_{5}-\mathrm{Na}{ }_{2} \mathrm{O}\right)$, $\mathrm{Si}-02$ and $\mathrm{Si}-05$, where $0.2 \%$ and $0.5 \% \mathrm{Ag}_{2} \mathrm{O}$ were substituted, respectively, for $\mathrm{SiO}_{2}$ in the control glass. The glasses were then ground, characterized and dissolved in tris buffer solution $(\mathrm{pH}=7.30)$ for 6,12 and 24 hours, with the $\mathrm{pH}$ rise of the solution being recorded (7.48 for SiControl, and 7.66 for both $\mathrm{Si}-02$ and $\mathrm{Si}-05$ after 24 hours) and the ions that were released into the tris buffer solution quantified. Samples of each glass were subsequently embedded into nonfluoridated toothpaste and samples of the paste were used to brush resin-mounted lamb molars after a $1.0 \mathrm{M} \mathrm{HCl}$ overnight demineralization challenge. Knoop microhardness measurements were recorded before and after brushing to determine the presence of remineralization on the surface of the teeth (Percent Surface Hardness Loss of 37\%, 35\% and 34\% for Si-Control, Si-02 and $\mathrm{Si}-05$ respectively after 24 hours). Four oral cavity bacterial strains were isolated through swabs of the inner cheek, gums and teeth surfaces of three volunteers, and placed on agar discs. $0.5 \mathrm{~g}$ of each glass were placed onto the discs and the resultant inhibition zones were measured after 6, 12 and 24 hours. Si-05 consistently performed better than Si-02 on all strains and timeframes, while Si-Control exhibited no antibacterial effect at any time point. 
A Rapidly-Dissolving Silica-Silver Bioactive Glass For Cariostatic Applications, Saad Arshad, MASc, Ryerson University, 2017

\section{Acknowledgements}

I would like to thank Dr. Mark Towler for his invaluable insight and help during this research project. His door was always open whenever I needed guidance and I am very grateful for him affording me the opportunity to pursue this project. His support and endorsement means the world to me.

I would also like to thank the entire CMD group, their assistance and knowledge was always appreciated. A very special thank you to my deskmate, Omar Rodriguez, who always took the time to patiently explain and advise me, despite my limitless questions, and for making the hours in between as fun as the work itself. Additionally, I would like to thank Declan Curran for his help and for always offering to show me the ropes.

Thank you also to Alan Machin, Joseph Amankrah and Andrew Heim (techincal officers, Mechanical Engineering) for their help and advice throughout the research project. Even when they could not help me, they always pointed me in the right direction.

Finally, I would like to thank my family and friends, for their support and love. A very special thank you to Nichi and Elaine, for always offering me a couch and a sympathetic ear when I needed them after the many, many late nights. To Ryan, John and Ray, for the laughs that kept me grounded, and the stress away. 
A Rapidly-Dissolving Silica-Silver Bioactive Glass For Cariostatic Applications, Saad Arshad, MASc, Ryerson University, 2017

\section{Table of Contents}

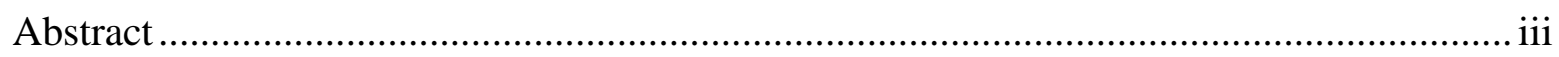

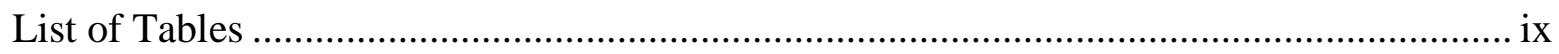

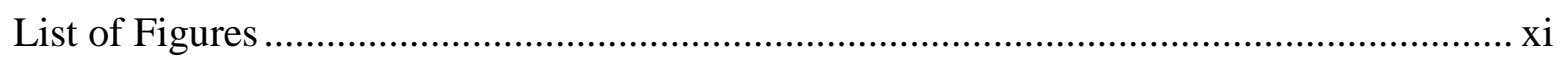

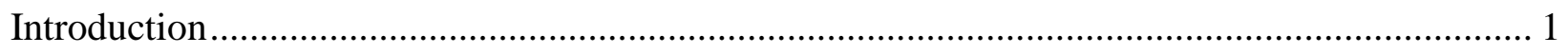

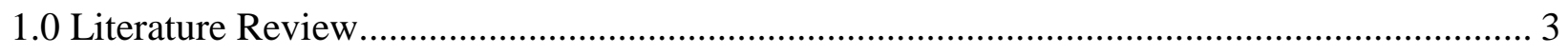

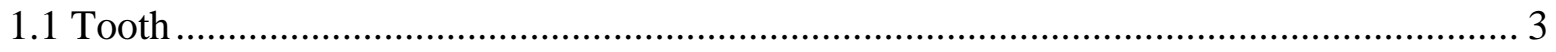

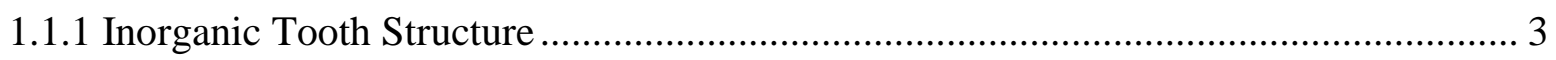

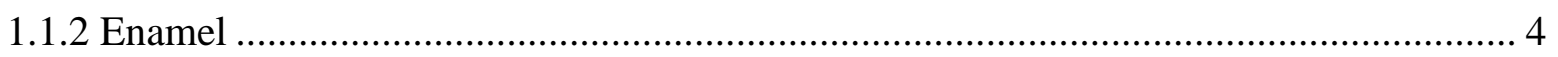

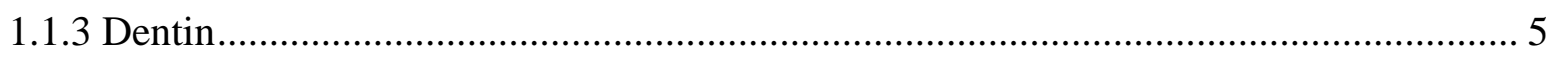

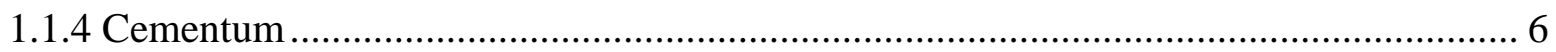

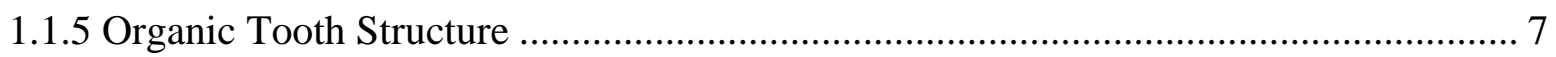

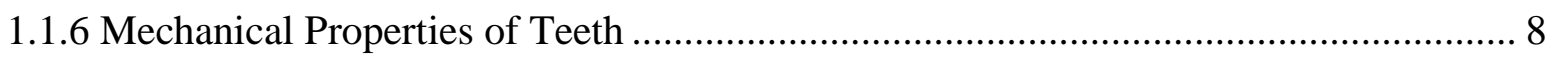

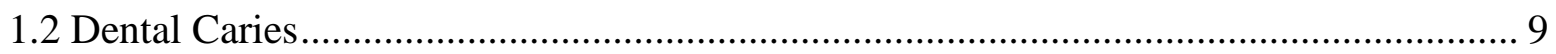

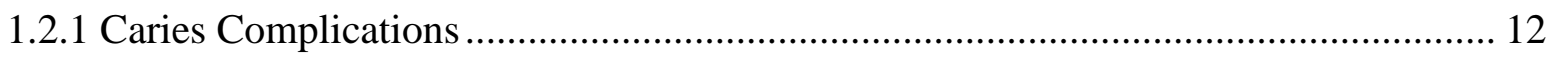

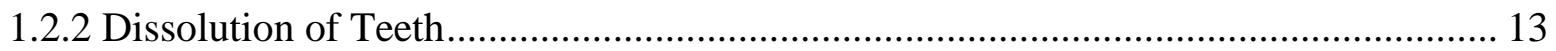

1.2.3 Effect of Fluorine on Caries and Cariogenic Bacteria ……………........................... 15

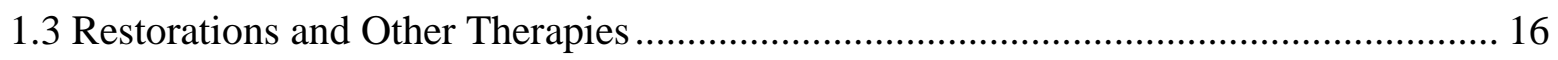

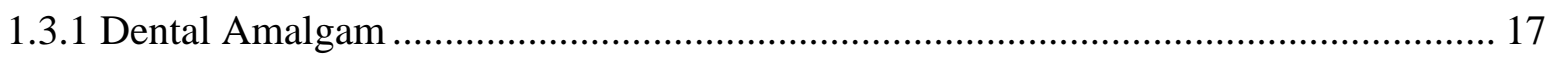

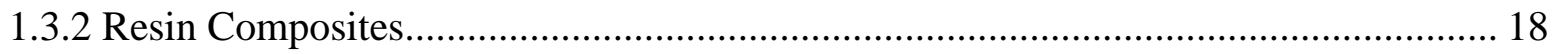


A Rapidly-Dissolving Silica-Silver Bioactive Glass For Cariostatic Applications, Saad Arshad, MASc, Ryerson University, 2017

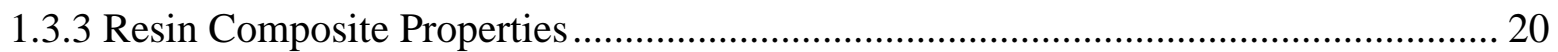

1.3.4 Resin Composite Polymerization Shrinkage …………........................................... 22

1.3.5 Resin Composite Toxicity.................................................................................... 25

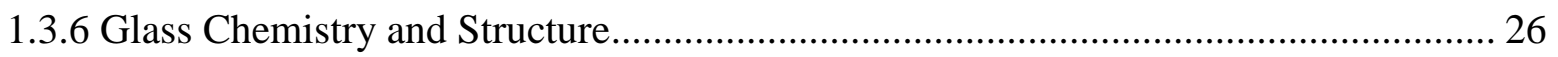

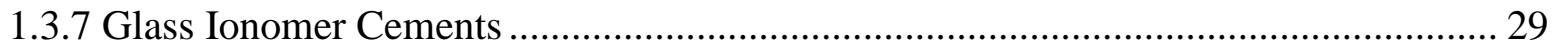

1.3.8 Glass Ionomer Cement Mechanical Properties ........................................................... 31

1.3.9 Glass Ionomer Cements - Acid Phase ..................................................................... 32

1.3.10 Glass Ionomer Cements - Glass Phase..................................................................... 33

1.3.11 Glass Ionomer Cement Cariostatic Efficacy ............................................................. 33

1.3.12 Polyacid-Modified Resin Composites (Compomers) …………............................... 35

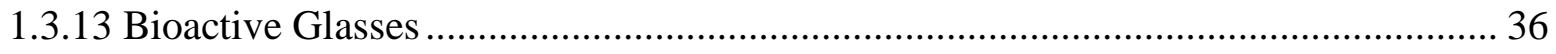

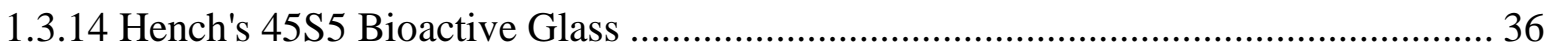

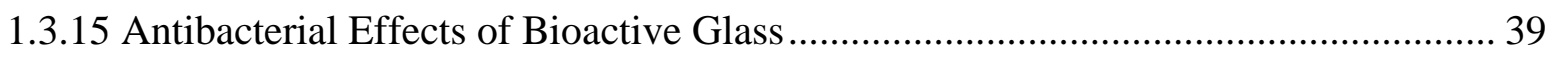

1.3.16 Remineralization Potential of Bioactive Glass ........................................................ 40

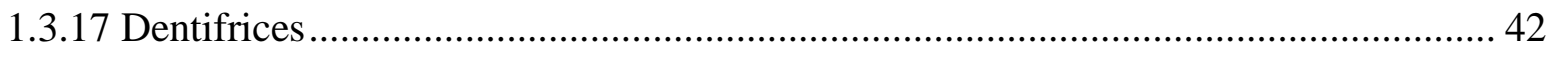

1.4 Innovations in Current Solutions ............................................................................. 47

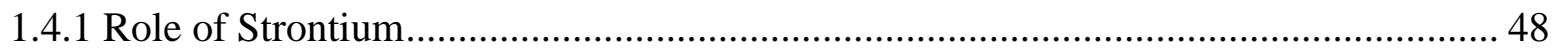

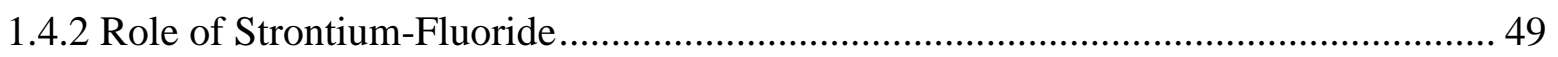

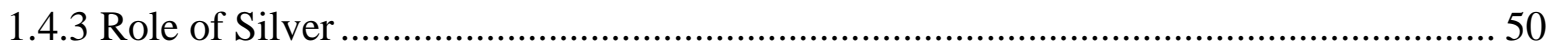

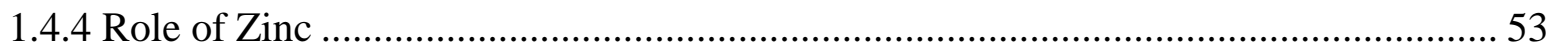


A Rapidly-Dissolving Silica-Silver Bioactive Glass For Cariostatic Applications, Saad Arshad, MASc, Ryerson University, 2017

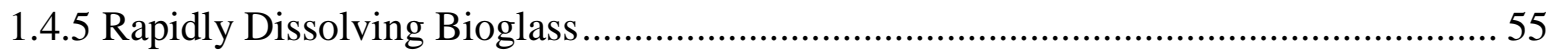

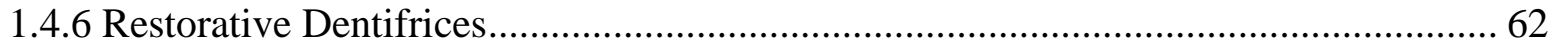

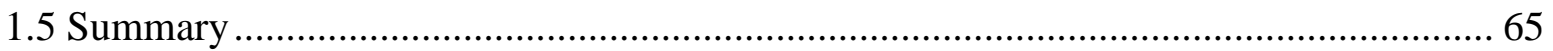

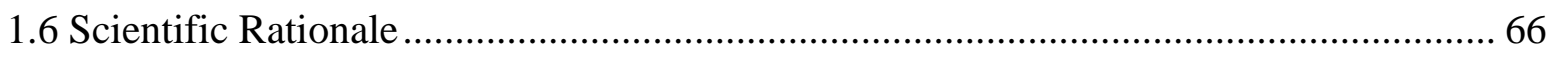

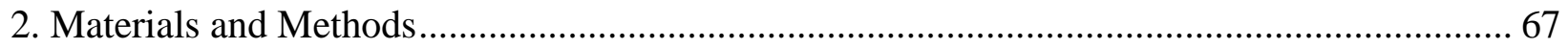

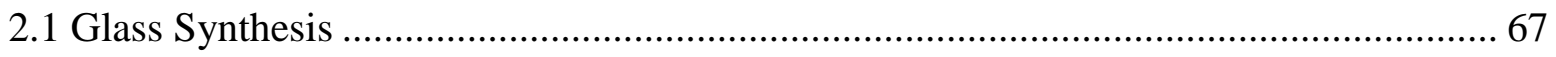

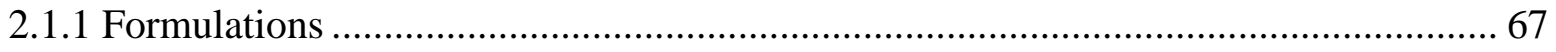

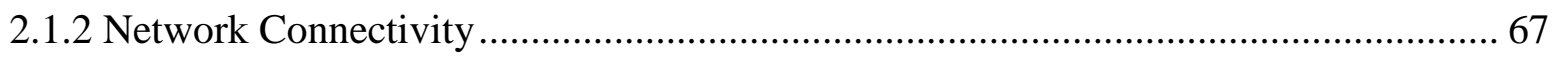

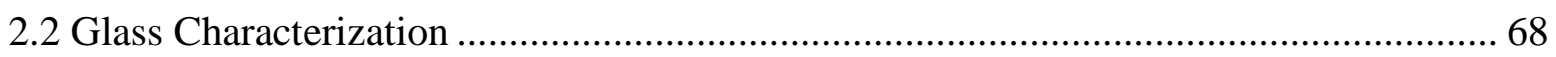

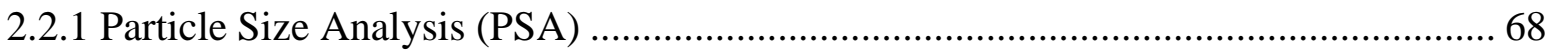

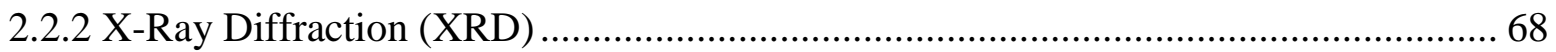

2.2.3 Fourier Transform Infrared Spectroscopy (FTIR) ........................................... 69

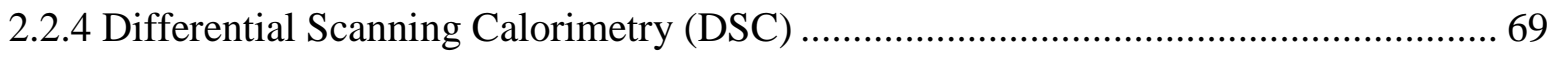

2.2.5 Scanning Electron Microscope-Energy Dispersive Xray Spectroscopy (SEM-EDX) 69

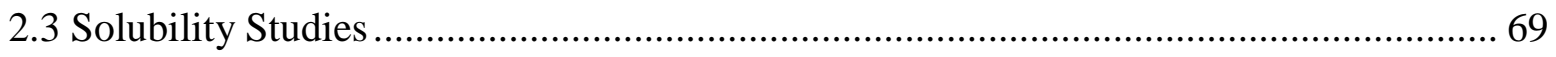

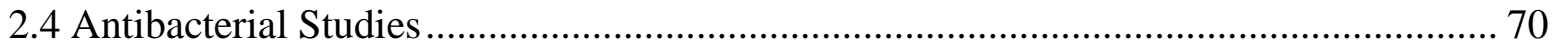

2.5 Toothpaste Remineralization Studies .............................................................. 71

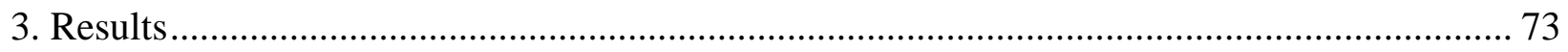

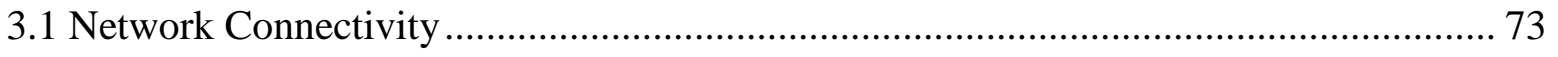

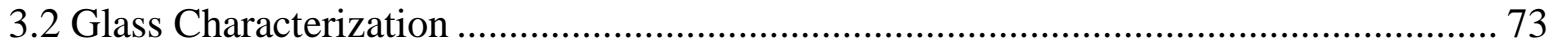


A Rapidly-Dissolving Silica-Silver Bioactive Glass For Cariostatic Applications, Saad Arshad, MASc, Ryerson University, 2017

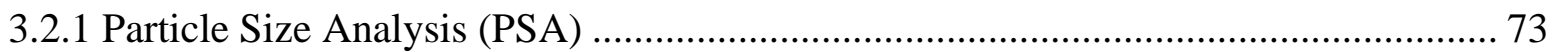

3.2.2 X Ray Diffraction (XRD) ...................................................................................... 74

3.2.3 Fourier Transform Infrared Spectroscopy (FTIR) ………………………………... 75

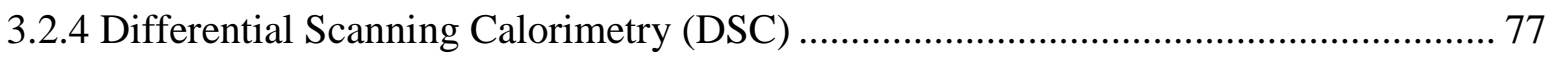

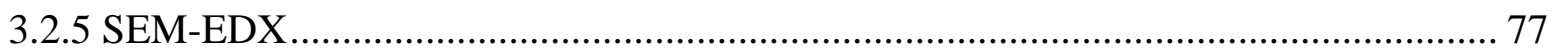

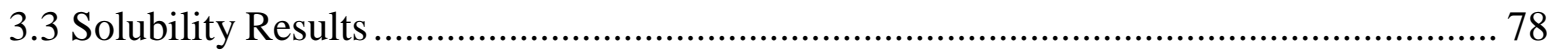

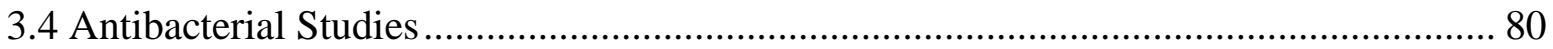

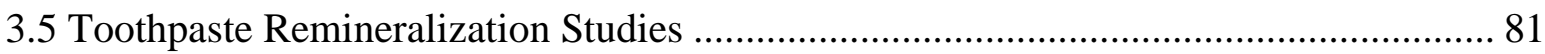

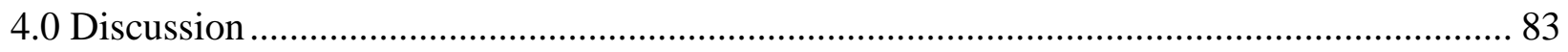

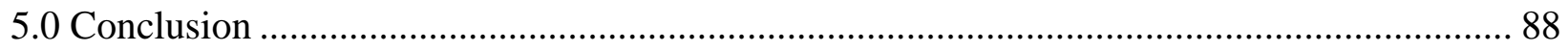

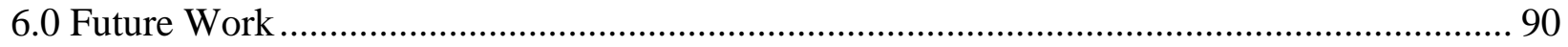

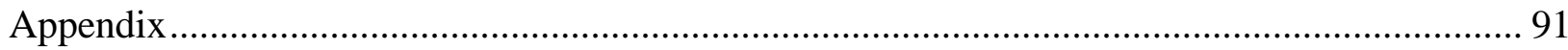

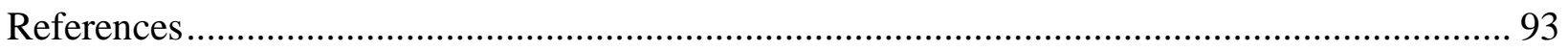


A Rapidly-Dissolving Silica-Silver Bioactive Glass For Cariostatic Applications, Saad Arshad, MASc, Ryerson University, 2017

\section{List of Tables}

Table 1: Most commonly substituted ions available in apatites[32].......................................... 4

Table 2: Previous studies on enamel strength adapted from Zaytsev and Panfilov (2014) [30].

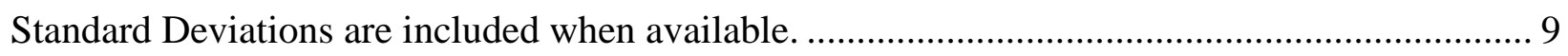

Table 3: Advantages and disadvantages of dental amalgam [65]........................................... 18

Table 4: Common matrix monomers and filler constituents [79] ................................................ 19

Table 5: In Vitro Tensile Bond Strength of three different dental composites bonded to three different media. $\mathrm{AC}$ is an adhesive composite, $\mathrm{TC}$ is a traditional composite and $\mathrm{BA}$ is a bonding agent. Standard deviations are included in parentheses [91]. Compressive fracture strength and compressive fatigue strengths are averages of other materials, but do not include bonding agents

Table 6: Regression analysis correlations indicationg which variables relate to shrinkage and how significant an impact they have, averaged over 17 different commercially available resin

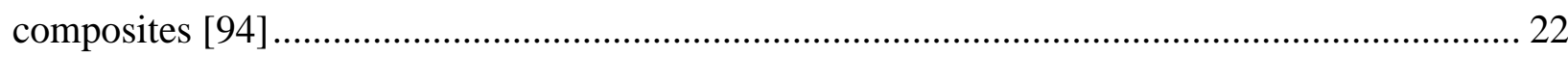

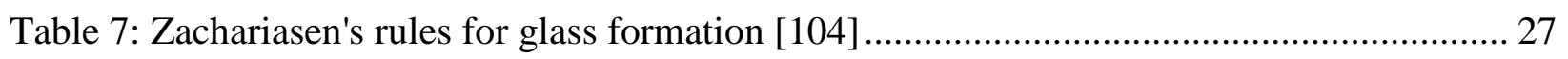

Table 8: Mean compressive strengths of commercially available GICs and resin-modified GICs. All strengths are expressed in MPa with standard deviations expressed in parentheses.[133] .... 32 Table 9: Fluroide release after twelve months and in twenty-four hours one year after curing

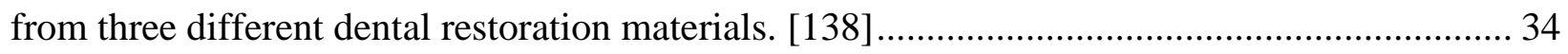

Table 10: Effect of various dentifrices on salivary amylase activity. All results are statistically

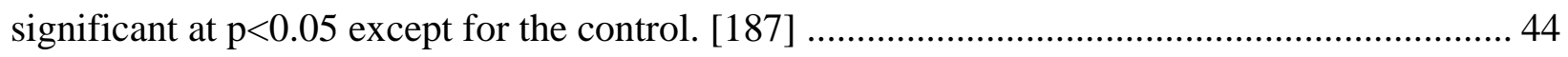

Table 11: Dentifrices containing bleaching agents tested by de Araujo et al. [189] ..................... 45 
A Rapidly-Dissolving Silica-Silver Bioactive Glass For Cariostatic Applications, Saad Arshad, MASc, Ryerson University, 2017

Table 12: Comparison of Conventional and Whitening Toothpaste on Compomer and Composite Restorations. Microhardness values are in VHN with $25 \mathrm{~g}$ for $20 \mathrm{~s}$. Colour was measured as $\Delta \mathrm{E}$ (total colour change) with a spectrophotometer with a 10mm aperture and D65 illuminant. Surface roughness was measured in $\mathrm{Ra}(\mu \mathrm{m})$ with a radius of $1.5 \mu \mathrm{m}$ at a constant speed of $0.1 \mathrm{~mm} / \mathrm{s}$ with a force of $0.7 \mathrm{~mm}$, with a cutoff at $0.25 \mathrm{~mm}$, measured with a surface roughness machine. [196] . 46

Table 13: Gillam's recommendations for an ideal bioglass material to treat sensitivity and caries. 56

Table 14: Some commercially available bioglasses based on $45 \mathrm{~S} 5$ with common applications [158]. 58

Table 15: Results of an in vitro enamel white-spot lesion microhardness study on bovine tooth crowns. [27] 59

Table 16: Percentage of bacteria killed in nutrient broth and artificial saliva by 45S5. [251] ..... 60 Table 17: Composition (wt\%) of Liu et al. CPG doped with Zn and F as determined by XRF... 61 Table 18: Commercial toothpastes with additives studied by Gjorgievskaet al. (2013). [181].... 62 Table 19: Silica glass series composition $(\mathrm{mol} \%)$ 67

Table 20: Network connectivity for each composition assuming silver is either a network

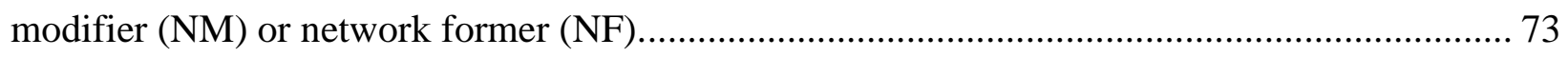

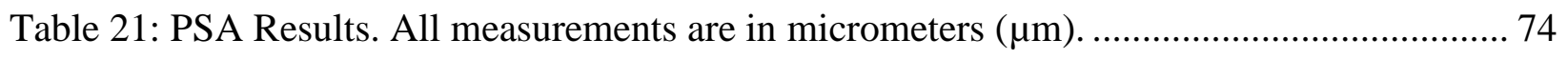

Table 22: Crystallization and Glass Transition Temperatures of glass compositions ................. 77

Table 23: Average of wt $\%$ in compositions for each composition ........................................ 78

Table 24: Percent Surface Hardness Loss (\%SHL) for each stage of treatment as compared with

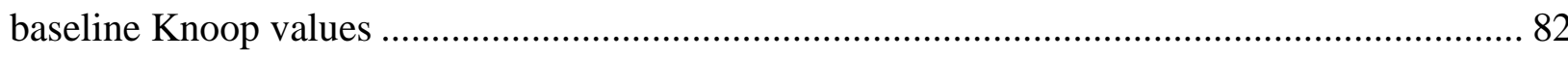


A Rapidly-Dissolving Silica-Silver Bioactive Glass For Cariostatic Applications, Saad Arshad, MASc, Ryerson University, 2017

\section{List of Figures}

Figure 1: Cross-section of a tooth structure[32] .................................................................. 3

Figure 2: Diagram of enamel rod. The dashed lines on the section view represent the orientation

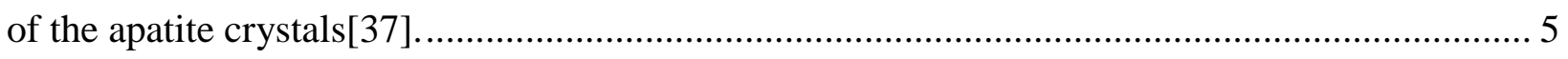

Figure 3: Images taken from BF-STEM of dentin tubules. (DT) represent dentinal tubules, (ID) represent intertubular dentin and (PD) represent peritubular dentin[41] ................................... 6 Figure 4: Adult human tooth light-micrograph at cervical tooth section. (E) represents enamel, (D) represents dentin and (C) represents cementum[42]. 7

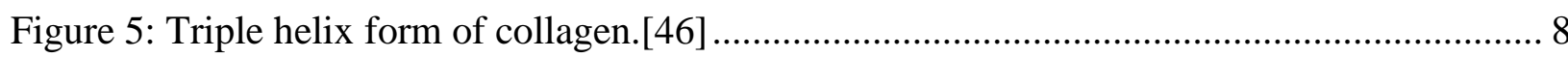

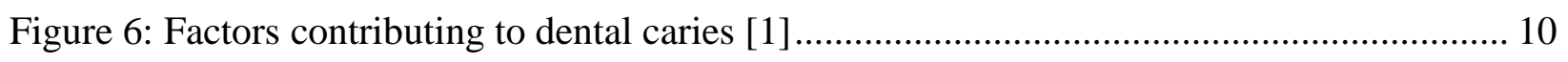

Figure 7: Biofilm formation. 1) Initial adhesion of bacterial cell to hard surface. 2) Induce adhesion through production of extracellular matrix, shown in green. 3) Develop biofilm structure. 4) Maturation of biofilm. 5) Cells break off from the biofilm and find new surface to

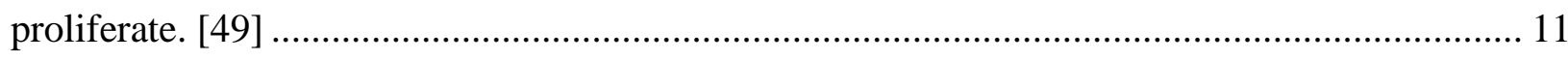

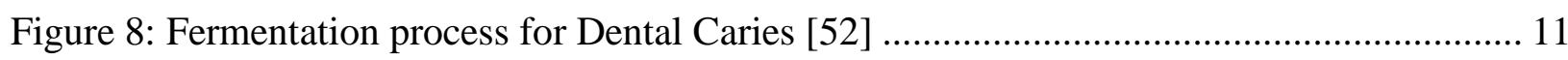

Figure 9: Diagram explaining the decay and repair of teeth [5] .............................................. 12

Figure 10: Bone loss from periodontitis on left vs. normal structure on right[52] ...................... 13

Figure 11: Solubility of Calcium ions versus $\mathrm{pH}$. The dashed line represents hydroxyapatite while the solid lines represent fluorohydroxyapatite, with different concentrations of fluoride listed. [54] 13

Figure 12: Artificial lesions produced in human enamel (A) and shark enamel (B). Human sample lesion penetration went up to 125 um while shark samples penetrated to about $40 \mathrm{um}$. $[56]$ 15 
A Rapidly-Dissolving Silica-Silver Bioactive Glass For Cariostatic Applications, Saad Arshad, MASc, Ryerson University, 2017

Figure 13: The picture on the left shows an amalgam filling in perfect condition after 10 years [67]. The picture on the right shows a resin composite filling in perfect condition after three years[72] 18

Figure 14: Polymerization Shrinkage vs Contraction Stress.[94]. 23

Figure 15: Microcracks form during the curing process due to contraction, which allows the stress to relieve itself. However if these cracks coalesce, they will lead to cohesive failure.

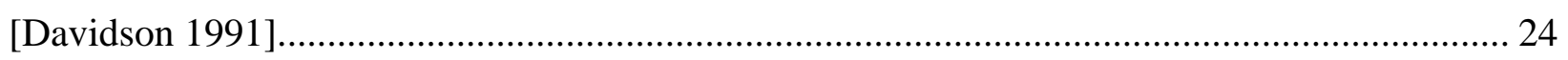

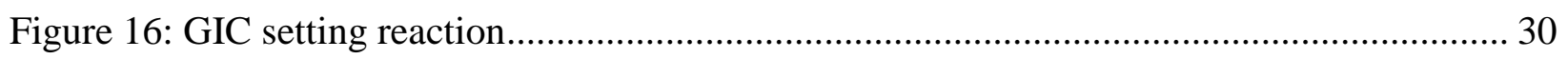

Figure 17: Cumulative fluoride release of a conventional GIC (Fuji II) vs a Compomer (Dyract)

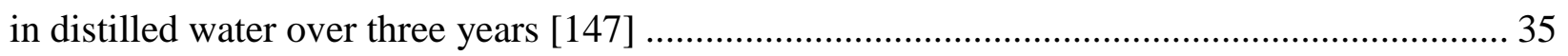

Figure 18: Bonding to bone between 45S5 glass and rat femur after 6 weeks. (c) represents the implant and (b) represents bone. The arrow points to osteoclasts forming at the interface between the remnants of the implant and the bone. Light microscopic image at x630 magnification [153]

Figure 19: Suggested action of enamel remineralization by 45S5 bioglass. A) Structure of 45S5 bioglass. B) Calcium, phosphate and sodium ions leached out of network structure. Phosphate ions pick up calcium ions and form calcium phophate salts. C) Calcium phosphate salts precipitate onto the enamel surface as they dissolve out of silanol compounds. D) Calcium phosphate salts begin to remineralize enamel in the surface and sub-surface of enamel lesions. [160]. 38

Figure 20: Cross-sectional microhardness at various enamel lesion depths when subjected to fluoride and bioglass treatments after erosion challenges. Connected bars are statistically significant $(\mathrm{p}<0.05)$. [160] 40 
A Rapidly-Dissolving Silica-Silver Bioactive Glass For Cariostatic Applications, Saad Arshad, MASc, Ryerson University, 2017

Figure 21: Remineralization Microradiographs. The faint grey areas near the top of the enamel specimens shows demineralization while the darker greys in the bulk of the specimen show mineralized enamel. [20] 50

Figure 22: A primary tooth treated by nano-silver solution after 12 months. Note the lack of black staining on the lesion.[227] 52

Figure 23: a) Antibacterial effect of $0.01 \mathrm{~g}$ of calcium phosphate glass on S. mutans. b) Antibacterial effect of $0.05 \mathrm{~g}$ of calcium phosphate glass on S. mutans [216].

Figure 24: SEM micrographs of mineralization effects of three different toothpastes. Arrows point to some of the deposits. (a) Hydroxyapatite containing toothpaste left deposits on enamel surface which fill irregularities, leaving porous enamel. (b) Bioactive glass containing toothpaste has created significant remineralization across the surface, sealing irregularities and leaving residual glass particles firmly attached to enamel surface. (c) Strontium-acetate and fluoride containing toothpaste has not created any significant remineralization and only few small deposits.

Figure 25: Enamel weight loss by different toothpaste and oral rinse treatments. Measurement error is estimated at $0.14 \%$. [252]. 64

Figure 26: Mean Knoop Hardness change as a measure of mineralization for four different dentifrices. [254] 65

Figure 27: Dental Pucks mounted in resin and with their buccal surfaces exposed. Picture is taken after they were brushed. 71

Figure 28: XRD patterns of glass compositions 74

Figure 29: FTIR spectra of three glass compositions in absorbance units 75

Figure 30: SEM photos of compositions: a) Si-Control b) Si-02 c) Si-05. 77 
A Rapidly-Dissolving Silica-Silver Bioactive Glass For Cariostatic Applications, Saad Arshad, MASc, Ryerson University, 2017

Figure 31: $\mathrm{pH}$ response of tris buffer solution upon glass dissolution after six, twelve and twentyfour hours 78

Figure 32 (a-d): Ion Release profiles for (a) Phosphorous, (b) Calcium, (c) Sodium and (d) Silver. Si-Control Silver release has been omitted from (d) as no silver was present in the composition. 79

Figure 33: (a) Inhibition Zone against bacterial strain D1 (b) Inhibition Zone against bacterial strain D2 (c) Inhibition Zone against bacterial strain D3 (d) Inhibition Zone against bacterial strain D4. The inhibition zone produced by glass powders against four bacterial isolate strains. Si-Control was excluded as it produced no inhibition zone throughout the time period measured.

Figure 34: Knoop Microhardness Remineralization and Demineralization on lamb molar dentin samples. All measurements are Knoop Hardness (HK). DI is deionized water, TP is toothpaste. 
A Rapidly-Dissolving Silica-Silver Bioactive Glass For Cariostatic Applications, Saad Arshad, MASc, Ryerson University, 2017

\section{Introduction}

Dental caries is among the most common preventable diseases worldwide [1]. It is caused by physiological issues such as poor salivary flow, poor dietary choices and inadequate oral hygiene [1]. $92 \%$ of adults aged between 20 and 64 years and 60 to $90 \%$ of children have been affected by caries at least once in their lifetime [2], [3]. Caries is the local dissolution of hard dental tissue by acids produced by bacteria in the mouth [1]. These bacteria, which exist within the plaque build up on teeth, process fermentable carbohydrates to produce weak acids [1], [4]. These acids cause calcium, carbonate and phosphate ions to leech out of the enamel and dentine, weakening the mineral and resulting in decay [1]. This process can be reversed by buffering the oral environment and restoring it to the original $\mathrm{pH}$ value; saliva is an effective natural buffer [5]. However, remineralization can only occur if $\mathrm{pH}$ is high enough or if there are enough calcium and phosphorous ions available in the mouth for uptake. Demineralization and remineralization constantly happen throughout the day. If the $\mathrm{pH}$ is not restored or if the ionic material needed for remineralization is not available, however, then demineralization can progress into lesions and cavities.

Cavities indicate advanced progression of the disease. Restorations such as amalgams, composites, glass ionomer cements and composite-cement hybrids are designed to simply refill the missing demineralized material. While these materials have been used for decades, they all have their drawbacks around their aesthetics, mechanical properties, cavity sealing and toxicity [6]-[10]. There exists a need for more proactive solutions which can prevent lesions from developing into cavities. 
A Rapidly-Dissolving Silica-Silver Bioactive Glass For Cariostatic Applications, Saad Arshad, MASc, Ryerson University, 2017

Bioactive glasses can be designed to deliver therapeutic ions which may bond with bone, encourage remineralization and provide antibacterial effects [11]-[16]. As they dissolve under acidic conditions, they act like 'smart' materials which activate under the same acidity with which caries is associated [17]. These glasses can be doped with ions such as strontium and fluoride which release as the glass degrades to promote remineralization [18]-[21], or antibacterial agents such as silver and zinc [22]-[26], to minimise further decay. While bioactive glasses have been used as components in glass ionomer cements (GICs) for decades, the idea of embedding glasses into other media for dental remineralization is a new approach [24], [27]-[29].

For the purposes of this project, a series of novel bioactive glasses were synthesized which were tailored to be a proactive solution to dental caries. These glasses were characterized through standard spectroscopic techniques, such as XRD, FTIR, SEM-EDX and DSC. The glasses were then tested for their efficacy as cariostatic agents and their remineralization potential on dentin. 
A Rapidly-Dissolving Silica-Silver Bioactive Glass For Cariostatic Applications, Saad Arshad, MASc, Ryerson University, 2017

\subsection{Literature Review}

\subsection{Tooth}

The tooth is composed of two major portions: the crown and the root. The crown is the portion of the tooth which protrudes from the gum-line and is coated with enamel, the hardest tissue in the human body [30]. Freshly formed enamel can be made of up to $30 \%$ protein but after it matures it becomes chiefly composed of mineral with less than $1 \%$ protein. The proteins primarily take the form of amelogenins; amino acid rich proline, histidine, leucine and glutamine. Up to $90 \%$ of the proteins in enamel are amelogenins. The other $10 \%$ are made up by proteins such as tuftelins and ameloblastins. The remaining protein tends to be found among enamel tufts, groups of hypomineralized crystalline defects of enamel which occur near the dentine-enamel junction[31].

\subsubsection{Inorganic Tooth Structure}

The root of the tooth buries itself into the jaw and holds the tooth in place. The root primarily consists of a mineral known as dentine which surrounds the pulp chamber. It is the pulp that provides the blood supply for the tooth in addition to containing the nerve endings [32]. Finally, the root is covered with a bone-like substance known as cementum. A diagram of the tooth can be found in Figure 1.

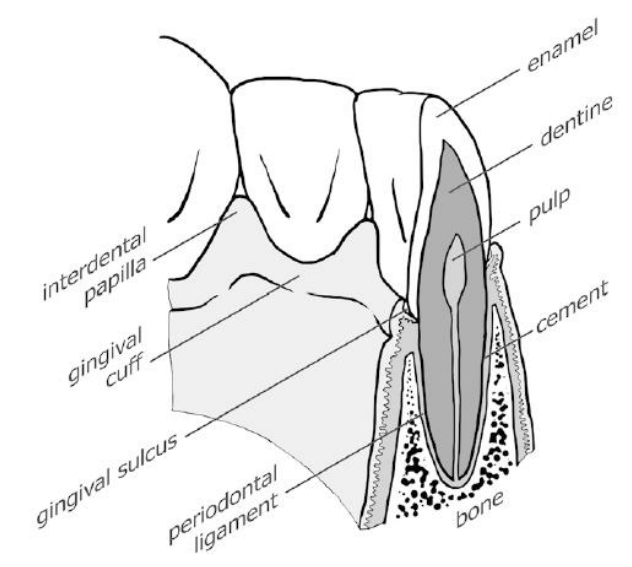

Figure 1: Cross-section of a tooth structure[32] 
A Rapidly-Dissolving Silica-Silver Bioactive Glass For Cariostatic Applications, Saad Arshad, MASc, Ryerson University, 2017

A tooth is made up mostly of inorganic material, ranging from $69 \%$ to $99 \%$ by weight. These minerals are typically different forms of apatite, following an idealized chemical formula of $\mathrm{Ca}_{5}\left(\mathrm{PO}_{4}\right)_{3} \mathrm{X}$ where $\mathrm{X}$ is usually one of $\left(\mathrm{OH}^{-}\right)$or $\mathrm{F}^{-}$. This formula is often doubled in order to express the unit cell content [33]. Hydroxyapatite $\left(\mathrm{Ca}_{10}\left(\mathrm{PO}_{4}\right)_{6}(\mathrm{OH})_{2}\right)$, HA, is the main inorganic constituent of both bone and tooth. However, at different sites even within the same tooth, the mineral content can vary smoothly between fluoroapatite (FA) and HA. Fluoride ions are typically supplied through ingestion of drinking water and exposure to fluoridated toothpastes [32]. Table 1 below lists other ions commonly available for substitution in apatite crystals.

Table 1: Most commonly substituted ions available in apatites[32]

\begin{tabular}{|l|l|}
\hline Apatite Ion & Substitutions available \\
\hline Calcium $\left(\mathrm{Ca}^{+}\right)$ & Strontium $\left(\mathrm{Sr}^{+}\right)$or Sodium $\left(\mathrm{Na}^{+}\right)$ \\
\hline Phosphate $\left(\mathrm{PO}_{4}{ }^{2-}\right)$ & $\begin{array}{l}\text { Orthophosphate }\left(\mathrm{HPO}_{4}{ }^{2-}\right), \text { Carbonate }\left(\mathrm{CO}_{3}{ }^{2-}\right) \text { or } \\
\text { Hydrogen carbonate }\left(\mathrm{HCO}_{3}{ }^{-}\right)\end{array}$ \\
\hline Hydroxyl $\left(\mathrm{OH}^{-}\right)$ & Chloride $\left(\mathrm{Cl}^{-}\right)$or Carbonate $\left(\mathrm{CO}_{3}{ }^{2-}\right)$ \\
\hline
\end{tabular}

Some amount of inorganic materials exist in the dental tissues which are not in an apatite phase, but rather in other forms of crystalline calcium phosphate including whitlockite $\left(\beta-\mathrm{Ca}_{3}\left(\mathrm{PO}_{4}\right)\right)$, brushite $\left(\mathrm{CaHPO}_{4} \cdot 2 \mathrm{H}_{2} \mathrm{O}\right)$, and octacalcium phosphate $\left(\mathrm{Ca}_{8}\left(\mathrm{HPO}_{4}\right)_{2}\left(\mathrm{PO}_{4}\right)_{4} \cdot 5 \mathrm{H}_{2} \mathrm{O}\right)$. Non-apatite minerals form more commonly as amorphous calcium phosphates. These structures are usually unstable as their composition is highly variable which leads them to break down into apatite phases[32].

\subsubsection{Enamel}

Enamel is a very hard, highly mineralized and brittle tissue with a toughness similar to glass [34]. It is unique in the body due to its acellular nature [35] and its microstructure made up of rods composed of tightly packed carbonated HA crystals [36]. Rods have an approximately 
A Rapidly-Dissolving Silica-Silver Bioactive Glass For Cariostatic Applications, Saad Arshad, MASc, Ryerson University, 2017

keyhole shape and have a mean diameter of about $5 \mu \mathrm{m}$ [37]. Figure 2 below shows a schematic drawing of an enamel rod. Each rod is aligned in parallel with other rods and run from the dentine-enamel junction towards the tooth surface [37]. They contain "fibre-like" apatite crystals that are orientated differently within the rod depending on if they are in the head or tail area of the rod.

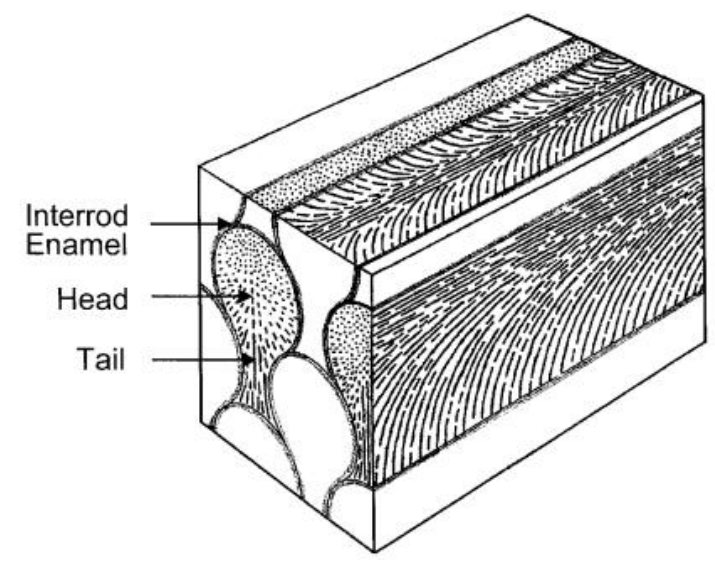

Figure 2: Diagram of enamel rod. The dashed lines on the section view represent the orientation of the apatite crystals[37].

Enamel crystallites are organized into rods seperated by interrod enamel. Interrod enamel differs from rod enamel only by its crystal orientation. Rod crystals are orientated axially along the rods but interrod enamel can vary $40^{\circ}$ to $65^{\circ}$ from the rod direction [35].

\subsubsection{Dentin}

Dentin is a hard, elastic tissue which constitutes the majority of the tooth. It is found between the enamel layer and the pulp chamber and provides support for the brittle enamel to handle forces that result from mastication [38], [39]. Dentin is composed of four main phases: tubules, a mineralized matrix, collagen fibers with embedded apatite crystals and, finally, fluid, including water and plasma [38]. Tubules are small tracts which radiate away from the pulp chamber and traverse the bulk of the material. They can vary in size from $2.5 \mu \mathrm{m}$ near the pulp chamber to 0.8 $\mu \mathrm{m}$ near the dentin-enamel junction. Collagen fibers are usually located perpendicular to tubules 
A Rapidly-Dissolving Silica-Silver Bioactive Glass For Cariostatic Applications, Saad Arshad, MASc, Ryerson University, 2017

but the two occasionally run in parallel[40]. Tubules have a strong influence on the fracture properties of dentin yet have little to no effect on elastic properties [40]. The walls of the tubules are made up of peritubular dentin, a highly mineralized tissue [41].

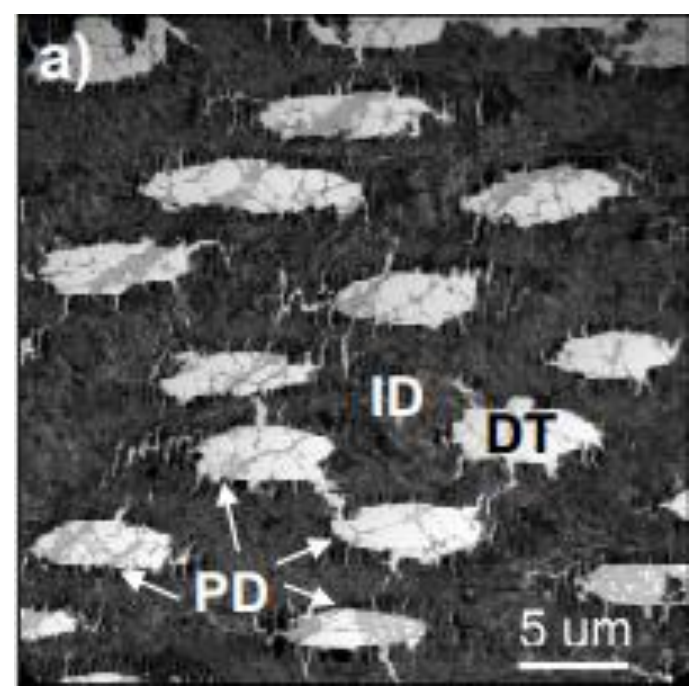

Figure 3: Images taken from BF-STEM of dentin tubules. (DT) represent dentinal tubules, (ID) represent intertubular dentin and (PD) represent peritubular dentin[41].

\subsubsection{Cementum}

Cementum lines the root up to the cervical or neck area of the tooth where the crown meets the root [32]. Cementum is not considered a primary bonding substrate, despite being identified as a source of microleakage contributing to high incidences of secondary caries [42], [43]. There are three main kinds of cementum: acellular afibrillar cementum, acellular extrinsic fiber cementum and cellular mixed stratified cementum. 
A Rapidly-Dissolving Silica-Silver Bioactive Glass For Cariostatic Applications, Saad Arshad, MASc, Ryerson University, 2017

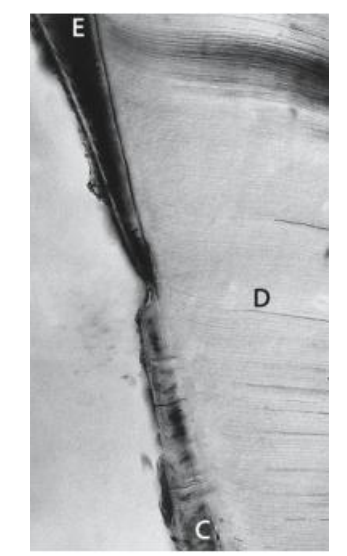

Figure 4: Adult human tooth light-micrograph at cervical tooth section. (E) represents enamel, (D) represents dentin and (C) represents cementum[42].

Acellular afibrillar cementum is a non-homogenous matrix chiefly found near the cement-enamel junction. It contains no collagen fibers, but is instead made up of multiple calcium layers [42]. Acellular extrinsic fiber constitutes the majority of cementum. It is characterized by a thin layer of mineral, about $50 \mu \mathrm{m}$ thick during its functional life. A slow continuous process grows the matrix over the life of the tooth [42]. Cellular mixed stratified cementum is actually composed of layers of acellular extrinsic fiber cementum and cellular intrinsic fiber cementum one after another. Pure cellular intrinsic fiber cement grows significantly quicker than acellular cementum and is only deposited during the repair processes that follow root resorption [42]. It can reach mean thicknesses of $200 \mu \mathrm{m}$ with the thickest layers found on the top third of the tooth. It performs the vital functions of maintaining the occlusion of teeth as well as repairing root surface areas which have undergone resorbtion [42].

\subsubsection{Organic Tooth Structure}

Organic materials are also present in the tooth. Approximately $20 \%$ of the weight of fresh bone and dentin is collagen, a fibrous protein that can be found in dentin, cementum, bone and, to a lesser extent, enamel [44]. It is a very tough structure and makes up about $30 \%$ of the proteins in the body[45]. It is formed by three different chains of amino acids which braid together in order 
A Rapidly-Dissolving Silica-Silver Bioactive Glass For Cariostatic Applications, Saad Arshad, MASc, Ryerson University, 2017

to form a larger spiral, as seen in Figure 5. These spirals can then be packed together into fibrils which range from $10 \mathrm{~nm}$ in diameter to $200 \mathrm{~nm}$ in diameter [32].

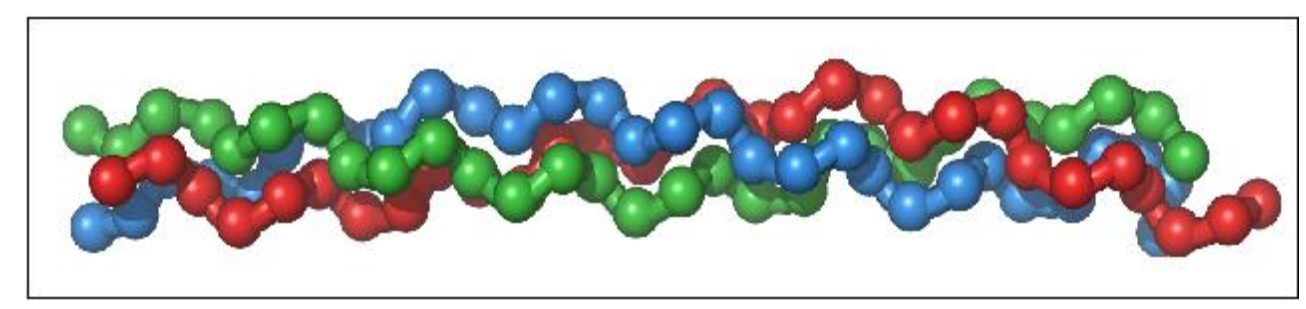

Figure 5: Triple helix form of collagen.[46]

Collagen is a stable protein which is not water soluble and is resistant to both bacterial and fungal attack [32]. It typically interweaves itself within the apatites to provide support and increase strength. Collagen was formerly believed to be absent in enamel, but Açil et al. showed that there are, in fact, small concentrations to be found [44]. Other than collagen, organic constituents are present as assorted proteins, lipids, peptides and other organic compounds. These are collectively referred to as ground substance and are usually amorphous [32].

\subsubsection{Mechanical Properties of Teeth}

The strength of tooth varies depending on which tooth the sample comes from, as well as the site on the tooth. This is due to the constant demineralization and remineralization processes affecting teeth. Table 2 details the findings of past studies explaining the strength of human enamel. Note that the strengths vary drastically based on the direction of the enamel rods. 
A Rapidly-Dissolving Silica-Silver Bioactive Glass For Cariostatic Applications, Saad Arshad, MASc, Ryerson University, 2017

Table 2: Previous studies on enamel strength adapted from Zaytsev and Panfilov (2014) [30]. Standard Deviations are included when available.

\begin{tabular}{|l|l|l|l|}
\hline Author & Rod Direction & $\begin{array}{l}\text { Ultimate Compressive Strength } \\
\text { (MPa) }\end{array}$ & Young's Modulus (MPa) \\
\hline Stanford et al. (1958) & Variable & $277 \pm 12.4$ & 47.5 \\
& Across & $194 \pm 15.2$ & 30.3 \\
& Along & $134 \pm 27.9$ & 8.96 \\
\hline Stanford et al. (1960) & Variable & $261 \pm 41.4$ & $46.2 \pm 4.8$ \\
& Across & $250 \pm 29.6$ & $32.4 \pm 4.1$ \\
& Along & $94.5 \pm 32.4$ & $9.65 \pm 3.45$ \\
& Along & $126.9 \pm 30.3$ & $11.0 \pm 2.1$ \\
\hline Craig et al. (2010) & Along & $384 \pm 85.3$ & $77.9 \pm 4.8$ \\
\hline & Along & $372 \pm 56$ & $84.1 \pm 6.2$ \\
\hline
\end{tabular}

Zaytsev and Panfilov suggest that the geometry of the enamel affects its strength [30]. In a study on 30 human molars, they found that the strength varied significantly based on the dimensions of the specimen tested; they show a relationship between Young's modulus, ultimate compressive strength, elasticity and plasticity with the ratio between sample height to sample length.

\subsection{Dental Caries}

One of the most common preventable diseases is caries, commonly referred to as tooth decay. Approximately $92 \%$ of adults aged 20 to 64 years old have had dental caries at least once in their permanent teeth. Furthermore, $23 \%$ of adults in the same age group have not had treatment for their decay. On average, this demographic is estimated to experience 3.28 decayed or missing permanent teeth [2]. Furthermore, the disease also affects $60 \%$ to $90 \%$ of children [3]. It can be caused by physiological issues, such as poor salivary flow and immunological conditions, poor 
A Rapidly-Dissolving Silica-Silver Bioactive Glass For Cariostatic Applications, Saad Arshad, MASc, Ryerson University, 2017

dietary choices and inadequate dental hygiene. In general, the causes of the disease can be summed up as in Figure 6.

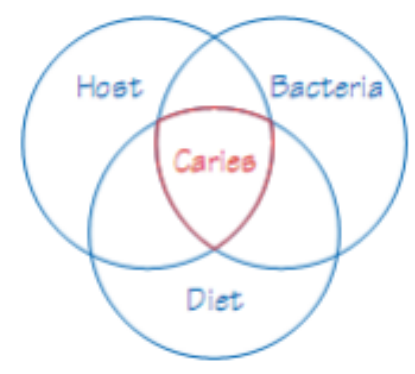

Figure 6: Factors contributing to dental caries [1]

Dental caries is defined as the localised decay of hard dental tissues by the acids which are produced from the bacterial processing of fermentable carbohydrates [1]. The disease originates in the biofilm formed by dental plaque [4]. Bacteria do not live in isolated cultures but in an aggregate network made up of extracellular material; this aggregate is called a biofilm [47]-[49]. The microorganisms consist of about $10 \%$ of the dry mass of this biofilm, while the extracellular matrix makes up $90 \%$ of its mass [47]. Plaque is the biofilm which accumulates on the surface of teeth in the oral cavity, consisting of over 500 different kinds of bacterial species and is affected by environmental conditions, such as saliva quantity and composition, as well as diet [1], [50]. Plaque formation is described in Figure 7. Fluoride is known to be a retardant in plaque activity [51]. Caries can occur in all portions of the tooth including the crown, root, cementum, dentin and enamel [1]. The disease eats away at material like dentin and enamel and causes carious lesions, commonly referred to as cavities [1]. Cavities are usually a sign of an advanced stage of the disease and are irreversible [1]. The cavity usually spreads into dentin towards the pulp chamber which can cause necrosis of the tooth and lead to periapical abscesses [1]. 
A Rapidly-Dissolving Silica-Silver Bioactive Glass For Cariostatic Applications, Saad Arshad, MASc, Ryerson University, 2017

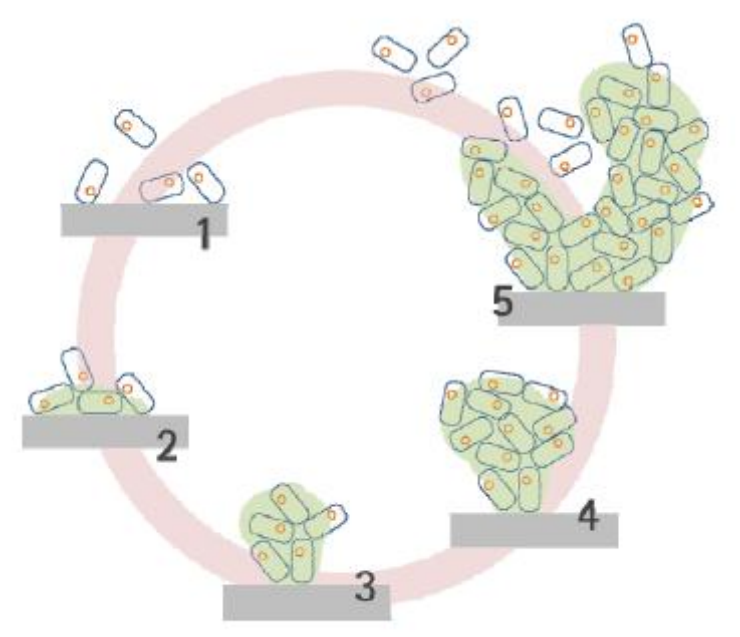

Figure 7: Biofilm formation. 1) Initial adhesion of bacterial cell to hard surface. 2) Induce adhesion through production of extracellular matrix, shown in green. 3) Develop biofilm structure. 4) Maturation of biofilm. 5) Cells break off from the biofilm and find new surface to proliferate. [49]

The engine by which the decay begins is through the processing of fermentable carbohydrates. Bacteria, primarily streptococcus mutans, streptococcus sobrinus, and lactobacillus consume these carbohydrates and produce a lactic acid [1]. Proteins and fats are seemingly not involved in cariogenic activity but the protein casein, found in milk, has been shown to have a protective effect [32]. The fermentation process is described by Figure 8.

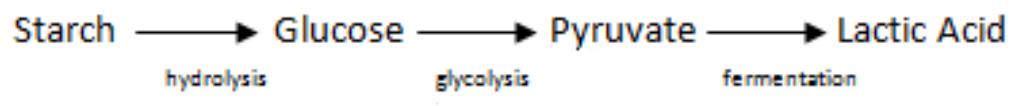

Figure 8: Fermentation process for Dental Caries [52]

The normal $\mathrm{pH}$ of the mouth is approximately 7.4 [1]. The weak acid produced by bacteria lowers the $\mathrm{pH}$, resulting in a more acidic environment which can lead to demineralization; a process by which calcium, carbonate and phosphate ions begin to leech out of the enamel or the cementum [1], resulting in decay. This process can easily be reversed by the natural buffer action of the saliva, which restores the $\mathrm{pH}$ in the mouth. It can also be reversed through the consumption of calcium, phosphate and fluoride ions. Fluoride acts as a catalyst for the diffusion 
A Rapidly-Dissolving Silica-Silver Bioactive Glass For Cariostatic Applications, Saad Arshad, MASc, Ryerson University, 2017

of calcium and phosphate ions by the formation of fluoroapatites and fluoridated hydroxyapatites, as well as rendering the tooth structure more resistant to acid attack. The processes of demineralization and remineralization constantly happen throughout the day and can either result in cavitation of the tooth, repair of cavities in the tooth, or an equilibrium phase [5]. Figure 9 below shows the relationships between the two processes.

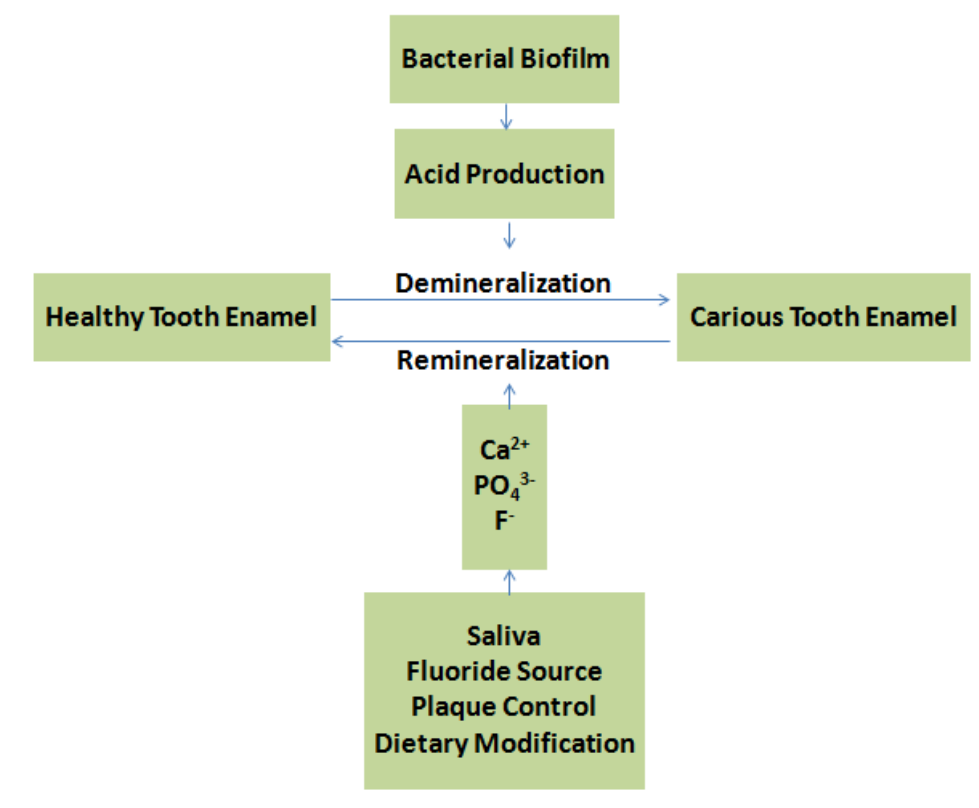

Figure 9: Diagram explaining the decay and repair of teeth [5]

\subsubsection{Caries Complications}

Left untreated, carious lesions are able to find their way into the pulp chamber of the tooth, which can lead to necrosis [1]. Other complications may include sinusitis, osteomyelitis, and swelling which can potentially block airways [53]. Bacterial infections can also affect other parts of the oral cavity, such as the gums and other supporting tissues which help hold the tooth. Diseases which can be caused by these bacteria include gingivitis and periodontitis [52]. Gingivitis is a condition caused by localized inflammation of the gums without the loss of supporting bones around the teeth, resulting in swollen, bleeding gums, superficial reddening of the gums, and halitosis [52]. Periodontitis affects the small bones which help hold the teeth in 
A Rapidly-Dissolving Silica-Silver Bioactive Glass For Cariostatic Applications, Saad Arshad, MASc, Ryerson University, 2017

place. Loss of these bones can result in abscesses and exposed teeth roots, as well as pain and swelling of the gums. It is often caused by chronic gingivitis [52].

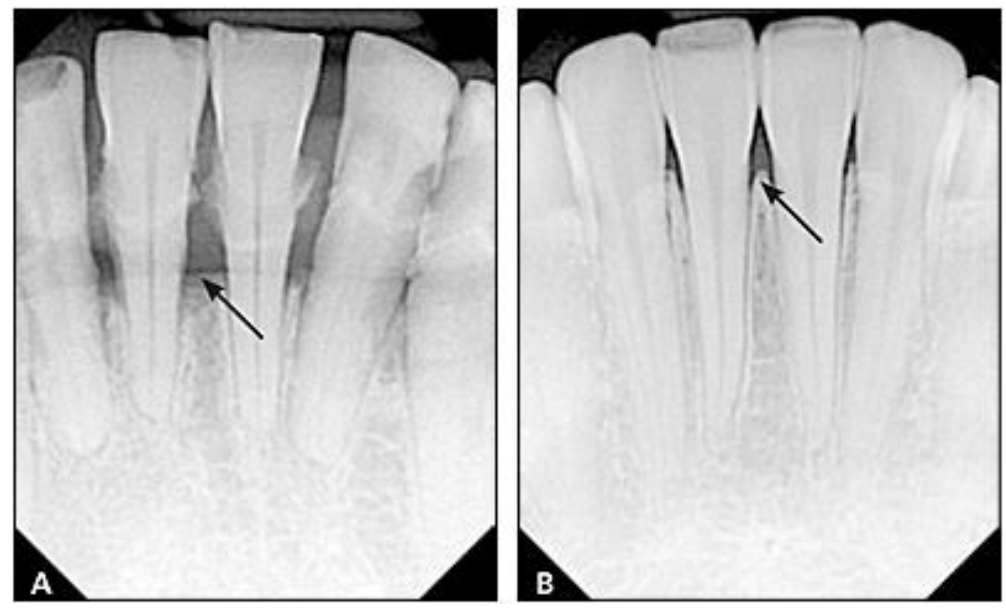

Figure 10: Bone loss from periodontitis on left vs. normal structure on right[52]

\subsubsection{Dissolution of Teeth}

Caries attacks are known to cause demineralization and dissolution of hard dental tissues. The solubility of dental tissues can increase rapidly as the host $\mathrm{pH}$ decreases. Larsen (1990) estimated that for $\mathrm{pH}$ values between $4-6$, the solubility can change by a factor of 7-8 for every $\mathrm{pH}$ unit [54].

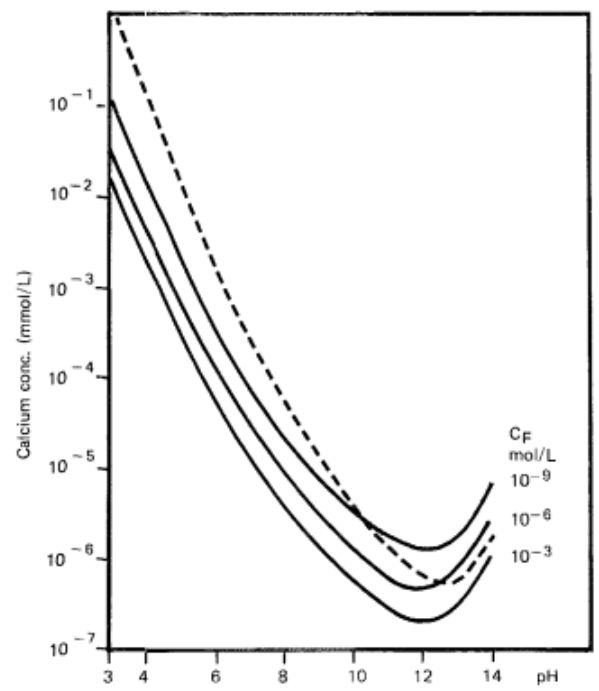

Figure 11: Solubility of Calcium ions versus pH. The dashed line represents hydroxyapatite while the solid lines represent fluorohydroxyapatite, with different concentrations of fluoride listed. [54] 
A Rapidly-Dissolving Silica-Silver Bioactive Glass For Cariostatic Applications, Saad Arshad, MASc, Ryerson University, 2017

The dissolution of valuable ions from the tooth can lead to a lower calcium to phosphate ratio, as well as a lower concentration of ions such as magnesium and carbonate [55]. These two ions are important as they are often used as an indicator of cariogenic activity. Early in the enamel attack, magnesium and carbonate tend to leech out of the mineral first. This explains the presence of magnesium rich and carbonate rich phases separate from the apatite [55]. Carbonate phases are believed to increase solubility and thereby increase caries risk. Generally, high carbonate and low fluorine phases represent a high caries risk while low carbonate and high fluorine phases represent low caries risk. In vitro experiments carried out by LeGeros et al. (1983) found that the depth of caries penetration was up to $33 \%$ higher in human enamel, which has a lower fluoride content, as compared to shark enamel, which has a higher fluoride content, over long exposure periods [56]. The study also found that the carbonate concentrations were higher in the human samples as opposed to the shark samples. Furthermore, there was up to a 50\% difference in solubility when the powdered enamel samples were suspended in an acidic buffer solution with a $\mathrm{pH}$ of 5 , with the human samples being more soluble. The study strongly suggested that both carbonate and fluoride ions have a significant impact on the solubility of apatite crystals: carbonate increases solubility while fluoride ions decrease solubility. LeGeros [56] also suggested that when both fluoride and carbonate phases are simultaneously present in apatite, the positive contributions of fluoride are more significant than the contributions of carbonate phases. However this phenomenon has not been fully investigated. 
A Rapidly-Dissolving Silica-Silver Bioactive Glass For Cariostatic Applications, Saad Arshad, MASc, Ryerson University, 2017
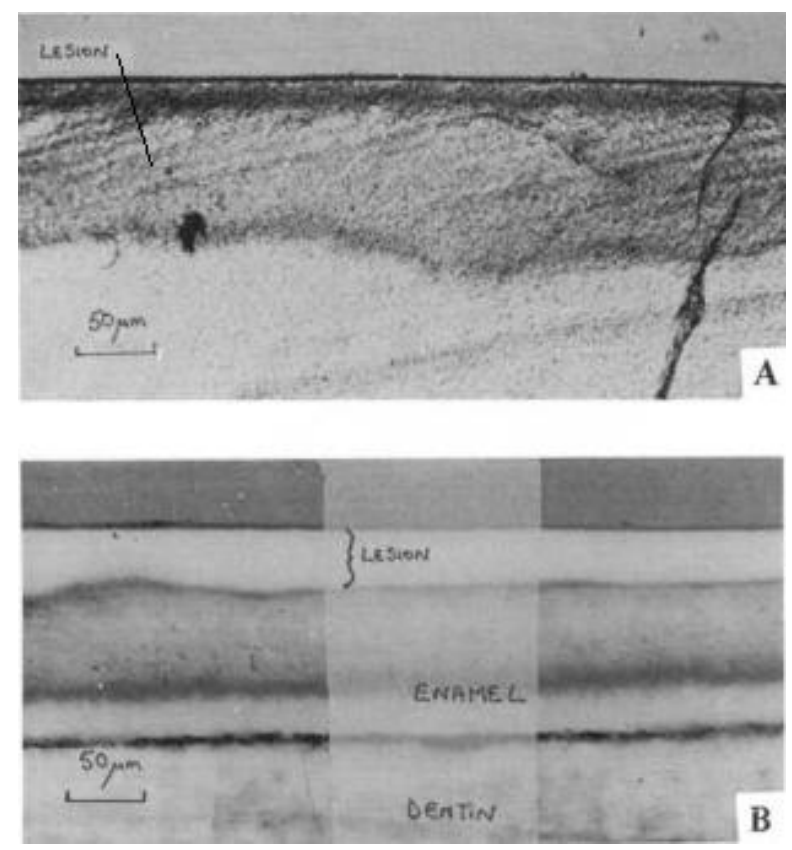

Figure 12: Artificial lesions produced in human enamel (A) and shark enamel (B). Human sample lesion penetration went up to 125 um while shark samples penetrated to about $40 \mathrm{um}$. [56]

Excessive fluoride concentrations can precipitate into $\mathrm{CaF}_{2}$ instead of fluorapatite. $\mathrm{CaF}_{2}$ is believed to create a barrier and act as a reservoir of fluoride for the enamel [57]. Mohammed et al. (2013) showed that the mineral may actually be detrimental to remineralization efforts as it can rob the apatite of valuable calcium ions [58]. The study found that above $45 \mathrm{ppm} \mathrm{F}$ concentration, $\mathrm{CaF}_{2}$ begins forming in greater quantities and that at above $136 \mathrm{ppm} \mathrm{F}$ concentration, demineralization is no longer reduced as $\mathrm{CaF}_{2}$ becomes the dominant phase.

\subsubsection{Effect of Fluorine on Caries and Cariogenic Bacteria}

Fluorine ions are widely regarded as effective cariostatic agents [1], [21], [59]. The mechanism by which they influence decay is not fully understood but there are some known effects that fluorine provides:

- The presence of small quantities of fluorine in the oral environment encourages remineralization. This is due to the fluorine ion replacing the less stable $\mathrm{OH}^{-}$of 
A Rapidly-Dissolving Silica-Silver Bioactive Glass For Cariostatic Applications, Saad Arshad, MASc, Ryerson University, 2017

hydroxyapatite and acting as a catalyst for calcium and phosphate ions to diffuse more easily into the apatite crystals [21].

- Fluorapatite crystals are more resilient to acid attack, thereby decreasing enamel dissolution during acid attacks [21]

- Fluorine acts as a retardant for plaque development, inhibiting acid build-up by interfering with the function of several enzymes which are considered essential to the production of the acid in the first place. Studies by Bibby and Van Kesteren (1940) found that $1 \mathrm{ppm}$ fluoride content was effective in inhibiting acid production, while $250 \mathrm{ppm}$ fluoride concentration was required to inhibit bacterial growth [51]. Since the acid is the main cause of tooth decay, the prevention of acid buildup is considered one of the most important factors of fluorine presence[60].

- Fluorine ingestion also affects the fissures on tooth biting surfaces by reducing their depth. Shallower fissures are believed to reduce the ability of plaque to remain unperturbed. This reduces acid build up and prevents the occurance of cavitation [60].

\subsection{Restorations and Other Therapies}

There are two main therapies available to treat advanced caries. One method is to extract the tooth, and thereby reduces pain. The other method is to fill the cavity so that bacteria may no longer reach the inner portions of the tooth and cause further damage. Untreated caries can result in many health complications; for example, growth, body weight and quality of life can be affected in preschool children with untreated caries and are at greater risk for adult caries [1], [61]-[64]. The most common filling materials are amalgams, resin-composites, glass ionomer cements (GICs) and compomers. Bioactive glasses and dentifrices can serve as cariostatic agents which can prevent the need for fillings in the first place [17]. 
A Rapidly-Dissolving Silica-Silver Bioactive Glass For Cariostatic Applications, Saad Arshad, MASc, Ryerson University, 2017

\subsubsection{Dental Amalgam}

Historically, amalgam was the primary choice of material used as a filling in order to repair teeth. Amalgam is an alloy of mercury, silver, copper, tin, zinc and other trace metals, as per the particular manufacturer of the restoration. It is a highly economical option and has both high strength and wear resistance [65]; high-copper variants of the alloy last as long as 12 years [66] as they contain less of the gamma-2 phase from the $\mathrm{Sn}-\mathrm{Hg}$ system. This phase causes progressive weakening of the alloy through corrosion and suffers from pitting [67]. Furthermore, fillings of amalgam were considered easy to use as they were not technique sensitive [65], [66].

Despite all this, the use of amalgam has waned for multiple reasons [66]. The most widely cited reasons were reports of mercury vapors leeching out and being consumed; in a study by Joselow et al. in 1968, it was shown that $14 \%$ of dental offices had mercurial vapors in excess of safe levels from the use and preparation of dental amalgam [68]. Another study by Gronka et al. found that one in seven dental offices had mercury contamination [9]. However, in 1973, a study by Lenihan, Smith and Harvey showed that there was "no evidence that the amount of mercury absorbed is harmful to the patient" [69]. Uçar and Brantley also reported that there is no evidence to support the claim of mercury release from amalgam fillings and neurological diseases [70]. The largest concern of amalgam was for patients allergic to mercury; these people represented 2 to $3 \%$ of the population [71]. From 1979 to 1990 , amalgam filling use had declined by $38 \%$, along with incidence of tooth decay. Reasons for their decline may include public perception of their safety; however, a larger factor for their decline has been due to a larger demand for aesthetics in restorative dentistry [10]. Table 3 below summarizes the advantages and disadvantages of amalgam fillings. 
A Rapidly-Dissolving Silica-Silver Bioactive Glass For Cariostatic Applications, Saad Arshad, MASc, Ryerson University, 2017

Table 3: Advantages and disadvantages of dental amalgam [65].

\begin{tabular}{|c|c|}
\hline Advantages & Disadvantages \\
\hline $\begin{array}{ll}\text { - } & \text { Low cost } \\
\text { - } & \text { Easy to use } \\
\text { - } & \text { High compressive } \\
\text { strength } \\
\text { - } \text { Good wear properties }\end{array}$ & $\begin{array}{l}\text { - Poor aesthetics } \\
\text { - Lack of bonding means tooth is not strengthened } \\
\text { - Microleakage due to lack of bonding } \\
\text { - Not as conservative of tooth structure and requires extensive } \\
\text { preparation, such as undercutting }\end{array}$ \\
\hline
\end{tabular}

\subsubsection{Resin Composites}

Modern restorations are shifting from amalgam towards resin-composites [72]. In 1999, approximately 86 million resin composite fillings were installed compared to 71 million amalgams [10]. Composites are typically tooth colored and are able to adhere to the tooth surface chemically. Composites work through the use of an organic matrix which provides the continuous phase for the material while an inorganic filler enhances its mechanical properties. The matrix often contains an initiator meant to begin free radical polymerization [73].

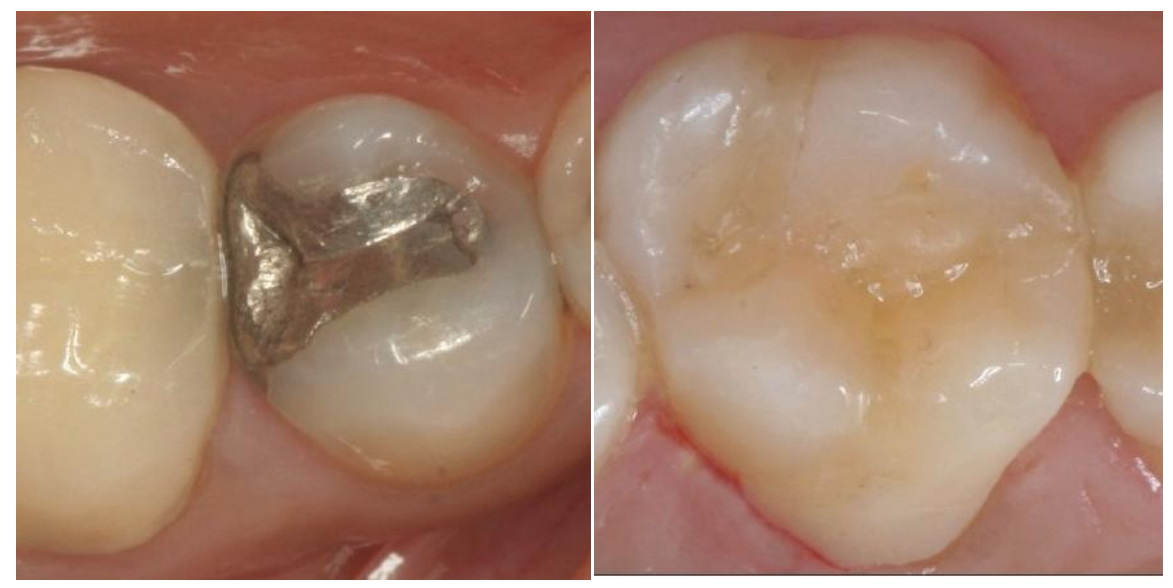

Figure 13: The picture on the left shows an amalgam filling in perfect condition after 10 years [67]. The picture on the right shows a resin composite filling in perfect condition after three years[72]

Often, it is a photo initiator which causes polymerization when irradiated with blue light from a halogen lamp. The light is often in the region of $450-480 \mathrm{~nm}$ and produces highly-crosslinked networks which protect against dissolution, [73], [74]. They cure rapidly and at room 
A Rapidly-Dissolving Silica-Silver Bioactive Glass For Cariostatic Applications, Saad Arshad, MASc, Ryerson University, 2017

temperature, generating radicals by breaking double bonds in the monomer chains and creating a three-dimensional cross-linked polymeric network [73]. One of the most frequently used photoinitiators is camphorquinone/amine (CQ/amine) [75], [76]. The CQ absorbs the light and enters an excited state where it extracts a free hydrogen atom from a tertiary amine. This amine then becomes a radical and starts causing a chain polymerization by attacking carbon double bonds while the $\mathrm{CQH}$ is used to terminate the reaction when it recombines with the radical [75], [76]. It is important that the filler bonds to the matrix for the material to work. The filler particles are usually coated in a silane bonding agent in order to facilitate this [77]. This agent contains functional groups which can interact with the inorganic materials of the filler as well as monomers which can copolymerize with the matrix groups [7]. Generally, the filler constitutes $75-85 \%$ by weight while the matrix constitutes $15-25 \%$ by weight [78]. Table 4 below lists common matrix monomers as well as what most fillers are composed of.

Table 4: Common matrix monomers and filler constituents [79]

\begin{tabular}{|l|l|l|}
\hline \multicolumn{2}{|l|}{ Matrix Compound } & Filler Compound \\
\hline Compound & Makeup & $\begin{array}{l}\text { Metals, ceramics, glasses, polymers, etc. } \\
\text { containing various compounds such as pigments, } \\
\text { antioxidants, antimicrobials, oxide glasses with } \\
\text { barium, strontium etc. for radiopacity }\end{array}$ \\
\hline BIS-GMA & $\begin{array}{l}\text { 2,2-bis[4-(2-hydroxy-3- } \\
\text { methacryloyloxypropoxy)-propane } \\
\text { phenyl]- }\end{array}$ & \\
\hline UDMA & $\begin{array}{l}\left.1,6 \text {-bis } \mathrm{H}_{36} \mathrm{O}_{8}\right) \\
\text { ethoxycarbonylamino)- } \\
2,4,4-\text {-trimethylhexan } \\
\left(\mathrm{C}_{23} \mathrm{H}_{38} \mathrm{~N}_{2} \mathrm{O}_{8}\right)\end{array}$ & \\
\hline TEGDMA & $\begin{array}{l}\text { Triethyleneglycol di- } \\
\text { methacrylate } \\
\left(\mathrm{C}_{14} \mathrm{H}_{22} \mathrm{O}_{6}\right)\end{array}$ & \\
\hline
\end{tabular}


A Rapidly-Dissolving Silica-Silver Bioactive Glass For Cariostatic Applications, Saad Arshad, MASc, Ryerson University, 2017

\subsubsection{Resin Composite Properties}

The advantages that composites provide over traditional amalgam fillings are those of aesthetics and adhesion to tooth. The fillings are often tooth colored or close to tooth colored which makes them more desirable for use in anterior teeth. Unfortunately, composites suffer from low strength and elastic moduli, as well as poor wear properties compared with amalgams [6], [7]. However they are still the most popular material for dental restorations [80]. Enamel has a modulus of about $80 \mathrm{GPa}$ while dentin has a modulus of about $18 \mathrm{GPa}$ [7]. Most composites have an elastic modulus between 15 to $25 \mathrm{GPa}$ [7]. Much work has been done on improving these materials in order to meet the mechanical needs imposed on them, such as minimizing shrinkage while also accounting for water sorption [81] and increasing fracture toughness [82], [83] and strength [84]-[86].

During polymerization, shrinkage can occur which puts an additional amount of stress onto the filling, as well as creating sites for microleakage [8]. These sites can then cause secondary caries to occur by allowing bacteria inside the cavity as well as cause pulpal inflammation. Shrinkage is a process inherent to the reaction itself as the polymer networks form [8], [87]. Furthermore, adhesion is considered unsatisfactory in cavity walls in the long term since bond strength would decrease with longer exposure to water [88]. Table 5 shows the bond strengths of composites to different media. Shrinkage may also exert stresses large enough to break the dentin-resin bonds, further opening up the cavity to microleakage effects [89]. Despite the shortcomings however, modern day composite fillings still have annual failure rates less than $9 \%$, only marginally higher than dental amalgams which were found to have a 7\% annual failure rate [90]. Table 6Table 5 shows the compressive strengths of five different composites. 
A Rapidly-Dissolving Silica-Silver Bioactive Glass For Cariostatic Applications, Saad Arshad, MASc, Ryerson University, 2017

Table 5: In Vitro Tensile Bond Strength of three different dental composites bonded to three different media. AC is an adhesive composite, TC is a traditional composite and BA is a bonding agent. Standard deviations are included in parentheses [91]. Compressive fracture strength and compressive fatigue strengths are averages of other materials, but do not include bonding agents [92].

\begin{tabular}{|l|l|l|l|l|l|l|}
\hline Composite & $\begin{array}{l}\text { Storage } \\
\text { Conditions }\end{array}$ & $\begin{array}{l}\text { Amalgam } \\
(\mathbf{M P a})\end{array}$ & $\begin{array}{l}\text { Dentin } \\
\mathbf{( M P a})\end{array}$ & $\begin{array}{l}\text { Enamel } \\
\mathbf{( M P a})\end{array}$ & $\begin{array}{l}\text { Compressive } \\
\text { Fracture } \\
\text { Strength }\end{array}$ & $\begin{array}{l}\text { Compressive } \\
\text { Fatigue } \\
\text { Strength }\end{array}$ \\
\hline \multirow{2}{*}{$\mathrm{AC}$} & $23^{\circ} \mathrm{C}$ & $12.8(1.6)$ & $9.0(0.9)$ & $13.9(5.6)$ & $341.7(13.6)$ & $206.7(8.1)$ \\
\cline { 2 - 5 } & Thermocylced & $13.6(2.6)$ & $8.2(3.6)$ & $16.5(8.6)$ & & \\
\hline AC+BA & $23^{\circ} \mathrm{C}$ & $21.8(6.6)$ & $14.2(3.6)$ & $15.6(1.4)$ & N/A & N/A \\
\cline { 2 - 5 } & Thermocycled & $26.2(6.5)$ & $13.9(4.7)$ & $18.3(2.9)$ & & \\
\hline TC+BA & $23^{\circ} \mathrm{C}$ & $9.7(3.7)$ & $9.6(4.7)$ & $21.3(5.1)$ & $259.8(8.18)$ & \multirow{2}{*}{$173.2(5.38)$} \\
\cline { 2 - 5 } & Thermocycled & $11.4(3.7)$ & $11.1(3.4)$ & $22.8(8.0)$ & & \\
\hline
\end{tabular}

As can be seen in the table above, composites bond better to enamel than to dentin, and even better to amalgam. Furthermore, while composites do exhibit some adhesion to dental media, bond strengths are greater when paired with luting cements. A higher bond strength is valuable in the clinical situation, as a strong bond between the restoration and the surrounding media is essential to prevent microleakage [91].

Masticatory loads are cyclical and so fatigue strengths are valuable in evaluating the life cycle of a restoration [92]. Evaluated under 10Hz, Table 5Error! Reference source not found. above lists both the static compressive strength and the dynamic fatigue strength. While the upper limit to chewing frequency is reported to be $2 \mathrm{~Hz}, 10 \mathrm{~Hz}$ was selected because it has been shown to be a good simulation of the oral environment without internal heating of the sample and ensures all probable fatigue effects observed in vivo would occur in vitro [92], [93]. 
A Rapidly-Dissolving Silica-Silver Bioactive Glass For Cariostatic Applications, Saad Arshad, MASc, Ryerson University, 2017

\subsubsection{Resin Composite Polymerization Shrinkage}

During the setting of resin-modified composite cements, a phenomenon known as polymerization shrinkage occurs. This is caused by monomers attempting to react and polymerize into polymers through the exchange of van der Waals bonds into covalent bonds [94]. The shrinkage can cause contractive stresses to be experienced in the material but it can also induce stresses and deformation of the surrounding tooth structure the cement is adhered to.

Such stresses can often be the underlying mechanism responsible for many restoration problems. The cement can often separate from the surrounding walls which results in microleakage. However, fractures can also be caused in surrounding tissues such as enamel and dentin as well as the fillings themselves [8]. If the surrounding tissues or the restoration do not have enough elastic compliance for the shrinking volume, some structure must eventually fracture in order to compensate [87]. This can create issues as the open spaces created by the restoration failure can result in secondary carious infections, pulpal irritation [8]. It is therefore a common practice in the dental field to employ the 'sandwich technique' [88] which involves the use of a luting cement to bond the restoration to the dental tissue while the composite is used for the bulk restoration.

Table 6: Regression analysis correlations indicationg which variables relate to shrinkage and how significant an impact they have, averaged over 17 different commercially available resin composites [94]

\begin{tabular}{|l|l|}
\hline Variables & Equation \\
\hline Contraction Stress vs Tensile Modulus & $\sigma(\mathrm{MPa})=-0.10+4.49 \mathrm{E}(\mathrm{GPa})$ \\
\hline Contraction Stress vs Shrinkage & $\sigma(\mathrm{MPa})=25.00-3.74 \varepsilon(\mathrm{vol} \%)$ \\
\hline Shrinkage vs Tensile Modulus & $\varepsilon(\mathrm{vol} \%)=6.62-1.17 \mathrm{E}(\mathrm{GPa})$ \\
\hline Shrinkage vs Filler Load & $\varepsilon(\mathrm{vol} \%)=8.65-0.097$ filler\% $(\mathrm{vol} \%)$ \\
\hline
\end{tabular}


A Rapidly-Dissolving Silica-Silver Bioactive Glass For Cariostatic Applications, Saad Arshad, MASc, Ryerson University, 2017

Table 6 lists the results of a regression analysis relating contraction, shrinkage and Young's Modulus, with the individual products tested listed in the appendix. As can be seen, there are strong correlations between each of the tested variables. Interestingly, the contraction stress, shrinkage, tensile modulus and filler load were correlated, despite the large variation in the number of products tested. Indeed, the 17 different commercial products varied in terms of resin type, filler size and load, and even including a system which was photo-initiated in the test [94].

Heliomolar (Ivoclar Vivadent, Schaan, Liechtenstein) demonstrated low shrinkage and low contraction stress, indicating superior performance compared to its competitors, as is made evident by its location below the regression line in Figure 14Error! Reference source not found.. This runs counter to the norm, in which low shrinkage is generally accompanied with high contraction stress [94]. Heliomolar accomplishes its result by using a microfilled resin with lower filler levels; the filler levels are close to $40 \%$ by volume. This suggests that the elastic modulus and contraction stress should be low while the shrinkage should be high. However, by including a filler which is pre-polymerized, a smaller shrinkage percentage can be obtained [94].

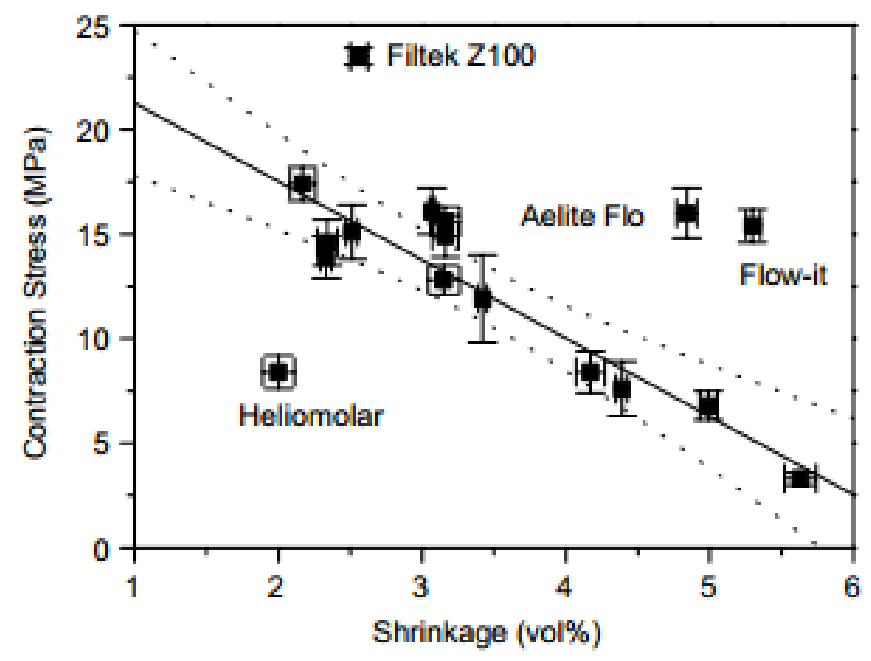

Figure 14: Polymerization Shrinkage vs Contraction Stress.[94] 
A Rapidly-Dissolving Silica-Silver Bioactive Glass For Cariostatic Applications, Saad Arshad, MASc, Ryerson University, 2017

Water sorption immediately following polymerization is known to relieve some of the residual stresses from shrinkage in composite restorations [8], [95]. Geometry also plays a large role in fractures stemming from shrinkage. When the ratio of the bonded surface of the restoration cement to free surface of the restoration cement is greater than 5, all shrinkage becomes uniaxial and can increase by up to 3 times more than expected [87]. In a study by Davidson, van Zeghbroek and Feilzer, it was found that a rigidly constrained cement had up to $25 \%$ less cohesive strength than a free shrinking cement after 20 minutes [8]. Stresses developing in luting cements were also observed and found to spike and then plateau. It is believed that this is due to the cements forming microcracks due to stresses in unset cement, which enlarges the free surface and thereby relieves stress, as per Figure 15 [96]. The microcracks relieve stress as it builds whilst increasing available free surface. As the setting process continues, however, the cement shrinks further and stress build up resumes. The presence of microcracks, however, would invariably result in premature failure as the cracks would serve as stress concentrators [96]. Furthermore, cariogenic bacteria could invade through the crack, rendering the filling useless as the patient would still suffer from dental decay.

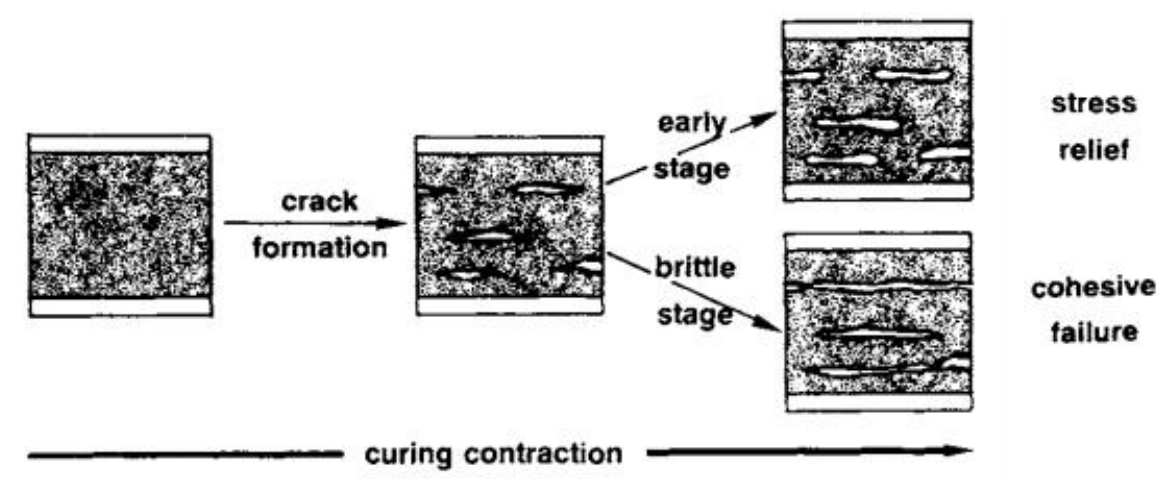

Figure 15: Microcracks form during the curing process due to contraction, which allows the stress to relieve itself. However if these cracks coalesce, they will lead to cohesive failure. [Davidson 1991] 
A Rapidly-Dissolving Silica-Silver Bioactive Glass For Cariostatic Applications, Saad Arshad, MASc, Ryerson University, 2017

\subsubsection{Resin Composite Toxicity}

The polymers in composites undergo degradation and erosion during their lifecycle. These processes break the chain into smaller segments as well as rob the polymer chain of material such as monomers or polymer fragments [79]. This can be caused by chemical, mechanical or thermal factors. Degradation usually happens due to hydrolysis or by attack from enzymes found in saliva. Erosion is usually caused by solvents, such as water, entering the bulk material. This can trigger chemical degradation which can result in the formation of pores in the microstructure. The material is then released through these pores [79]. Studies by Pearson and Longman and by Tanaka et al. found that a greater irradiation time correlated with less solubility and thus less degradation and erosion [97], [98]. However, Ferracane found a poor correlation between conversion of monomers to polymer and solubility in water but a much better correlation between a $50 \%$ ethanol and $50 \%$ water solution [84]. It is therefore believed that more than simply conversion to a polymer is significant in preventing elution. Further investigation by Lee et al. point to the type of solvent being significant and that ethanol was far more effective at penetrating the matrix and leeching out soluble chains than saliva [99]. It is estimated that between approximately $1.5 \%$ of material by weight is water soluble whilst $5-10 \%$ of material by weight is soluble in organic solvents. Studies by Soderholm and Oysaed \& Ruyter showed that barium containing glasses were more soluble than quartz or silica fillers in aqueous environments [100], [101]. From the matrices, the resins were found to release triethylene glycol dimethacrylate (TEG-DMA) in higher quantities than other comonomers[79]. TEG-DMA is known to show cytotoxic effects, and it may also break down during conversion to a monomer into more toxic components, including formaldehyde [102]. Clinical studies also suggest that TEG-DMA inhibits dentin remineralization through the interference of bonding agents [103]. 
A Rapidly-Dissolving Silica-Silver Bioactive Glass For Cariostatic Applications, Saad Arshad, MASc, Ryerson University, 2017

\subsubsection{Glass Chemistry and Structure}

Glasses are defined by two major criteria: the lack of long-range repeating atomic arrangments and a time dependent glass tranformation [104]. This glass transformation behaviour occurs over a temperature range known as the glass transformation range. Any amorphous material, including organic, inorganic and metallic which exhibit glass transformation behaviour can be described as a glass regardless of which technique produces them [104]. Techniques usually employed to form glasses include melt-quench, sol-gel, vapor deposition, and neutron irradiation of crystalline materials [104].

Silicate bioactive glasses are frequently studied for their biomedical applications, which include synthetic bone grafts and scaffolds [105], [106] as well as dental applications when used as part of glass polyalkenoate cements and composites [107]. Silicate bioactive glasses often contain silicon dioxide $\left(\mathrm{SiO}_{2}\right)$, calcium oxide $(\mathrm{CaO})$, sodium oxide $\left(\mathrm{Na}_{2} \mathrm{O}\right)$, and phosporous pentoxide $\left(\mathrm{P}_{2} \mathrm{O}_{5}\right)$ but can often contain chemical modifications by incorporating cations [105]. These cations can function as network formers or as network modifiers which provide useful effects such as modifying the mechanical and structural properties of the glass [108], [109], as well as offering therapeutic effects such as anabolic and antibacterial action[110]-[112].

The structure of glass formation is often discussed in accordance with Zachariasen's rules which have been called the random network theory [104], [113]. The rules are listed in Table 7. While they are not definitive as a strucutral model, they are useful for explaining glass formation behaviour, and have been expanded to include more complex glass formation models as well. These rules also do not necessarily describe glass formation but rather the formation of a continous 3D network structure and can also be applied to crystalline material formation. In order to relate them more accurately to glass formation, a caveat must be added: the networks 
A Rapidly-Dissolving Silica-Silver Bioactive Glass For Cariostatic Applications, Saad Arshad, MASc, Ryerson University, 2017

described by these rules must be disrupted so that long-range periodicity does not occur [104].

These disruptions can occur in the form of variations in bond lengths, bond angles and rotation of structural units about their axes [104].

Table 7: Zachariasen's rules for glass formation [104]

\begin{tabular}{|l|}
\hline Zachariasen's Rules for Glass Formation in Simple Oxides \\
\hline 1. \\
2. The oxygen atom is linked to no more than two cations \\
3. Oxygen polyhedra share only corners and not edges or faces \\
4. At least three corners of each oxygen polyhedron must be shared in order to form a 3D network \\
Modified Rules for Complex Glasses \\
1. The sample must contain a high percentage of network cations which are surrounded by \\
2. The tetrahedra or triangles only share corners with each other \\
3. Some oxygens are linked to only two network cations and do not form further bonds with \\
any other cations
\end{tabular}

Silicate bioactive glasses are characterized by their $\mathrm{SiO}_{4}{ }^{3-}$ tetrahedra, in which $\mathrm{Si}$ atoms are bound to four oxygen atoms while each oxygen atom is bound to two $\mathrm{Si}$ atoms. This results in a three dimensional (3D) network in which each $\mathrm{SiO}_{4}$ tetrahedral unit is bound at the corners to other tetrahedral units, with cations balancing the charges [114]. The difference in the electronegativity of $\mathrm{Si}$ (electronegativity of 1.90) and $\mathrm{O}$ (electronegativity of 3.44) atoms allows for the formation of ionic Si-O-Si bonds, which form the backbone of the glass system [115], [116]. However, Si atoms can also bond to other species in the glass composition as dictated by electronegativity [105], [117]. Generally, when two atoms bond with different electronegativities, an electron flow goes from the lower electronegative atom to the greater electronegative atom [117]. It has also been shown that silica glasses experience a modification 
A Rapidly-Dissolving Silica-Silver Bioactive Glass For Cariostatic Applications, Saad Arshad, MASc, Ryerson University, 2017

to their network when other cations or alkali species are added, and that these cations find themselves near non-bridging oxygens [116]. This modification typically increases degradation as alkali concentration is increased, forming meta, pyro and ortho-silicates in order of increasing alkali concentration [116]. Units such as $\left[\mathrm{SiO}_{4 / 2}\right]^{0},\left[\mathrm{SiO}_{3 / 2} \mathrm{O}\right]^{-},\left[\mathrm{SiO}_{2 / 2} \mathrm{O}_{2}\right]^{-2},\left[\mathrm{SiO}_{1 / 2} \mathrm{O}_{3}\right]^{-3}$ and $\left[\mathrm{SiO}_{4}\right]^{-4}$, which are present in silicate glasses are designated as $\mathrm{Q}_{4}, \mathrm{Q}_{3}, \mathrm{Q}_{2}, \mathrm{Q}_{1}$ and $\mathrm{Q}_{0}$ respectively, where the subscripts on the $\mathrm{Q}_{\mathrm{n}}$ designate the number of bridging oxygens centered on a given $\mathrm{Si}$ atom and through which they are connected to other $\mathrm{Si}$ atoms in the glass structure [116]. The addition of glass former cations in silicate glasses will result in decreased solubility in these systems [116].

Transition metals can function as network formers or network modifiers, depending on their valences; oxygen atoms bound to highly charged cations, such as $\mathrm{MoO}_{4}$, cannot form bonds with Si and therefore must act as network modifiers [118]. While transition metals can form glasses, sometimes they are only able to do so in combination with other glass forming oxides [105]. For example, $\mathrm{Va}_{2} \mathrm{O}_{5}$ can form glasses by forming chains of tetrahedra linked through two corners, while a fifth oxygen atom links to chains together to form double chains. Each Va atom therefore can be said to have five oxygen neighbours [105], [119], [120].

Glass dissolution is commonly described by one of two models: the "homonogenous" model and the "heterogeneous" model [121]. In the homogeneous model, the liquid completely enters the particles and reacts throughout them at all times. The dissolution reaction is governed by a homogeneous first-order reaction. In the heterogeneous model, glass dissolution is driven by two steps: the first step involves alkali ions being replaced with hydronium ions $\left(\mathrm{H}_{3} \mathrm{O}^{+}\right)$from the solution with the square root of time [121]. The second step is the dissolution of the glass network which is linear with time [121]. Both models have been criticized as being inadequate. 
A Rapidly-Dissolving Silica-Silver Bioactive Glass For Cariostatic Applications, Saad Arshad, MASc, Ryerson University, 2017

There are deviations from the $t^{1 / 2}$ kinetics in the first stage of heterogeneous model which are affected by environmental $\mathrm{pH}$ and the extent of network hydrolysis [122], [123]. A clear transition from the first stage to the second is not always apparent due to the formation of a microporous surface hydrated layer formed by silica dissolution [122], [123]. This layer acts as a stiff gel which does not craze but plastically deforms to relieve induced tensile stresses. The hydrated surface layer is usually brittle and crazing causes etching (dissolution) of the silicate glass network [123].

\subsubsection{Glass Ionomer Cements}

Glass Ionomer Cements (GICs) were developed by Smith (1968) and refined by Wilson and Kent (1972) [107]. They are tooth-coloured materials which bond chemically to dental hard tissues and release fluoride for a relatively long period [124]. As acid-base cements, there are three essential ingredients for GICs: a polymeric water-soluble acid, a basic ion-leachable glass and water [125]. These are usually presented as an aqueous polymeric acid and a fine, aciddegradable glass powder which are mixed to form a viscous paste that sets rapidly [125]. They can also, however, be presented in other forms, such as with the acid and glass mixed in a powder and pure water starting the reaction, or with some of the acid mixed with the glass powder while the rest of the acid is in a dilute solution in water; these varying formulations do not appear to show any obvious effect on the final properties of the cement [125]. The International Organization for Standardization (ISO) classifies their proper name as "glass polyalkenoate cements" but glass-ionomer is recognized and widely accepted in the dentistry profession [126]. The GIC setting reaction is described in Figure 16. 
A Rapidly-Dissolving Silica-Silver Bioactive Glass For Cariostatic Applications, Saad Arshad, MASc, Ryerson University, 2017

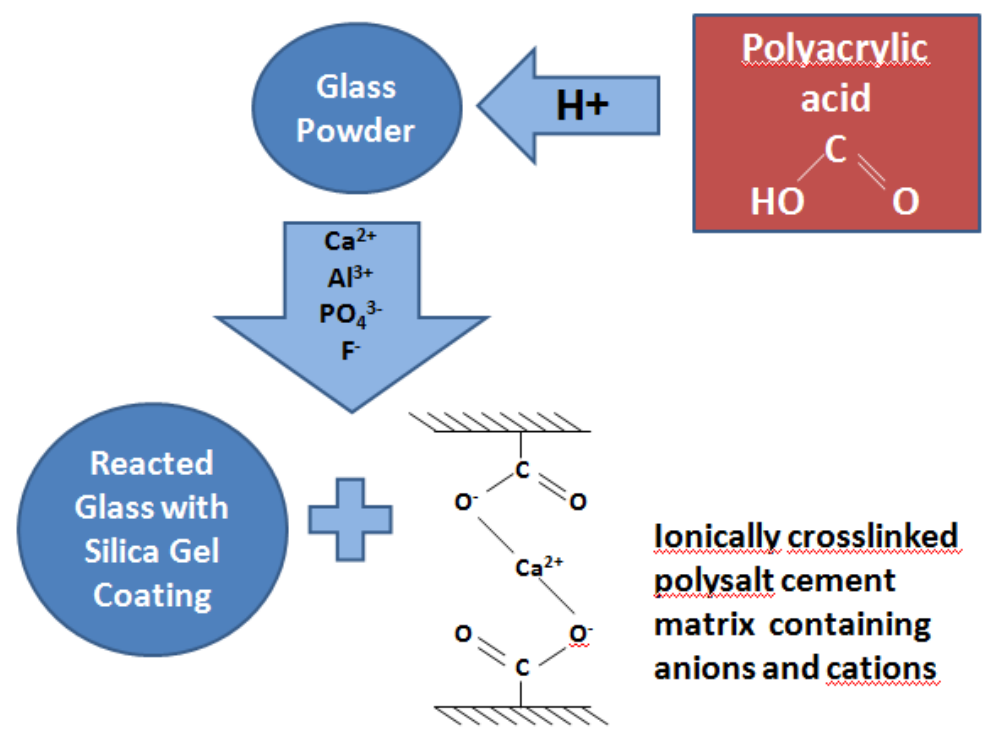

Figure 16: GIC setting reaction

Conventionally, GICs are made through an aqueous polyacrylic acid and a fluoroaluminosilicate glass component, which polymerise through an acid-base reaction [124], [125]. As metallic polyalkenoate salts begin to precipitate in the form of calcium acrylate and aluminum acrylate, gelation occurs until the cement sets [124], [127]. The final structure contains a substantial amount of unreacted glass which functions as a filler to reinforce the cement once set [125]. The carboxylic chains that form during the reaction can react with the calcium in hydroxyapatite in order to bond the cement to the tooth without the need for bonding agents [7], [128]. This is considered one of the greatest advantages of GICs as it allows the cement to be used as substitutes for missing bits of enamel and dentin during restoration procedures, instead of just a filling for cavities. If the glasses are ground smaller than $15 \mu \mathrm{m}$, the cements can also be used as luting cements in the "sandwich" technique [88], [127]. A luting cement is a lining of cement used to bond the dentin to the filling material, leveraging the superior bonding capability of the cement to create a greater seal and prevent microleakage [88]. 
A Rapidly-Dissolving Silica-Silver Bioactive Glass For Cariostatic Applications, Saad Arshad, MASc, Ryerson University, 2017

\subsubsection{Glass Ionomer Cement Mechanical Properties}

GICs have many of the same advantages of composites. They boast good esthetics and adhesion to hard dental tissues. Frequently, a therapeutic bioglass is employed in mixing which releases beneficial ions, such as fluoride, calcium, and even antibiotic agents like zinc, silver and strontium [128], [129].

The major drawback of GICs is their lack of strength and toughness; they are weak when first set and unstable in water [128]. This is because the the water can act like a plasticizer which reduces compressive and flexural strength, as well as act as a solvent for the cements components [130], [131]. However, their compressive strengths can increase up to $400 \mathrm{MPa}$ after one year [128]. Surface treatments of enamel and dentin were not found to produce significant differences in bond strength with enamel or dentin according to [132]. The mechanical properties of commercially available GICs were measured by Xie et al. (2000) after seven days and are listed in Table 8. 
A Rapidly-Dissolving Silica-Silver Bioactive Glass For Cariostatic Applications, Saad Arshad, MASc, Ryerson University, 2017

Table 8: Mean compressive strengths of commercially available GICs and resin-modified GICs. All strengths are expressed in MPa with standard deviations expressed in parentheses.[133]

\begin{tabular}{|l|l|}
\hline Glass Ionomer Cement & Mean Compressive Strength (MPa) \\
\hline Ketac-Bond & $225.7 \pm 7.3$ \\
\hline$\alpha-$ Silver & $176.0 \pm 6.5$ \\
\hline$\alpha$-Fil & $196.5 \pm 8.3$ \\
\hline Ketac-Silver & $211.8 \pm 3.2$ \\
\hline Ketac-Fil & $251.2 \pm 10.0$ \\
\hline Ketac-Molar & $301.3 \pm 10.1$ \\
\hline Fuji II & $202.0 \pm 10.0$ \\
\hline Vitremer (Tricure) & $265.3 \pm 7.5$ \\
\hline Fuji II LC & $306.2 \pm 6.8$ \\
\hline Photac-Fil & $243.5 \pm 7.9)$ \\
\hline Vitro Fil DFL GIC & $54.00 \pm 6.56$ \\
\hline Vitro Fil LC resin-modified GIC & $105.1 \pm 17.29$ \\
\hline
\end{tabular}

To overcome their poor mechanical properties, resin-modified GICs were developed by adding methacrylate to the polyacrylic acid component. According to a 2007 study by Mallmann et al. , resin-modified GICs were found to be stronger in compression [134].Error! Reference source not found. Table 8 compares an unmodified GIC (Vitro Fil DFL GIC) with a resin modified version (Vitro Fil LC resin-modified GIC). This is likely due to the extra polymer links from the resin which produce a stronger material [133], [135].

\subsubsection{Glass Ionomer Cements - Acid Phase}

The most common polymeric acids are homopolymer poly(acrylic acid) or a 2:1 copolymer of acrylic acid and maleic acid [136]. The properties of the polymer affect the cements made from them. High molecular weight acids increase the strength of the resultant cement but increase the 
A Rapidly-Dissolving Silica-Silver Bioactive Glass For Cariostatic Applications, Saad Arshad, MASc, Ryerson University, 2017

viscosity, making them difficult to mix. An optimum weight for restorative cements is said to be an average molecular weight of 11,000 (number average) or 52,000 (mass average) [137].

Cements derived from homopolymers show increases in compressive strength over the first 4-6 weeks while cements derived from copolymer acids show an increase in compressive and flexural strength over the first few months of the cements lifetime before declining to an equilibrium value. This has been attributed to the progressive slow reactions stemming from the higher crosslink density of cements deriving from copolymers as compared with cements derived from homopolymers [127]. This higher crosslink density causes the cement to be more brittle, increasing sensitivity to surface flaws and other imperfections within the cement with aging [127].

\subsubsection{Glass Ionomer Cements - Glass Phase}

Glasses must be basic in order for the acid-base reaction to occur and salts to form [127]. While in principal many glass formulations could form salts, in practice, only aluminosilicate glasses with sodium calcium, fluoride and phosphate additives are used [125]. This is because pure silica glasses would form $\mathrm{SiO}_{4}$ tetrahedra linked at the corners to form chains with no charge, since $\mathrm{Si}$ has a $4^{+}$charge. The addition of alumina results in similar geometry $\left(\mathrm{AlO}_{4}\right.$ units), but aluminum carries a formal $3^{+}$charge which does not counteract the negatively charged oxygen atoms as effectively, resulting in a basicity which is vulnerable to acid attack [125], [127]. Extra cations such as $\mathrm{Na}^{+}, \mathrm{Ca}^{2+}$ or $\mathrm{Sr}^{2+}$ balance the charge and break the continous bridging oxygen network [125]. Glass chemistry will be discussed in greater detail in Chapter 1.6.

\subsubsection{Glass Ionomer Cement Cariostatic Efficacy}

A study by Aboush and Torabzadeh (1998) determined that cumulative fluoride release from

GICs is up to five times higher than compomers and up to twenty-one times more than resin composites at the end of twelve months in deionized water [138]. Additionally, during a 24 
A Rapidly-Dissolving Silica-Silver Bioactive Glass For Cariostatic Applications, Saad Arshad, MASc, Ryerson University, 2017

month span, the fluoride release from GICs was five to six times higher than compomers. Table 9 summarizes the findings. Furthermore, Benelli et al. (1993) found that plaque formed on enamel blocks adjacent to GICs in situ contained six times more fluoride than plaque adjacent to resin composites after 28 days [139]. The same study also showed a greater microhardness at several depths in the enamel from the surface, as well as at some distance from the filling as compared to composite resins. This suggests a more potent remineralizing effect from GICs than from composite resins as the increased fluorine concentration can limit the cariogenic effects of S. mutans. Furthermore, the increased microhardness result at several depths demonstrates that the mineral phase of the enamel blocks have undergone significant remineralization.

Table 9: Fluroide release after twelve months and in twenty-four hours one year after curing from three different dental restoration materials. [138]

\begin{tabular}{|c|c|c|c|c|c|}
\hline \multicolumn{3}{|c|}{ After twelve months $\left(\mu \mathrm{g} / \mathrm{cm}^{2}\right)$} & \multicolumn{3}{|c|}{$\begin{array}{l}\text { During last } 24 \text { hour period of twelve-month } \\
\text { test period }\left(\mu \mathrm{g} / \mathrm{cm}^{2}\right)\end{array}$} \\
\hline GIC & Compomer & Resin Composite & GIC & Compomer & Resin Composite \\
\hline Fuji Cap II (GC & Dyract (De Trey & Tetric (Ivoclar & Fuji Cap II (GC & Dytract (De Trey & Tetric (Ivoclar \\
\hline International) & Dentsply) & Vivadent) & International) & Dentsply) & Vivadent) \\
\hline $480 \pm 42$ & $87 \pm 17$ & $22 \pm 2$ & $1.3 \pm 0.20$ & $0.21 \pm 0.04$ & $0.23 \pm 0.02$ \\
\hline
\end{tabular}

The cariostatic effect of GICs and composite resins have been compared. Ersin et al. (2006) and Levy and Jensen (1990) showed that there is no significant caries preventative difference on either primary or permanent teeth between the two materials [140], [141]. However, Mickenautsch et al. (2009) showed that permanent teeth restored with GICs have significantly less carious lesions after six years as compared to teeth restored with amalgam [142]. While the difference was not statistically significant in primary teeth, GICs were still favoured. 
A Rapidly-Dissolving Silica-Silver Bioactive Glass For Cariostatic Applications, Saad Arshad, MASc, Ryerson University, 2017

\subsubsection{Polyacid-Modified Resin Composites (Compomers)}

Poly*-acid-modified resin composites, commonly referred to as compomers, are a class of dental materials that are designed to provide the benefits of both resin composites and GICs [7]. The introduction of components from GICs into the resin composite as well as additional monomers with carboxylic acid groups means that as they mature, they take up small amounts of moisture to facilitate an acid-base reaction [7], [143]. This allows compomers to take in and release clinically significant amounts of fluoride [58-60]. A study by Asmussen and Peutzfeldt found that while compomers release relatively little fluoride upon setting compared to the 'burst' that GICs provide, the long term fluoride release rate of compomers is comparable to GICs [147]. This gives compomers a similar effect to GICs in their ability to act as fluoride reservoirs, albeit with smaller quantities of fluoride. It is believed that this is due to the fluoride being bonded to the filler particles rather than being free, making the compomer behave far more like a resin composite during the first phase of the setting process [148].

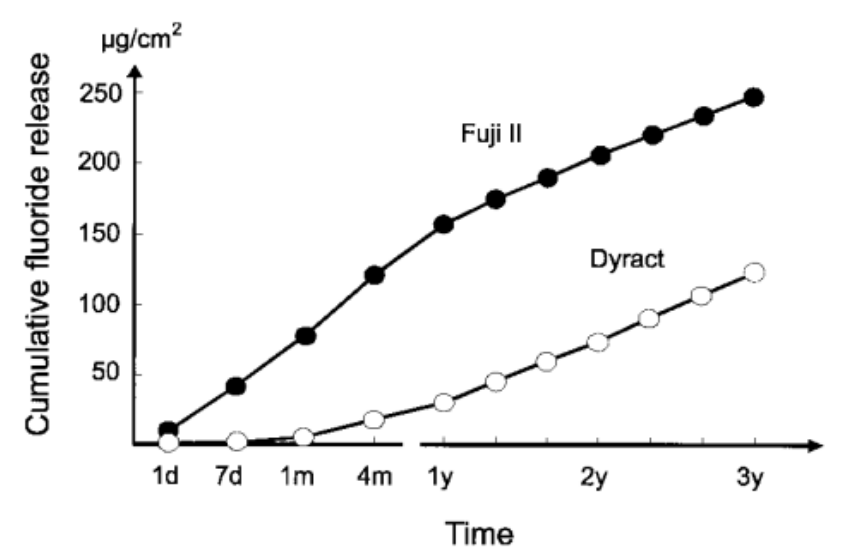

Figure 17: Cumulative fluoride release of a conventional GIC (Fuji II) vs a Compomer (Dyract) in distilled water over three years [147]

Compomers also boast good esthetics, high diametral compression and flexural strengths compared to resin composites and conventional GICs [6], [143]. They have better wear 
A Rapidly-Dissolving Silica-Silver Bioactive Glass For Cariostatic Applications, Saad Arshad, MASc, Ryerson University, 2017

properties than conventional GICs and resin composites [149], [150] but lack the ability to bond to hard dental tissues [7], [151].

\subsubsection{Bioactive Glasses}

Before the advent of bioactive materials, most implant devices would not bond with hard body tissues. Rather, the body would form scar tissue which would not allow the implant to adhere to the site [11]. Therefore, initial biomaterials were designed to be bio-inert in order to not provoke a reaction between the foreign body and the host site. Metallic implants were designed to have very high corrosion resistance due to the dangers of electrochemical dissolution; it was therefore suggested that dissimilar metals must never be placed in the same patient, as they can cause an electrolytic reaction [12]. Only Vitallium and surgical stainless steel implants were used as orthopaedic implants [11], [12], [152]. Polymeric implants were designed to prevent degradation [11], [12]. However, Hench and Greenlee changed the approach to biomaterials by developing a soda-lime-phosphate-silicate bioglass which was designed to bond with bone [11], [12], [153]. The materials were bioactive as they promoted adhesion to bone and bone regrowth [154].

\subsubsection{Hench's 45S5 Bioactive Glass}

A silica-based glass with network modifiers of $\mathrm{Na}_{2} \mathrm{O}$ and $\mathrm{CaO}$, along with an amount of $\mathrm{P}_{2} \mathrm{O}_{5}$ to simulate the $\mathrm{Ca} / \mathrm{P}$ ratio of hydroxyapatite, 45S5 did not form scar tissue and instead bonded to femoral rat bone and could not be removed from the host site, as shown in Figure 18 [11], [12], [153]. Using transmission electron microscopy, it was found that the growing bone mineral had interlocked with collagen fibers in the bonded interface, suggesting a bond to bone. Furthermore, X-ray diffraction of the glasses in a calcium-phosphate solution showed the growth of biologically active hydroxyapatite crystal phases on the surface of the glass that were similar to the spectra of HA in living bone, again showing the bonding to bone [11], [153], [155]. These materials are commonly used as coatings for other implant devices to promote bonding to bone, 
A Rapidly-Dissolving Silica-Silver Bioactive Glass For Cariostatic Applications, Saad Arshad, MASc, Ryerson University, 2017

bone grafts in which they are used to fill bone defects, or as bulk implants to restore teeth [11], [156], [157].

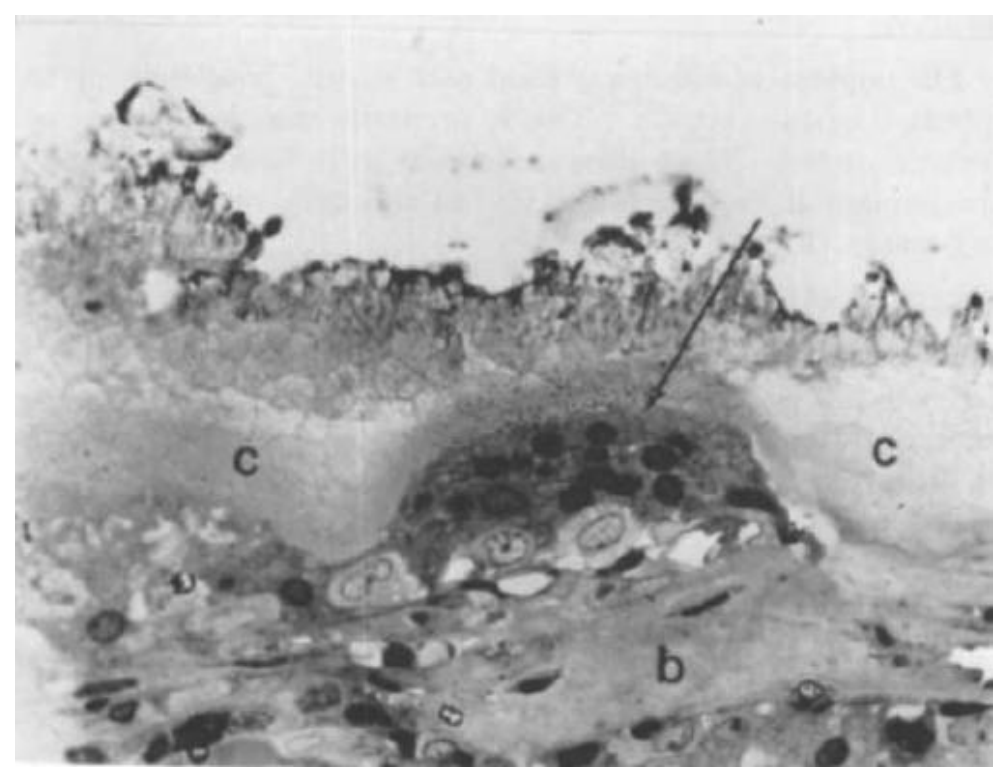

Figure 18: Bonding to bone between $45 \mathrm{~S} 5$ glass and rat femur after 6 weeks. (c) represents the implant and (b) represents bone. The arrow points to osteoclasts forming at the interface between the remnants of the implant and the bone. Light microscopic image at x630 magnification [153]

Bioglasses are marketed under several different tradenames. The bioglass 45S5 has been altered to tailor it to several different applications including bone grafts (NovaBone, NovaBone Products, FL, USA), dentinal hypersensitivity and periodontal defects (NovaMin, GlaxoSmithKline, UK) [11], [158]. NovaMin is incorporated into dentifrices (Sensodyne Repair and Protect, GlaxoSmithKline, UK) to promote remineralization of enamel and treat dental hypersensitivity [159]. Calcium-phosphate crystals can plug up dentinal tubules, decreasing sensitivity and dentin permeability [160], [161].

45S5 remineralizes enamel by precipitating the calcium and phosphate ions onto the enamel surface layer. The calcium, sodium and phosphate ions are leached out of the glass network structure during an acid attack and go into aqueous solution in which the phosphate ions pick up and bond to the calcium ions to form calcium phosphate salts[160]. The enamel may also give up 
A Rapidly-Dissolving Silica-Silver Bioactive Glass For Cariostatic Applications, Saad Arshad, MASc, Ryerson University, 2017

calcium and phosphate ions to the aqueous solution [162]. These salts then precipitate onto the dentin surface as they dissolve out of the remaining silanol compounds. The silanol compounds are soluble in water and elemental analysis shows that only trace amounts of silica are found in the interaction layer [163], although it is believed that the silica may enhance remineralization for early cariogenic lesions, especially in dentin [13], [14], [164]. Some of the smaller crystals are able to penetrate the deeper sub-surface lesion through the porous outer enamel layer to saturate the lesion with calcium and phosphate ions while surface enamel will have a layer of brushite, an acidic calcium-phosphate salt form [160], [163]. They are then remineralized in to the surface and sub-surface of the enamel lesions [160]. The process is illustrated in Figure 19 below.

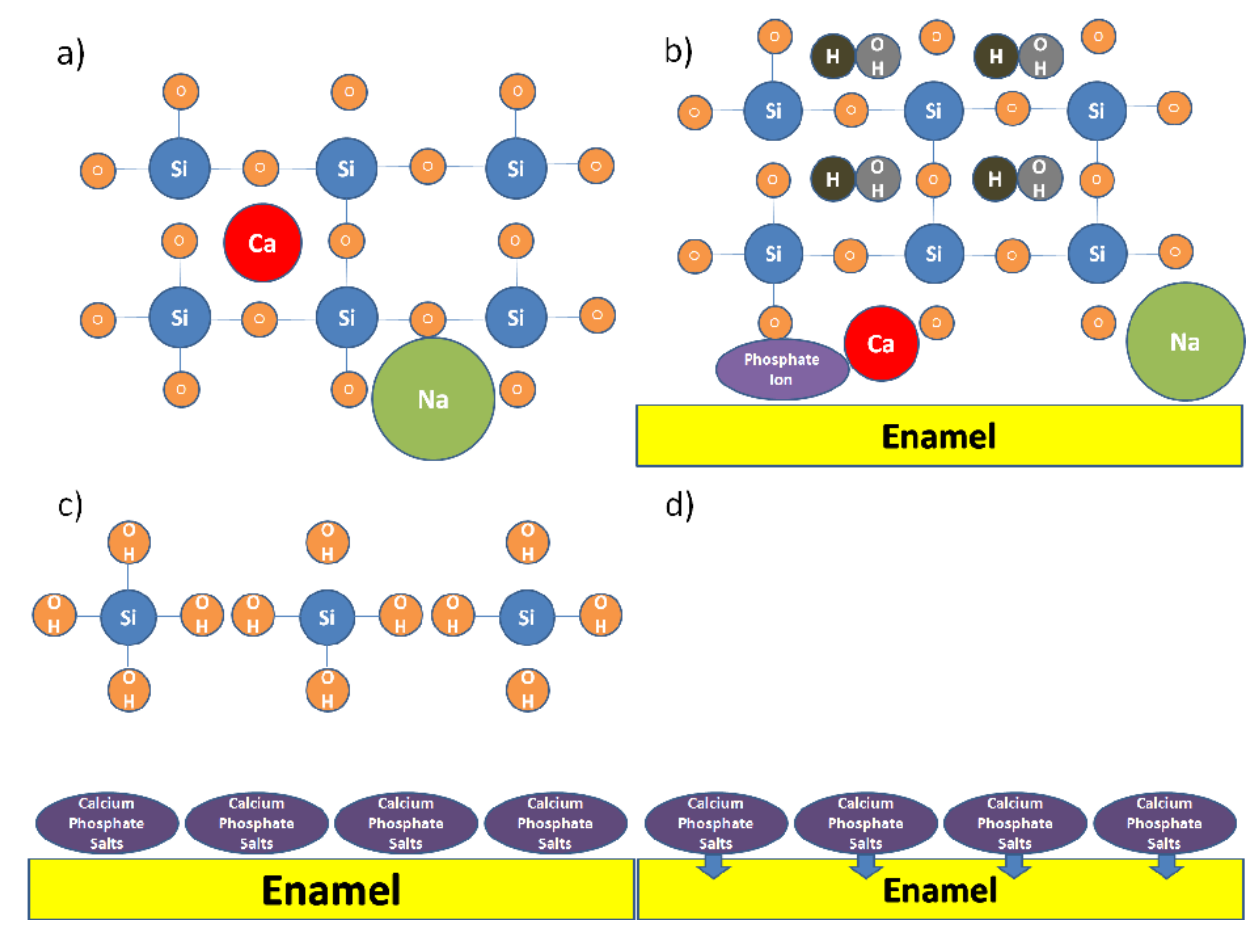

Figure 19: Suggested action of enamel remineralization by $45 \mathrm{~S} 5$ bioglass. A) Structure of $45 \mathrm{S5}$ bioglass. B) Calcium, phosphate and sodium ions leached out of network structure. Phosphate ions pick up calcium ions and form calcium phophate salts. C) Calcium phosphate salts precipitate onto the enamel surface as they dissolve out of silanol compounds.

D) Calcium phosphate salts begin to remineralize enamel in the surface and sub-surface of enamel lesions. [160] 
A Rapidly-Dissolving Silica-Silver Bioactive Glass For Cariostatic Applications, Saad Arshad, MASc, Ryerson University, 2017

\subsubsection{Antibacterial Effects of Bioactive Glass}

Bioactive glasses can also demonstrate antibacterial effects. Studies by Prabhakar and Kumar (2010) found that 45S5 was effective against enterococcus faecalis, a bacterial strain commonly associated with apical periodontitis, when compared with controls [15]. A similar study by Zehnder et al. (2004) found that the bioactive glass S53P4 was also effective against $e$. faecalis [16] when compared with controls. Apical periodontitis is an inflammation of the tip of the root area of a tooth due to infection of mixed, mostly anaerobic bacteria [165]. The addition of powdered dentin increased the antibacterial effect against many oral microorganisms after 24 hours and three days, although the effect reduced after five days. The antibacterial effect of bioactive glass is a function of the ability of the glasses to raise the $\mathrm{pH}$ of an aqueous solution [15]. Bacteria and host cells are not well suited to surviving in the higher $\mathrm{pH}$ environments. However, raising the $\mathrm{pH}$ in the host environment does not provide an immediate antibacterial effect like potassium iodide, sodium hypochlorite or chlorhexidine but rather a sustained, longlasting, slow-acting effect [16]. The antibacterial effect of adding dentin powder is not fully understood but is believed to provide a source of calcium and phosphate ions, allowing the bioactive glass to "mineralize" the bacteria by forming $\mathrm{Ca} / \mathrm{P}$ precipitates on the surface, destroying their cell integrity [16]. Adding powdered enamel did not significantly increase the antibacterial effect of bioactive glasses after 24 hours or three days, but did demonstrate an increased effectiveness after five days [15]. Furthermore, particle size was found to have a significant effect on the antibacterial action of bioactive glasses; the increased surface area makes the glass more reactive by exposing a greater portion of the glass to acid attack thus resulting in the release of more ions [166]. Additionally, Perioglass, commonly used as a bone graft material, has particle sizes near $20-63 \mu \mathrm{m}$ and exhibits a lower antimicrobial effect since the 
A Rapidly-Dissolving Silica-Silver Bioactive Glass For Cariostatic Applications, Saad Arshad, MASc, Ryerson University, 2017

glass cannot enter the deeper portions of the dentinal tubules, which can be full of microorganisms [166].

\subsubsection{Remineralization Potential of Bioactive Glass}

A study by Bakry et al. (2014) investigated the effect of NovaMin particles dissolved in a phosphoric paste on demineralized enamel [160]. Enamel slices were subjected to an erosion challenge and then treated with either fluoride gels for short and long term exposures or a bioglass paste, made by mixing 45S5 bioglass with $0.2 \mathrm{~mL}$ of $50 \mathrm{wt} \%$ phosphoric acid (Wako Chemicals, Japan). They found that the sub-surface enamel lesions demonstrated significantly better micro-mechanical properties after treatment with the bioglass when compared with the control group and fluoride treatments at depths of $30 \mu \mathrm{m}, 40 \mu \mathrm{m}$ and $50 \mu \mathrm{m}$. Fluoride treatments improved remineralization at depths of $30 \mu \mathrm{m}$ and long term exposure improved remineralization at depths up to $40 \mu \mathrm{m}$. However, the remineralization from bioglass treatments was more significant than the fluoride treatments, as evidenced in Figure 20. This is likely due to the fluoride ions combining with superficial layers of the enamel lesion, making it difficult for fluoride ions to penetrate any deeper in to the lesion [167], [168].

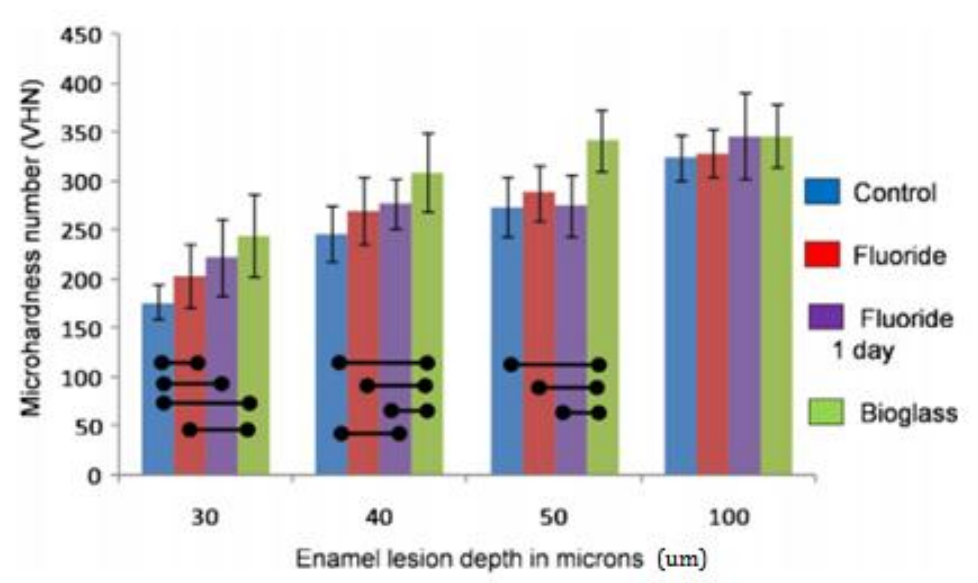

Figure 20: Cross-sectional microhardness at various enamel lesion depths when subjected to fluoride and bioglass treatments after erosion challenges. Connected bars are statistically significant $(p<0.05)$. [160] 
A Rapidly-Dissolving Silica-Silver Bioactive Glass For Cariostatic Applications, Saad Arshad, MASc, Ryerson University, 2017

However, a study by Diamanti et al. (2010) found that fluoridated dentifrices were more effective than NovaMin containing toothpastes at remineralizing dentin after an acid challenge [13]. Ten daily cycles of demineralization and remineralization cycles were applied to dentin slabs in a 30 minute demineralization phase followed by a four hour remineralization period. A second demineralization phase lasting another 30 minutes was then followed up by an overnight remineralization period lasting 16 hours. The dentin slabs were then submersed in toothpaste slurries consisting of 1:3 dentifrice to distilled water, where the dentifrices included three different concentrations of fluoride containing toothpaste (5000ppm F, 2800ppm F, 1450ppm F), a 7.5\% NovaMin containing toothpaste as well as a non-fluoridated toothpaste as a control. Knoop hardness measurements were taken to determine the remineralization efficacy of each treatment. The fluoridated treatments showed the greatest hardness, with the 5000ppm F treatment the most effective at $28.85 \pm 1.06 \mathrm{KHN}$, followed by the $2800 \mathrm{ppm} \mathrm{F}$ at $26.48 \pm 1.41$ KHN, then the 1450ppm $\mathrm{F}$ at $23.96 \pm 1.60 \mathrm{KHN}$ and finally the $7.5 \%$ NovaMin treatment $21.62 \pm 2.83$. The control measured in at $20.85 \pm 1.78 \mathrm{KHN}$. It is suspected that the presence of silica near dentin precipitates into hydroxyl-carbonate apatite more favourably than fluorhydroxyl apatite, forming a far more soluble crystal [169].

It can be surmised from the above studies that while bioactive glass therapies are better at remineralizing enamel, high fluoride treatments are better at remineralizing dentin. Fluoride ions precipitate in superficial layers on the enamel and are unable to pentetrate deeper into lesions, making them ineffective at remineralizing them. In dentin remineralization tests however, fluoride performed better as it is able to reach the deeper levels it could not during enamel remineralizatoin challenges. Additionally, the silica content in bioactive glasses favors the 
A Rapidly-Dissolving Silica-Silver Bioactive Glass For Cariostatic Applications, Saad Arshad, MASc, Ryerson University, 2017

formation of hydroxyl-carbonate apatite, which is a more soluble mineral when compared with fluor-hydroxyl apatite.

A study by Deng et al. found that the use of 45S5 bioactive glass during hydrogen peroxide whitening treatments helped reduce the microhardness loss of enamel [170]. Bioactive glass alone could not whiten teeth but hydrogen peroxide alone caused significant microhardness loss and morphological change of enamel. The symbiotic effect of bioactive glass in hydrogen peroxide took advantage of the alkalinity and accelerated the ionic leaching of the bioactive glass in order to offset the damage of bleaching therapies [170].

\subsubsection{Dentifrices}

Most dental therapies are generally reactive measures in that they are employed when lesions have grown into cavities. Ideally, therapies should be more proactive in that they address demineralized enamel before lesions can form. Dentifrices can be useful in impeding erosive tooth surface loss [171]. A dentifrice is a preparation which is generally used with a toothbrush in order to clean or polish teeth [172]. Modern dentifrices often claim various beneficial effects such as plaque removal, anti-caries effects, remineralization effects, antibacterial effects, tooth whitening, reduction in oral malodor, anti-gingivitis effects, desensitization effects, periodontal healing among many other effects [172].

Dentifrices often contain remineralization agents such as various fluoride compounds, potassium, calcium and phosphate as well as Novamin [28], [171], [173]. Fluoride compounds, as discussed earlier, can reduce dissolution through forming compounds which prevent it. $\mathrm{SnF}_{2}$, an ingredient in many toothpastes, has been shown to form complexes which are more resistant to acid attack in vitro [174]-[176] and well as in situ using toothpastes and rinses [177] through the deposition of a tin-rich surface on the enamel [171], while $\mathrm{ZnF}_{2}$, another common ingredient in toothpaste, 
A Rapidly-Dissolving Silica-Silver Bioactive Glass For Cariostatic Applications, Saad Arshad, MASc, Ryerson University, 2017

can provide the antibacterial action of zinc in addition to the cariostatic effect of fluoride [175], [178], [179]. Potassium can provide relief from dentin hypersensitivity through occlusion of tubules [17], [28], [173], [180] . Calcium and phophate compounds are valuable in remineralizing hydroxyapatite [181]. Novamin is a bioactive glass which provides a source of calcium and phosphate, as well as limited antiseptic capability [15].

It is commonly accepted that use of dentifrices have shown an ability to remove plaque buildup [182]. Plaque is a microbiological biofilm and is the chief cause of dental caries and periodontal disease [4]. However, Valkenburg et al. found that toothbrushing with a dentifrice does not provide a benefit for mechanical removal of dental plaque [172]. They suggested that the mechanical action provided by the toothbrush itself and the skill of the individual play a larger role in reducing plaque [182], [183]. While toothpastes often contain abrasives, these are not effective in removing plaque build-up [183], [184]. The abrasives in toothpastes are far more effective at removing stained pellicle, and preventing teeth from becoming stained [185], [186]. The pellicle is a thin film which is considerably tougher to remove than plaque and cannot be broken through the bristles on a toothbrush [186]. Abrasive particles penetrate and remove the stained pellicle films [186].

Sapra et al. tested an herbal extract, Spilanthes calva, an herb found in India commonly known as Akarkarah (toothache plant), along with an herbal dentifrice (Arodent) and a commercial dentifrice (Colgate) [187] against salivary amylase. They found that s. calva was effective in reducing plaque build-up through inhibiting salivary amylase [187]. Salivary amylase is a digestive enzyme produced in the salivary glands which plays a key role in metabolizing Streptococcus, leading to the formation of dental plaque and dental caries [188]. The results are summarized in Table 10. 
A Rapidly-Dissolving Silica-Silver Bioactive Glass For Cariostatic Applications, Saad Arshad, MASc, Ryerson University, 2017

Table 10: Effect of various dentifrices on salivary amylase activity. All results are statistically significant at $\mathbf{p}<0.05$ except for the control. [187]

\begin{tabular}{|l|l|l|l|}
\hline Dentifrice & $\begin{array}{l}\text { Pre-Application }(\mathbf{m g} \\
\text { maltose/ml) }\end{array}$ & $\begin{array}{l}\text { Post-Application (mg } \\
\text { maltose/ml) }\end{array}$ & Difference \\
\hline S. Calva & $8.08 \pm 0.60$ & $4.11 \pm 0.33$ & $3.97 \pm 0.46$ (maximum) \\
\hline Arodent & $8.01 \pm 0.66$ & $6.05 \pm 0.83$ & $1.96 \pm 0.69$ \\
\hline Colgate & $8.22 \pm 0.68$ & $6.73 \pm 0.95$ & $1.49 \pm 0.41$ \\
\hline Control & $7.58 \pm 0.69$ & $7.40 \pm 0.92$ & $0.18 \pm 0.13$ (minimum) \\
\hline
\end{tabular}

As shown above, s. calva was more effective than traditional dentifrices in inhibiting plaque build-up. The amylase activity was measured through how much maltose was produced from starch supplied to the assays [187].

Tooth whitening is another function of dentifrices. Whitening agents promote decomposition of pigmented organic materials through their oxidation [189]. They release free radicals, such as oxygen or hydroxyl, which have unpaired electrons in the outermost electron shell, giving them a strong tendency to interact with other electrons under the same conditions, stabilizing their incomplete orbits [190], [191]. The released free radicals initiate an oxidation process on the teeth in which dark-coloured, high-weight molecules break down into lighter-coloured lowweight molecules, whitening the teeth [191]. However, while they are effective at attacking organic pigment-generating tissues, they also produce adverse effects such as tooth demineralization and irritation of neighbouring tissues [189], [192]. When whitening agents are embedded into dentifrices, it is believed the mineral loss is greater from the mechanical action of brushing than from the whitening agents [193], [194]. It is believed that the duration of exposure on enamel of the whitening agent has a far greater effect than the concentration of the agent 
A Rapidly-Dissolving Silica-Silver Bioactive Glass For Cariostatic Applications, Saad Arshad, MASc, Ryerson University, 2017

[194], [195]. A study by de Araujo et al. tested three dentifrices containing various bleaching agents, as listed in Table 11 below [189].

Table 11: Dentifrices containing bleaching agents tested by de Araujo et al. [189]

\begin{tabular}{|l|l|l|}
\hline Dentifrice & Manufacturer & Bleaching Agent \\
\hline Mentadent & $\begin{array}{l}\text { (Chesebrough Pond's USA Co., } \\
\text { Oral Division, Greenwich, CT, } \\
\text { USA) }\end{array}$ & Hydrogen Peroxide \\
\hline Rembrandt & $\begin{array}{l}\text { (Den-Mat Corporation, Santa } \\
\text { Maria, CA, USA) }\end{array}$ & Carbamide peroxide \\
\hline Colgate & (Colgate-Palmolive Company, S. & Sodium Bicarbonate \\
\hline Colgate Total 12 & Paulo, Brazil) & \\
\hline
\end{tabular}

They found that while all were effective as whitening agents, the abrasive sodium bicarbonate treatment resulted in lesions of the greatest severity while treatments involving carbamide peroxide produced lesions of the least severity.

An in vitro study by Roopa et al. found that compomer and composite restorations treated with conventional toothpastes and whitening toothpastes showed no significant differences in microhardness after two and four weeks, while they did detect a significant colour difference with the compomer and composite restorations when using the whitening toothpaste as compared with the conventional toothpaste [196]. They also found that the whitening toothpaste produced a more significant change in surface roughness than conventional toothpastes on both compomer and composite restorations at both two and four weeks. The results are summarized in Table 12 below. 
A Rapidly-Dissolving Silica-Silver Bioactive Glass For Cariostatic Applications, Saad Arshad, MASc, Ryerson University, 2017

Table 12: Comparison of Conventional and Whitening Toothpaste on Compomer and Composite Restorations. Microhardness values are in VHN with $25 \mathrm{~g}$ for $20 \mathrm{~s}$. Colour was measured as $\Delta \mathrm{E}$ (total colour change) with a spectrophotometer with a $10 \mathrm{~mm}$ aperture and 065 illuminant. Surface roughness was measured in $R a(\mu \mathrm{m})$ with a radius of $1.5 \mu \mathrm{m}$ at a constant speed of $0.1 \mathrm{~mm} / \mathrm{s}$ with a force of $0.7 \mathrm{~mm}$, with a cutoff at $0.25 \mathrm{~mm}$, measured with a surface roughness machine. [196]

\begin{tabular}{|c|c|c|}
\hline Group & 2 Weeks Mean Change & 4 Weeks Mean Change \\
\hline $\begin{array}{l}\text { Compomer With Conventional } \\
\text { Toothpaste }\end{array}$ & $\begin{array}{l}\text { Microhardness } 0.18 \pm 0.47 \\
\text { Colour Stability } 0.71 \pm 0.47 \\
\text { Surface Roughness } 0.09 \pm 0.47\end{array}$ & $\begin{array}{l}\text { Microhardness } 0.81 \pm 1.13 \\
\text { Colour Stability } 1.03 \pm 0.62 \\
\text { Surface Roughness } 0.16 \pm 0.05\end{array}$ \\
\hline $\begin{array}{l}\text { Composite With Conventional } \\
\text { Toothpaste }\end{array}$ & $\begin{array}{l}\text { Microhardness } 0.39 \pm 0.93 \\
\text { Colour Stability } 1.02 \pm 0.11 \\
\text { Surface Roughness } 0.01 \pm 0.03\end{array}$ & $\begin{array}{l}\text { Microhardness } 0.21 \pm 1.06 \\
\text { Colour Stability } 0.97 \pm 0.31 \\
\text { Surface Roughness } 0.12 \pm 0.04\end{array}$ \\
\hline $\begin{array}{l}\text { Compomer With Whitening } \\
\text { Toothpaste }\end{array}$ & $\begin{array}{l}\text { Microhardness } 0.35 \pm 0.98 \\
\text { Colour Stability } 2.12 \pm 0.32 \\
\text { Surface Roughness } 0.10 \pm 0.04\end{array}$ & $\begin{array}{l}\text { Microhardness } 1.17 \pm 0.91 \\
\text { Colour Stability } 2.19 \pm 0.06 \\
\text { Surface Roughness } 0.21 \pm 0.01\end{array}$ \\
\hline $\begin{array}{l}\text { Composite With Whitening } \\
\text { Toothpaste }\end{array}$ & $\begin{array}{l}\text { Microhardness } 0.75 \pm 1.37 \\
\text { Colour Stability } 1.93 \pm 0.29 \\
\text { Surface Roughness } 0.05 \pm 0.03\end{array}$ & $\begin{array}{l}\text { Microhardness } 0.01 \pm 0.52 \\
\text { Colour Stability } 1.98 \pm 0.22 \\
\text { Surface Roughness } 0.20 \pm 0.04\end{array}$ \\
\hline
\end{tabular}

The whitening toothpaste contained an ingredient known as perlite, an amorphous mixed glossy silicate compound which is chemically inert and $\mathrm{pH}$ neutral [196]. It is often used in professional prophylactic pastes as it demonstrates an excellent ability to clean and polish; when combined with silica in toothpaste, it has also proven to be a potent stain removal and stain prevention agent [197].

Dentifrices normally contain an abrasive, which can be useful for reducing or eliminating stains [196], [198]. Dentifrices containing carbamide or hydrogen peroxide, along with alumina, silica and calcium carbonate are known to produce changes in surface roughness [198]. Tooth brushing can erode the soft polymer matrix of resin composite materials [198]. The difference in the 
A Rapidly-Dissolving Silica-Silver Bioactive Glass For Cariostatic Applications, Saad Arshad, MASc, Ryerson University, 2017

surface roughness reported by Roopa et al. in the composite and compomer materials can be attributed to the differences in the wear resistance between composite and compomer [196].

\subsection{Innovations in Current Solutions}

A major problem with implantatable devices are infections due to biofilm growth near an implant. Implants tend to produce ideal substrates for biofilms to develop on [199]-[201] and often, implant sites require revision surgery to deal with biomaterial-centered infections [202], [203]. The use of invasive devices and can allow microorganisms to bypass the natural immune system and create infections [201], [204]. Therefore, many biomaterials are doped with antimicrobial ions such as silver or gallium, which can provide an effective alternative to antibiotic treatments, especially with inhibiting biofilm growth [205]-[210].

Strontium has also garnered significant attention as it can be readily accepted into HA crystals through substitution for $\mathrm{Ca}$ and creates stronger bones [32]. Osteoporotic patients treated with strontium ranelate were found to have fewer fracture incidences [211]. Strontium ions $\left(\mathrm{Sr}^{2+}\right)$ has been found to enhance preosteoblastic cell replication and collagen synthesis while simultaneously inhibiting osteoclasts, resulting in increased bone mass [212]. Some studies have shown that $\mathrm{Sr}^{2+}$ may possess antibacterial properties through a synergistic action with fluorine ions, however this mechanism is not well understood [201], [213], [214]. $\mathrm{Sr}^{2+}$ have shown antibacterial properties when tested against periodontal bacteria such as S. mutans, lactobacillus, P.gingivalis and E. coli [215], [216]. However, others still have challenged the antibacterial properties of $\mathrm{Sr}^{2+}$ as actually being very weak, and that the observed cariostatic effect is due to the enhanced remineralization effect of $\mathrm{Sr}^{2+}$, rendering enamel stronger against caries attacks [217], [218]. 
A Rapidly-Dissolving Silica-Silver Bioactive Glass For Cariostatic Applications, Saad Arshad, MASc, Ryerson University, 2017

Other ions that have been included in biomaterials include known antibacterial ions such as $\mathrm{Zn}^{2+}$ and $\mathrm{Ag}^{+}$[214]. Silver nitrate has been used to treat wounds and ulcers, while silver containers are used for disinfecting food and water [219]. The exact mechanism by which silver exerts its antimicrobial activity is not fully understood but the most commonly accepted explanation describes silver as bonding to sulfhydryl groups on the surface of cell membranes, blocking respiration and electron transfer inside the cell as well as blocking the proton motive force have been proposed [220], [221]. These actions can deenergize the cell membrane and ultimately lead to cell death.

\subsubsection{Role of Strontium}

Strontium has a similar atomic radius to calcium and is readily substituted for calcium in the apatite lattice. In a study by Curzon et al., strontium concentrations in drinking water were taken from Fort Recovery, Delphos and Portsmouth (all OH, USA) while children were surveyed for decayed, missing and filled surfaces (DMFS) scores [18]. Fort Recovery and Delphos boasted strontium concentrations of about 5.3 and 5.45 ppm respectively whilst Portsmouth only had 0.2 ppm. Children were found to have DMFS scores of 3.56 per child in the former two cities while Portsmouth had a score of 5.54. Ten years later, the concentrations and surveys were completed again and it was found that Fort Recovery and Delphos had an increased Strontium concentration; up to 10.98 and $7.25 \mathrm{ppm}$ respectively. Portsmouth remained the same. However, DMFS scores for Portsmouth went up to 7.63 while Fort Recovery and Delphos went down to 2.4 on average. Increasing strontium concentrations in enamel and plaque were correlated with decreasing DMFS scores. This is a mathematical relationship and a cause-and-effect condition was not established [18]. 
A Rapidly-Dissolving Silica-Silver Bioactive Glass For Cariostatic Applications, Saad Arshad, MASc, Ryerson University, 2017

Another study, also performed by Curzon et al., in Wisconsin, USA, corroborated these results [19]. Seven communities were surveyed for caries scores and strontium content in drinking water. $\mathrm{Sr}^{2+}$ concentrations in water varied from $0.022 \mathrm{ppm}$ at their lowest to $33.9 \mathrm{ppm}$ at their highest. The two communities with the lowest caries scores had strontium concentrations of 5.4 and $8.3 \mathrm{ppm}$ respectively. Strontium ion concentrations higher or lower than these were associated with higher caries scores. This suggests that there is an optimum level of strontium required for the maximum remineralization effect. It is also worth noting that all communities had reported a similar fluoride concentrations in their water, ranging from 1.00 and $1.29 \mathrm{ppm}$. It is believed that strontium may end up in plaque and is available for remineralization [19]. However, a synergistic effect between fluoride and strontium is the most plausible explanation for the low-caries incidences in these communities.

\subsubsection{Role of Strontium-Fluoride}

Yassen performed a study to investigate the effects of strontium and strontium-fluoride combinations on caries and found that strontium alone did not increase remineralization [222]. However, when combined with fluoride, a synergistic effect was noticed and this provided the second strongest remineralizing effect, after the fluoride without strontium group. Specifically, the $10 \mathrm{ppm}$ strontium combined with $0.05 \mathrm{ppm}$ fluoride group repaired lesions the best with the exception of $0 \mathrm{ppm}$ strontium and $0.05 \mathrm{ppm}$ fluoride group. This claim is further supported by Thuy et al. who performed a similar study [20], where fluorine was added to a remineralization solution in varying concentrations. Strontium was then mixed in at $10 \mathrm{ppm}$. The study reported strontium providing more mineralization in terms of both quality and quantity. Figure 21 below shows microradiographs of enamel remineralization due to different concentrations of fluoride and strontium. The addition of strontium was found to produce approximately $10 \%$ greater average remineralization than fluoride alone. 
A Rapidly-Dissolving Silica-Silver Bioactive Glass For Cariostatic Applications, Saad Arshad, MASc, Ryerson University, 2017
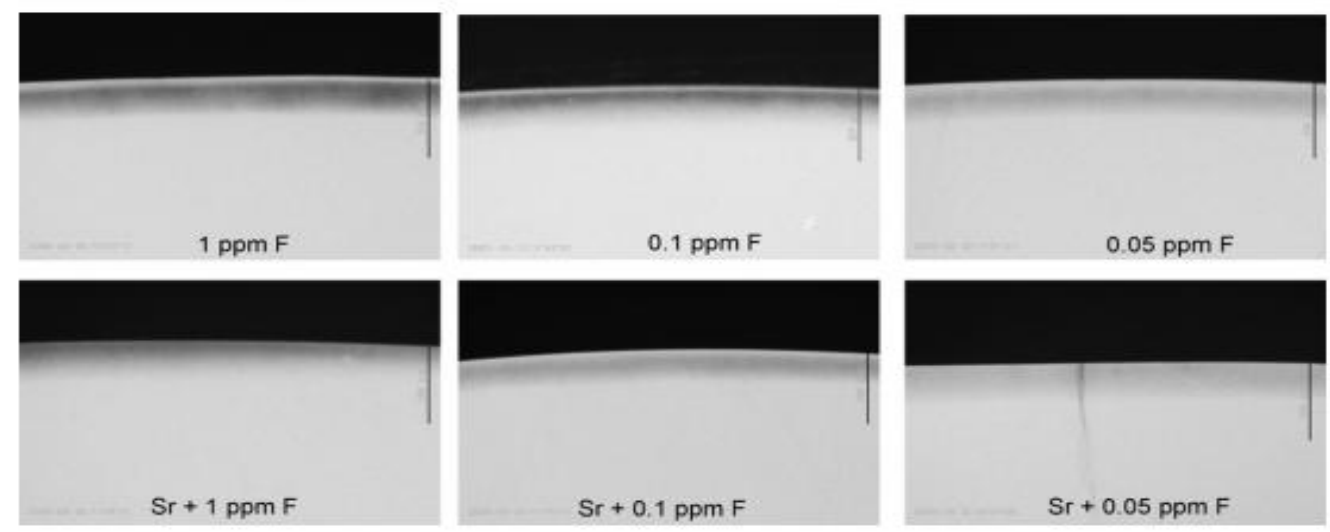

Figure 21: Remineralization Microradiographs. The faint grey areas near the top of the enamel specimens shows demineralization while the darker greys in the bulk of the specimen show mineralized enamel. [20]

Strontium regimens are also very effective in increasing acid resistance in enamel. In a study by Koletsi-Kounari et al., strontium-fluorine regimens were identified as one of the strongest candidates in terms of remineralization and acid resistance properties as compared with the other regimens such as aluminum and fluoride, strontium with aluminum, and fluoride alone [223]. Fluorine ranked the highest at $\mathbf{1 5 . 4 2 \%}$ mean surface hardness recovery while strontium-fluorine provided greater than $13 \%$ mean surface hardness recovery. However, strontium-fluorine had the highest acid resistance, with $75.6 \%$ relative loss, the lowest of all tested groups. This value was closely followed by the aluminum-fluorine which boasted an acid resistance of $75.8 \%$ relative loss. Unfortunately, the aluminum-fluorine group only supported $9.61 \%$ mean surface hardness during remineralization. Therefore, it can be surmised that $\mathrm{Sr}-\mathrm{F}$ and $\mathrm{Al}-\mathrm{F}$ treatments are more effective than $\mathrm{F}$ treatments alone in pre-softened enamel, showing enhanced remineralization of enamel and inhibited acid dissolution [223].

\subsubsection{Role of Silver}

Silver has long been used for its antimicrobial properties and low toxicity to human cells in topical burn creams, dental amalgams and even water system disinfectants [221]. The use of silver as an antimicrobial agent has increased due to concerns with antibiotic resistant 
A Rapidly-Dissolving Silica-Silver Bioactive Glass For Cariostatic Applications, Saad Arshad, MASc, Ryerson University, 2017

microorganisms. Due to the broad-spectrum nature of silver-based antiseptics, it is believed to be less likely to induce microbial resistance as compared to antibiotics [22]. While human toxicology to silver is not well documented, studies by Drake and Hazelwood (2005) and by Lansdown (2010) report low health risks from systemic absorption of silver ions [224], [225]. The most common consequence to silver exposure is argyria, an irreversible condition in which silver deposits into skin and eyes, leaving a bluish-grey hue [221]. It is not believed to be a life threatening condition and does not cause irreversible tissue damage [224]. The World Health Organization (WHO) recommends a maximum lifetime intake of $10 \mathrm{~g}$ of silver as this has no observable adverse health effects on humans [221]. Drinking water concentrations are limited to $0.1 \mathrm{mg} / \mathrm{m}^{3}$ according to the National Institute for Occupational Safety and Health and the American Conference of on Governmental Industrial Hygienists. WHO has reported that it is unlikely for a person to consume enough silver over a lifetime in order to develop symptoms of argyria [226]. Risks may increase depending on geographical location however; for example, residents of the San Francisco Bay area may deal with silver residues from factory wastes entering the food supply and this may increase the risks of developing argyria.

Nano-silver particles have been investigated for their cariostatic properties on primary teeth. A study by Santos V.E. et al. (2014) found the effectiveness to be $66.7 \%$ when applied once a year [227]. Additionally, the treatment did not stain any teeth black as the nano-silver compounds did not oxidise. This is in contrast to $30 \%$ silver diamine fluoride solutions which had a caries arrest rate of $66.9 \%$ when applied once per year. However, the black staining of teeth is still encountered with silver diamine fluoride treatments [228]. Furthermore, silver nanoparticles have also demonstrated a significant antibacterial effect on s. mutans, a bacterial strain commonly associated with dental caries [23]. Bacteria exposed to silver nanoparticles had a 
A Rapidly-Dissolving Silica-Silver Bioactive Glass For Cariostatic Applications, Saad Arshad, MASc, Ryerson University, 2017

survival rate of about $2 \%$ whereas chlorhexidine, a common antiseptic agent yielded a survival rate of $60 \%$.

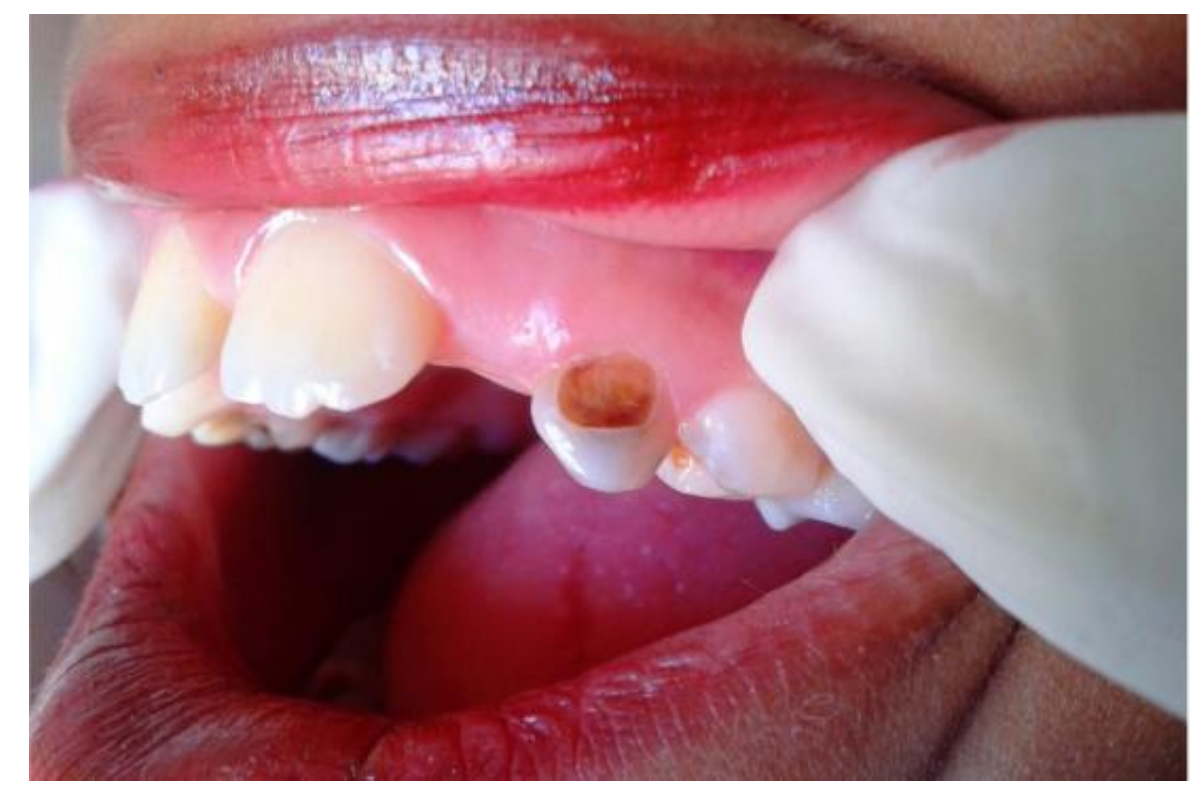

Figure 22: A primary tooth treated by nano-silver solution after 12 months. Note the lack of black staining on the lesion.[227]

While the antibacterial action of silver has been well documented [22], [112], [204], [206], [221], the mechanism of action is not fully understood [229]. Several proposals to explain the antibacterial effect of $\mathrm{Ag}^{+}$ions have been developed. They have been reported to inactivate metabolism and inhibit bacterial growth [230], uncouple the respiratory chain from phosphorylation [231], interfere with membrane permeability to protons and phosphate [232, p.], and react with thiol groups of membrane-bound enzymes and proteins to inactivate bacteria [229]. It is observed that the most common site of action at low concentrations is the cytoplasmic membrane [233]. Many important proteins, such as enzymes for respiratory chains reside here [231], [233]. At higher concentrations, $\mathrm{Ag}^{+}$ions have been observed to interact with cytoplasmic components within the cell [229]. In a study by Holt and Bard, $\leq 10 \mu \mathrm{M} \mathrm{AgNO}_{3}$ were added to immobilized E. coli. Measurement of $\mathrm{Ag}^{+}$uptake by the cell found that approximately $60 \%$ of the silver was transported into the cell while the remaining $40 \%$ was bound to the outside of the 
A Rapidly-Dissolving Silica-Silver Bioactive Glass For Cariostatic Applications, Saad Arshad, MASc, Ryerson University, 2017

cell [231]. The bacteria reacted to the addition of silver with stimulated respiration before death, suggesting the interaction of $\mathrm{Ag}^{+}$and enzymes of the respiratory chain.

\subsubsection{Role of Zinc}

An essential trace element to the body, zinc is naturally present in bone $(0.6 \mathrm{~g})$, muscle tissue $(1.2 \mathrm{~g})$ and even skin $(0.1 \mathrm{~g})$ [234]. It is often added to toothpastes and mouth rinses as an antibacterial agent to fight against plaque, calculus formation and halitosis [24], [25]. Zinc ions react with volatile sulfur compounds such as hydrogen sulfide in the mouth, and it is in these compounds which are responsible for the malodour associated with halitosis [235]. In a study by Giertsen et al, caries incidences on partially desalivated rats were treated with zinc combined with either chlorhexidine or cetylpyridinium chloride [236]. Zinc was effective at significantly reducing smooth-surface caries incidences but showed no significant synergistic effect with either chlorhexidine or cetylpyridinium chloride, while sodium fluoride showed the greatest cariostatic effect in reducing smooth-surface incidences. However, in determining total viable populations of streptococcus sobrinus, zinc showed a great synergistic effect with cetylpyridinium chloride, as this combination was the most successful in suppressing the bacteria. Interestingly, zinc alone was not more effective than placebo. From the results, it can be suggested that perhaps a stronger concentration of zinc may be required to inhibit caries development in teeth when subjected to strong cariogenic challenges.

Zinc was found to be almost as effective at fluoride in equimolar concentrations due to its ability to form insoluble zinc-phosphate compounds [236], [237]. A study by Mohammed et al. confirmed that $\mathrm{Zn}^{2+}$ ions were effective at reducing enamel demineralization by acting on enamel surfaces to form zinc phosphate phases [26]. Additionally, zinc retards the ability of fluoride to arrest lesions, allowing more complete remineralization of the lesion at greater depths. Due to the 
A Rapidly-Dissolving Silica-Silver Bioactive Glass For Cariostatic Applications, Saad Arshad, MASc, Ryerson University, 2017

highly mineralized surface zone, which is characteristic of lesion arrests, diffusion deeper into the enamel and the hypomineralized lesions is reduced which ultimately hinders remineralization efforts [179]. Zinc maintains surface porosity through its ability to inhibit crystal growth, which allows ions such as calcium and fluoride to penetrate deeper into the enamel and repair lesions more effectively. However, a three-year study by Stephen et al. found that there was no noticeable difference between groups of children using zinc citrate and groups using zinc-free toothpastes in caries incidence [29]. 3000 12-year old children were evaluated using six custom toothpastes with three different concentrations of sodium monofluorophosphate, 1000 ppm 1500 ppm, and $2500 \mathrm{ppm}$ while $0.5 \%$ zinc citrate was either included or not included in each of the toothpastes. The dentifrices also contained 50\% alumina trihydrate abrasive, surfactant, flavouring and minor excipients. While differing concentrations of sodium monofluorophosphate provided different DMFS index scores, there were no significant differences between the dentifrices including and excluding zinc citrate. It was concluded that the insignificance of zinc citrate on dental caries was independent of the fluoride level. Turning then to the antiglycolytic activity of zinc, in vivo acid production by plaque can be reduced up to four hours after a minute long rinse of $10 \mathrm{~mL}$ of $20 \mathrm{mM} \mathrm{ZnCl} 2$ [238]. While zinc may not reduce s. sobrinus counts, Giertsen still found a 30\% reduction in oral flora [236]. It is suspected that zinc may either suppress other bacteria present in the oral environment, or it may interfere with the acidproduction of bacteria, or perhaps a combination of these effects. Indeed, studies by Gallagher and Cutress suggested that s. mutans is sensitive to zinc [239]. These results are further backed by a study by He et al. in which different bacterial strains such as streptococcus mutans, streptococcus salivarius, streptococcus sobrinus, actinomyces naeslundii and lactobacillus casei were tested singly and in mixed cultures to determine the glycolysis-inhibiting effect of zinc 
A Rapidly-Dissolving Silica-Silver Bioactive Glass For Cariostatic Applications, Saad Arshad, MASc, Ryerson University, 2017

[240]. S. mutans was the most sensitive to zinc, followed by s. salivarius and s. sobrinus. Mixed cultures demonstrated similar effects to zinc as the streptococci tested but this may be due to the larger share of streptococci bacteria in the mixtures. Therefore, it is currently suspected that the zinc ion helps remineralization chiefly through its antibacterial ability and synergistic effects with other ions rather than its ability to remineralize and diffuse through enamel, although no clear link between antibacterial effects and cariostatic effects has been determined [234]. Greater mechanistic studies are required to better understand zinc-enamel interactions and the efficacy of zinc regarding its ability to fight dental caries.

Zinc has shown great oral substantivity. Typically, $15-40 \%$ of zinc doses are retained in the mouth [234] while up to one third of the dose from toothpaste can be retained for at least two hours [241]. Loosely bound zinc is removed rapidly while more firmly bound zinc clears at a slower rate [24]. Repeated applications have demonstrated a kind of build-up effect [242], [243].

\subsubsection{Rapidly Dissolving Bioglass}

Recent work by Hill and Wadke has resulted in a bioglass with an open network structure[244]. An open network structure enables alkali and alkali-earth cations $\left(\mathrm{Na}^{+}, \mathrm{K}^{+}, \mathrm{Ca}^{2+}\right)$ to be accommodated as network modifiers, disrupting the continuity of the network of Si-O-Si bonds, leading to the formation of non-bridging oxygen groups (Si-O-NBO) [245]. This allows the glass to dissolve quickly in the presence of saliva. Ions such as calcium and phosphate are released from the dissolution, which is $\mathrm{pH}$ dependent, and form an apatite-layer on the enamel surface[246]. Furthermore, the glass particles themselves can block exposed tubules, relieving patients of tooth pain [161]. Tooth pain and sensitivity is caused through stimulation in dentinal tubules. The stimulation may be due to hot or cold fluids, or even mechanical stimulation. These tubes are typically covered but, as the gums recede or tooth decay breaks down the enamel layer, 
A Rapidly-Dissolving Silica-Silver Bioactive Glass For Cariostatic Applications, Saad Arshad, MASc, Ryerson University, 2017

the tubes become exposed. Mechanical agitation through activities such as brushing one's teeth can also expose them [247]. However, there are some products which can physically block or occlude the tubules due to their structure and particle sizes such as NovaMin [28]. There is increasing evidence that bioglasses dissolve more rapidly during acidic conditions, such as those related to dental caries [17]. This makes them especially desirable as they can act as a 'smart' material which responds to caries incidences. In developing a rapidly dissolving bioglass treatment, Gillam proposed a list of properties an ideal material would possess. Even though a material meeting these criteria may not necessarily be suited for all purposes, the properties still serve as a good general design criteria. Note these properties are primarily tailored towards treating dentin sensitivity but can be just as effective at treating caries with minor adjustments.

Table 13: Gillam's recommendations for an ideal bioglass material to treat sensitivity and caries. [17]

\begin{tabular}{|l|l|}
\hline Dissolve time & Rapid dissolution into apatite in less than six hours. \\
\hline Apatite Formation & $\begin{array}{l}\text { Forms fluoroapatite (FA) instead of hydroxycarboapatite } \\
\text { (HCA). }\end{array}$ \\
\hline Particle Size & $\begin{array}{l}\text { A binary distribution of small particles for occlusion of } \\
\text { tubules }(<3 \text { um) and large particles for longer-term } \\
\text { dissolution }\end{array}$ \\
\hline Ion Composition & $\begin{array}{l}\text { Strontium and Fluoride are recommended for their caries } \\
\text { inhibition effects as well as their remineralization } \\
\text { capabilities. }\end{array}$ \\
\hline Acid Neutralization & $\begin{array}{l}\text { Potassium can also numb nerves to relieve pain from } \\
\text { sensitivity. }\end{array}$ \\
\hline Mechanical Properties & Be able to keep pH from rising above 8.0 \\
\hline Cost & $\begin{array}{l}\text { Should not be significantly harder than enamel at 3.5 } \\
\text { GPa. }\end{array}$ \\
\hline
\end{tabular}

NovaMin is the commercial iteration of 45S5 bioglass that is designed to treat dentinal hypersensitivity [11], [158]. Table 14 lists some commonly available bioglass products and their 
A Rapidly-Dissolving Silica-Silver Bioactive Glass For Cariostatic Applications, Saad Arshad, MASc, Ryerson University, 2017

applications. NovaMin, a calcium sodium phosphosilicate bioactive glass, serves as the current solution in rapidly dissolving bioglasses but has several drawbacks[17].

- It is believed to form hydroxycarboxylic apatite, which is more soluble than hydroxyl apatite. It is more advantageous to form fluorapatite, a more durable mineral less likely to be susceptible to acid attacks.

- The 45S5 glass it employs has a higher hardness value than enamel, which can cause additional abrasion and enamel loss. A glass with a hardness closer to enamel would be ideal as it would minimize the enamel loss from glass-enamel abrasion. Changing the particle shape to be less sharp and angular and instead, be more rounded can also reduce the abrasive effect of the glass on enamel. This can be achieved through grinding. Ball milling tends to produce more rounded particles while vibratory milling yields more angular particles [17]. Additionally, the hardness of 45S5 is too high for softer exposed dentin surfaces and thinner enamel surfaces. Ideally, the bioglasses would have a hardness no greater than $3.7 \mathrm{GPa}$.

- NovaMin raises the $\mathrm{pH}$ in the environment upon dissolution by releasing alkali components such as $\mathrm{Ca}^{2+}$ and $\mathrm{PO}_{4}{ }^{3-}$ ions. While the $\mathrm{pH}$ levels are deemed safe, it is still far more desirable to not cause $\mathrm{pH}$ spikes since local $\mathrm{pH}$ levels can exceed the $\mathrm{pH}<8.0$ due to concentration of dissolution products, even when global $\mathrm{pH}$ levels are considered acceptable.

NovaMin also lacks a biocidal or anti-caries agent, as well as a nerve numbing agent to couple with the occlusion in order to minimize patient discomfort. Apatite formation can take up to weeks with NovaMin while relief from pain may be needed more urgently. The inclusion of potassium instead of sodium can help offset the pain as it will not change key properties of the 
A Rapidly-Dissolving Silica-Silver Bioactive Glass For Cariostatic Applications, Saad Arshad, MASc, Ryerson University, 2017

bioglass but its dissolution can aid in blocking nerves. The replacement of sodium with potassium also has the additional advantage of reducing glass hardness slightly.

Table 14: Some commercially available bioglasses based on 45 S5 with common applications [158]

\begin{tabular}{|c|c|}
\hline $\begin{array}{l}\text { Product Name } \\
\text { (Manufacturer) }\end{array}$ & Applications \\
\hline Perioglass (NovaBone) & $\begin{array}{l}\text { - Restore bone loss from periodontal disease in infrabony defects } \\
\text { - Alveolar ridge augmentation } \\
\text { - Tooth extraction sites }\end{array}$ \\
\hline NovaBone (NovaBone) & - Non-load bearing site orthopaedic bone grafting \\
\hline NovaMin (GlaxoSmithKline) & $\begin{array}{l}\text { - Dentinal hypersensitivity } \\
\text { - } \quad \text { Cariostatic agent }\end{array}$ \\
\hline
\end{tabular}

NovaMin was not specifically formulated for dental applications and so many of these drawbacks were simply not in the scope of design. This increases the need for a specifically tailored solution designed to deal with caries and hypersensitivity effectively and promptly [169]. Despite that, NovaMin has demonstrated limited effectiveness as a cariostatic agent; NovaMin-fluoride treatments were found to have the greatest remineralization effect on whitespot lesions in bovine enamel. Casein phosphopeptide-amorphous calcium phosphate, or Recaldent as its commercially known, combined with fluoride was found to be the least effective, as can be seen in 
A Rapidly-Dissolving Silica-Silver Bioactive Glass For Cariostatic Applications, Saad Arshad, MASc, Ryerson University, 2017

Table 15.

Table 15: Results of an in vitro enamel white-spot lesion microhardness study on bovine tooth crowns. [27]

\begin{tabular}{|l|l|}
\hline Tested Specimen & Knoop Microhardness $\left(\mathbf{g}_{\mathbf{f}} / \mathbf{m m}^{\mathbf{2}}\right)$ \\
\hline Prepared enamel & $119.36 \pm 6.78$ \\
\hline Artificial lesion & $5.17 \pm 0.35$ \\
\hline 5000ppm F & $14.40 \pm 1.30$ \\
\hline $\begin{array}{l}\text { Casein phosphopeptide-amorphous calcium phosphate } \\
\text { (CPP-ACP) with 900ppm F }\end{array}$ & $6.53 \pm 0.70$ \\
\hline NovaMin with 5000ppm F & $33.52 \pm 4.96$ \\
\hline
\end{tabular}

NovaMin remineralizes enamel through ion exchange with bone which results in the increase of hydroxyapatite phases around NovaMin particles [248]. Particle size influences the activity of bioglasses in oral applications. A study by Vollenweider et al. [249] found that nanoparticle bioglass treatments were more effective than conventional NovaMin treatments. After 10 minutes in solution, nanoparticle treatments released up to 20 times more calcium and silicon than NovaMin. Smaller particle sizes correlate to greater dissolution rates [250]. However, promoting remineralization is not enough; Vollenweider et al. (2007) also found that there was no increase in flexural strength or Young's Modulus after 30 days of remineralization [93]. This suggested that if the apatite does not form a composite with the collagen, a mechanically unstable mineral will form. Furthermore, 45S5 has been found to have significant antibacterial 
A Rapidly-Dissolving Silica-Silver Bioactive Glass For Cariostatic Applications, Saad Arshad, MASc, Ryerson University, 2017

effects in both supra and subginvial bacteria. A study by Allan et al. (2001) found that particulate 45S5 bioglass was effective against Streptococcus mutans, Streptococcus sanguis, and Actinomyces viscosus, with the greatest effect being noticed after three hours, regardless of the suspending solution [251]. The mean bacteria killing percentage was found to be $93 \%$ in nutrient broth and and $85 \%$ in artificial saliva after one hour while the mean killing percentages were $99 \%$ in nutrient broth and $98 \%$ in artificial saliva after three hours. In subgingival bacterial species, bioglass particulate was found to kill $100 \%$ of Prev. intermedia in basal medium.

Table 16: Percentage of bacteria killed in nutrient broth and artificial saliva by 45S5. [251]

\begin{tabular}{|c|c|c|c|}
\hline \multirow[t]{2}{*}{ Bacteria and Medium } & \multicolumn{2}{|c|}{ \% supra-gingival bacteria killed } & \multirow{2}{*}{$\begin{array}{c}\text { \% sub-gingival } \\
\text { bacteria killed } \\
\text { after } 1 \text { hour }\end{array}$} \\
\hline & After 1hour & After 3 hours & \\
\hline S. sanguis + nutrient broth & 98.0 & 99.5 & $\mathrm{n} / \mathrm{a}$ \\
\hline S. sanguis + artificial saliva & 65.8 & 94.4 & $\mathrm{n} / \mathrm{a}$ \\
\hline S. mutans + nutrient broth & 83.1 & 97.3 & $\mathrm{n} / \mathrm{a}$ \\
\hline S. mutans + artificial saliva & 94.4 & 98.4 & $\mathrm{n} / \mathrm{a}$ \\
\hline A.viscosus + nutrient broth & 97.3 & 99.5 & $\mathrm{n} / \mathrm{a}$ \\
\hline A.viscosus + artificial saliva & 96.2 & 99.6 & $\mathrm{n} / \mathrm{a}$ \\
\hline$P$. gingivalis + basal medium & $\mathrm{n} / \mathrm{a}$ & $\mathrm{n} / \mathrm{a}$ & 91.2 \\
\hline F. nucleatum + basal medium & $\mathrm{n} / \mathrm{a}$ & $\mathrm{n} / \mathrm{a}$ & 95.0 \\
\hline Prev. intermedia + basal medium & $\mathrm{n} / \mathrm{a}$ & $\mathrm{n} / \mathrm{a}$ & 100 \\
\hline $\begin{array}{l}\text { A.actintomycetemcomitans }+ \\
\text { basal medium }\end{array}$ & $\mathrm{n} / \mathrm{a}$ & $\mathrm{n} / \mathrm{a}$ & 98.6 \\
\hline
\end{tabular}

Another study by Liu et al. (2014) created a novel calcium phosphate glass (CPG) with an intended $\mathrm{Ca} / \mathrm{P}$ molar ratio of 0.6 [216]. The analyzed composition of CPG as determined by $\mathrm{X}$ Ray Fluorescence (XRF) is described in Table 17. 
A Rapidly-Dissolving Silica-Silver Bioactive Glass For Cariostatic Applications, Saad Arshad, MASc, Ryerson University, 2017

Table 17: Composition (wt\%) of Liu et al. CPG doped with Zn and F as determined by XRF

\begin{tabular}{|c|c|c|c|c|}
\hline $\begin{array}{c}\text { Component } \\
(\mathbf{w t} \%)\end{array}$ & $\begin{array}{c}\text { Calcium } \\
\text { Phosphate Glass } \\
\text { (CPG) }\end{array}$ & CPG + Zn & CPG + F & CPG + Zn + F \\
\hline $\mathrm{CaO}$ & 36.4 & 36.0 & 37.7 & 36.5 \\
\hline $\mathrm{MgO}$ & 1.2 & 1.1 & 1.3 & 1.1 \\
\hline $\mathrm{Na}_{2} \mathrm{O}$ & - & - & 1.3 & 1.0 \\
\hline $\mathrm{P}_{2} \mathrm{O}_{5}$ & 62.3 & 61.7 & 59.7 & 60.2 \\
\hline $\mathrm{ZnO}$ & - & 1.2 & - & 0.2 \\
\hline $\mathrm{NaF}$ & - & - & 0.5 & 0.61 \\
\hline $\begin{array}{c}\text { Cacluated Ca/P } \\
\text { ratio }\end{array}$ & 0.58 & 0.58 & & \\
\hline
\end{tabular}

Antibacterial studies on this bioglass found it was effective against S. mutans (Figure 23). The greatest effect on viability was noticed at $0.01 \mathrm{~g}$ of CPG doped with zinc after two hours. After 4 hours, both CPG with zinc and CPG with fluoride demonstrated complete biocidal activity for the length of the study. The increased concentration of the $0.05 \mathrm{~g}$ study showed maximum biocidal activity at two hours instead of four, with the base CPG completely inhibiting bacterial growth at four hours. The effects of CPG with both zinc and fluoride were unaffected by the change in concentration. 
A Rapidly-Dissolving Silica-Silver Bioactive Glass For Cariostatic Applications, Saad Arshad, MASc, Ryerson University, 2017
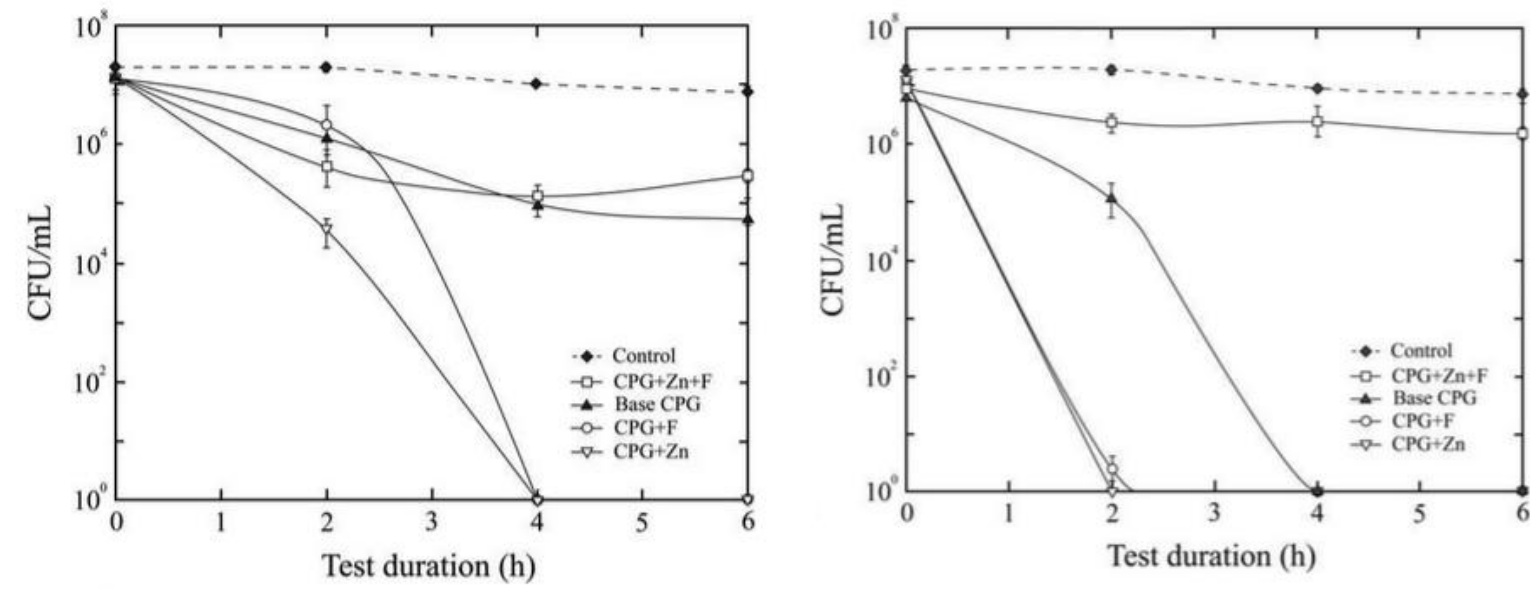

Figure 23: a) Antibacterial effect of $0.01 \mathrm{~g}$ of calcium phosphate glass on $S$. mutans. b) Antibacterial effect of $0.05 \mathrm{~g}$ of calcium phosphate glass on $S$. mutans [216]

\subsubsection{Restorative Dentifrices}

Fluorapatite is a more resistant mineral to acid attack than HA, which in turn is more resistant than carbonated apatite [181]. Gjorgievska et al. studied the remineralizing effects of several toothpastes with different additives in order to compare their effects [181]. The toothpastes and their respective additives are listed below in Table 18.

Table 18: Commercial toothpastes with additives studied by Gjorgievskaet al. (2013). [181]

\begin{tabular}{|l|l|}
\hline Toothpaste (Manufacturer) & Additive \\
\hline $\begin{array}{l}\text { Mirasensitive HA+ (Miradent, Hager \& Werken GmbH } \\
\text { \& Co, KG, Germany) }\end{array}$ & $30 \% \mathrm{HA}$, xylitol, $1450 \mathrm{ppm}$ fluoride \\
\hline $\begin{array}{l}\text { Mirawhite tc (Miradent, Hager and Werken GmbH \& } \\
\text { Co, KG, Germany) }\end{array}$ & $\begin{array}{l}5.5 \% \text { 45S5 (<90 } \mu \mathrm{m} \text { particle size, calcium-sodium- } \\
\text { phospho-silicate glass })\end{array}$ \\
\hline Sensodyne rapid relief (GlaxoSmithKline, UK) & $8 \%$ strontium acetate, $1040 \mathrm{ppm} \mathrm{NaF}$ \\
\hline
\end{tabular}

The study found that dentifrices containing HA and bioglass were the most effective at enamel remineralization on human permanent molars. Their use resulted in the formation of protective deposits of bioactive glass attached to the enamel surface. The use of the HA containing 
A Rapidly-Dissolving Silica-Silver Bioactive Glass For Cariostatic Applications, Saad Arshad, MASc, Ryerson University, 2017

toothpaste, Mirasensitive HAp+ (Miradent, Hager \& Werken GmbH \& Co, KG, Germany), resulted in an increase in calcium and phosphorous content in the enamel layer while the bioactive glass containing paste resulted in an increased concentration of fluorine, magnesium, aluminium, silica, phosphorous, chlorine, calcium, copper and zinc in the enamel layer. The strontium acetate toothpaste did not result in any significant remineralization [181]. SEM micrographs of the remineralization from the dentifrices can be seen in Figure 24 below.

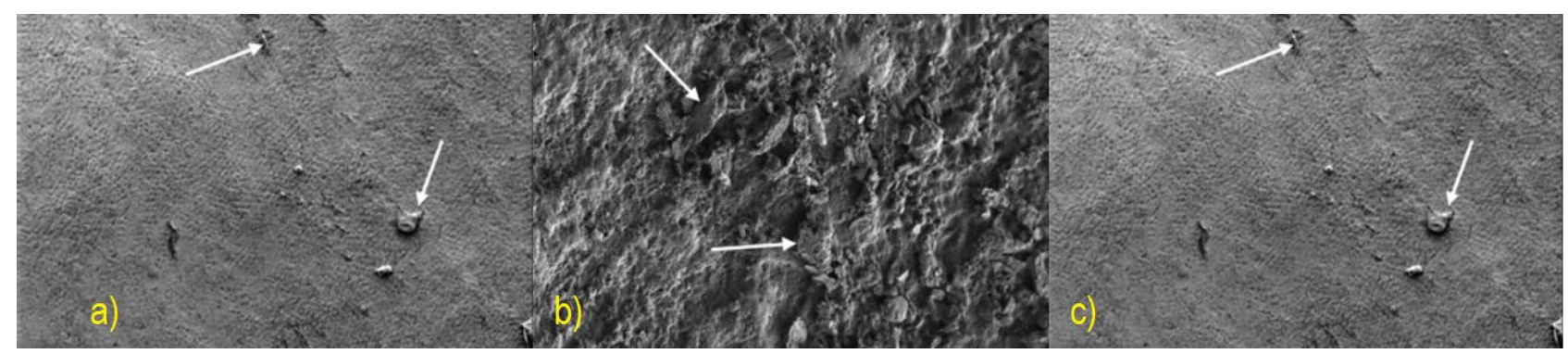

Figure 24: SEM micrographs of mineralization effects of three different toothpastes. Arrows point to some of the deposits. (a) Hydroxyapatite containing toothpaste left deposits on enamel surface which fill irregularities, leaving porous enamel. (b) Bioactive glass containing toothpaste has created significant remineralization across the surface, sealing irregularities and leaving residual glass particles firmly attached to enamel surface. (c) Strontium-acetate and fluoride containing toothpaste has not created any significant remineralization and only few small deposits.

A commercial toothpaste and oral rinse containing $\mathrm{F}$ and HA were also investigated by Hill [252]. Ultradex Recalcifying and Whitening is a commercial product which aims to combine the effects of fluorine remineralization with the calcium and phosphate present in order to repair teeth. The toothpastes contained $1000 \mathrm{ppm}$ fluoride and nano-hydroxyapatite (7.5\%). Using $\mathrm{F}$ magic-angle spinning nuclear magnetic resonance (MAS-NMR) which uses the ${ }^{19} \mathrm{~F}$ isotope to identify fluorine containing compounds with greater accuracy than diffraction based tests when evaluating disordered systems [253], enamel slices were analyzed to determine the weight loss after demineralisation treatments. The toothpaste containing only HA corresponded to the largest enamel loss at just under $2 \%$ while the toothpaste with only fluorine corresponded to an enamel loss of about $0.5 \%$. The oral rinse containing both HA (5\%wt) and fluorine (600 ppm) performed between the two toothpastes at around 1.5\%. The toothpaste with both HA and fluoride 
A Rapidly-Dissolving Silica-Silver Bioactive Glass For Cariostatic Applications, Saad Arshad, MASc, Ryerson University, 2017

corresponded to the smallest enamel loss (Figure 25). However, smaller concentrations of fluorine are recommended as they form the more valuable fluorapatite instead of the fluorite $\left(\mathrm{CaF}_{2}\right)$ that larger volumes tend to precipitate [252].

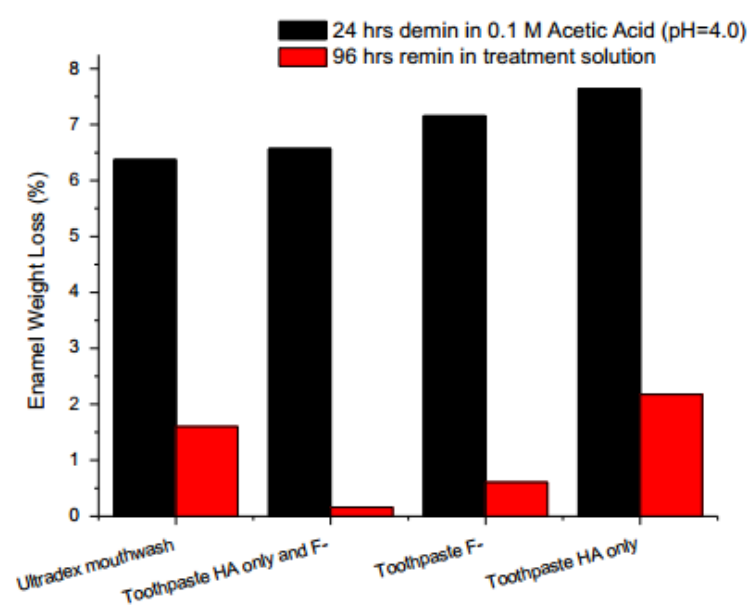

Figure 25: Enamel weight loss by different toothpaste and oral rinse treatments. Measurement error is estimated at $0.14 \%$. [252]

Similar results were also found in a study by Porcelli et al. (2015) in which an ordinary fluoridated commercial toothpaste was found to be the most effective at remineralizing enamel erosive lesions, as indicated by their $9.91 \%$ mean Knoop hardness change [254]. The nano-HA containing dentifrice performed at $7.96 \%$ mean Knoop hardness change and was the second most effective tested treatment at remineralizing enamel. Interestingly, the high fluoride content dentifrice exhibited limited effectiveness, netting only $2.12 \%$ mean Knoop hardness change. The study determined that the nano-HA dentifrice and the ordinary fluoridated toothpaste were both able to arrest lesion growth and also remineralize teeth and decrease the erosions already present. This is in contrast to the high fluoride content toothpaste and the calcium carbonate containing dentifrices which only delayed the new erosive lesions formation. The results of the study are summarized in Figure 26. 
A Rapidly-Dissolving Silica-Silver Bioactive Glass For Cariostatic Applications, Saad Arshad, MASc, Ryerson University, 2017

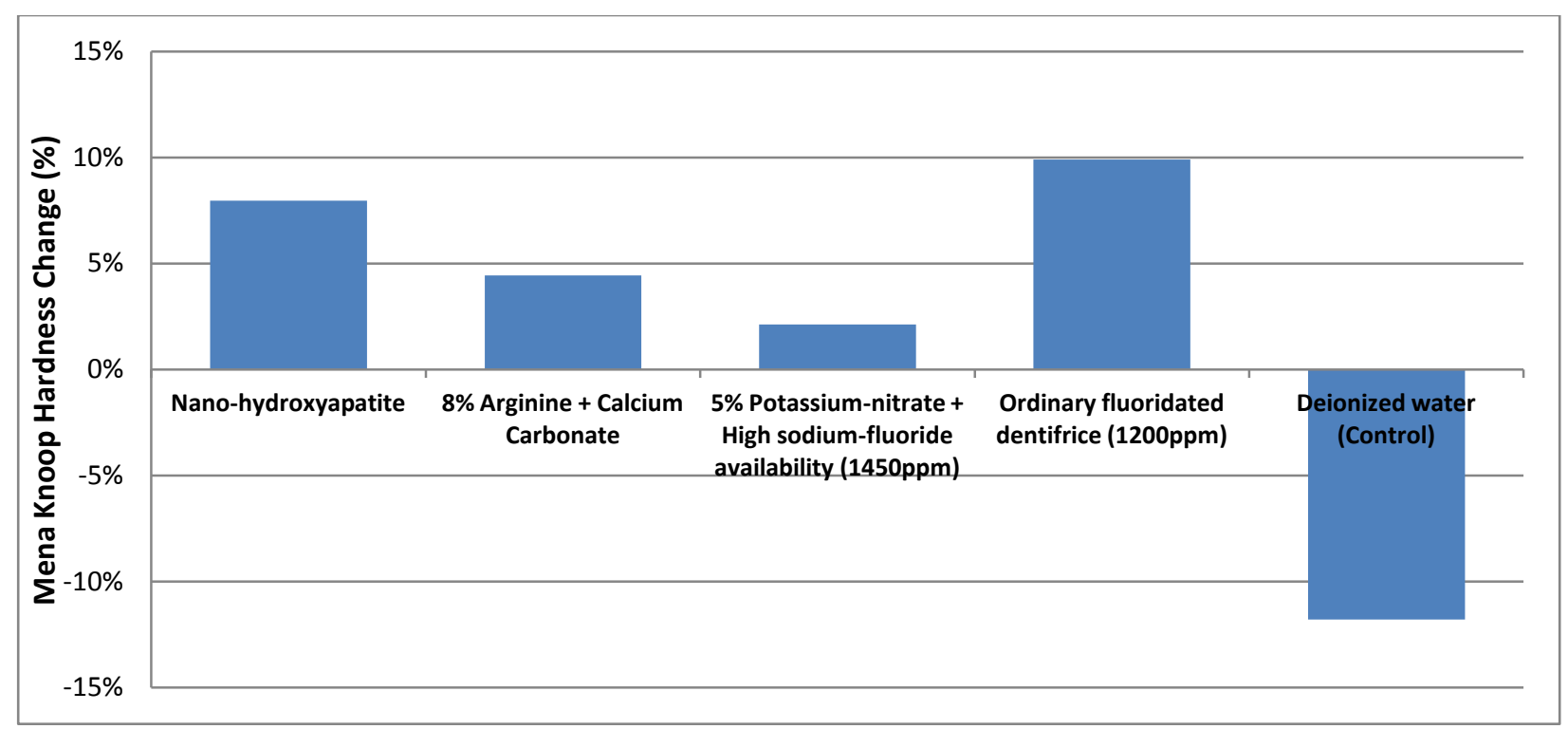

Figure 26: Mean Knoop Hardness change as a measure of mineralization for four different dentifrices. [254]

Danelon et al. (2015) studied the effects of trimetaphosphate (TMP) additive to fluoridated toothpastes and their efficacy against dental caries in situ [255]. A toothpaste containing 1100 ppm F, 1100 ppm F with 3\% TMP and 1100 ppm F with 3\% nano-sized TMP were tested against a control toothpaste with no F or TMP. The addition of nano-sized TMP particles were found to be the most effective, increasing mineral hardness by $20 \%$ compared to the $1100 \mathrm{ppm} F$ and demonstrated $66 \%$ more fluorine uptake than the non-nano sized TMP. It is believed that the nano-sized particles yield a larger surface area to volume ratio which makes them more reactive.

\subsection{Summary}

Caries is the most common preventable disease in the world today [1]. It is characterized by cariogenic bacteria such as s. mutans and lactobacillus, which exist in plaque to produce acids which demineralize enamel and dentin by leeching out calcium and phosphorous from the HA that they are made of. If the disease reaches an advanced stage, it will cause lesions and cavities to form in the teeth, allowing the bacteria to infect the pulp. This can lead to cell death and further complications from infection. There are a variety of restorations which can fill these 
A Rapidly-Dissolving Silica-Silver Bioactive Glass For Cariostatic Applications, Saad Arshad, MASc, Ryerson University, 2017

cavities, ranging from amalgams to composites to cements. New restorations are being developed which involve the use of bioactive glasses. These materials can be used in conjunction with cements to give a therapeutic benefit to the filling such as antibacterial effects, remineralization effects and even relief from hypersensitivity. However, most of these restorations are solutions that are used after the disease has reached an advanced stage. There exists a need for better preventative dental treatments. Most dental procedures deal with repairing teeth after damage or decay; usually by filling in lesions or creating restorations. Many of these procedures have their own limitations, such as strength, toxicity, durability and aesthetics. New glasses are being developed which can be used proactively, preventing cariogenic bacteria from forming biofilms by killing them, as well as promoting remineralization of dental tissues. These glasses can be embedded in dentifrices which is used as a delivery vehicle, depositing the glass in the mouth until an acidic challenge dissolutes them and releases their therapeutic ions.

\subsection{Scientific Rationale}

This research aims to create a novel, rapidly dissolving bioglass treatment which can be used regularly to minimize caries risks. By embedding it in a dentrifice such as toothpaste, the dissolution of the glasses will release therapeutic ions to teeth.

The glasses will be fired through the melt-quench method and tested to ensure they can provide the necessary effects a daily preventative dental treatment will need. Calcium and phosphorous are included in order to increase the remineralization effects, as both are key parts of HA. Silver is included as an antibacterial agent as its antibacterial properties have been well understood for centuries. By investigating a series of glasses with variable silver content, their effects on enamel remineralization and biofilm formation can be determined. 
A Rapidly-Dissolving Silica-Silver Bioactive Glass For Cariostatic Applications, Saad Arshad, MASc, Ryerson University, 2017

\section{Materials and Methods}

\subsection{Glass Synthesis}

\subsubsection{Formulations}

Three $\mathrm{SiO}_{2}-\mathrm{CaO}-\mathrm{P}_{2} \mathrm{O}_{5}-\mathrm{Na}_{2} \mathrm{O}_{5}-\mathrm{Ag}_{2} \mathrm{O}$ glasses were synthesized in a series with increasing silver content at the expense of silica. Appropriate amounts of analytical grade reagents were measured out and mixed together thoroughly. The mixture was then fired using the melt-quench method in which the mixture was placed in a platinum crucible. The crucible was then placed in a furnace and fired at $1600^{\circ} \mathrm{C}$ for one hour. After the allotted time, the melt was shock quenched in cool water. The resulting glass frit was retrieved and dried for 24 hours in an incubator at $37^{\circ} \mathrm{C}$. The required reagents are listed in Table 19. The quantity of each reagent was selected through trial and error, as concentrations involving greater amounts of silver or phosphorous would not form glass or would not incorporate silver in to the network structure.

Table 19: Silica glass series composition (mol\%)

\begin{tabular}{|l|l|l|l|l|l|}
\hline Glass & $\mathbf{S i O}_{2}$ & $\mathbf{C a O}$ & $\mathbf{P}_{2} \mathbf{O}_{\mathbf{5}}$ & $\mathbf{N a}_{\mathbf{2}} \mathbf{O}$ & $\mathbf{A g}_{\mathbf{2}} \mathbf{O}$ \\
\hline Si-Control & 70 & 12 & 3 & 15 & 0 \\
\hline Si-02 & 69.8 & 12 & 3 & 15 & 0.2 \\
\hline Si-05 & 69.5 & 12 & 3 & 15 & 0.5 \\
\hline
\end{tabular}

\subsubsection{Network Connectivity}

Network connectivity can be calculated using the equation below. The network formers are assumed to be $\mathrm{SiO}_{2}$ while the network modifiers are assumed to be $\mathrm{CaO}, \mathrm{Na}_{2} \mathrm{O}$ and $\mathrm{P}_{2} \mathrm{O}_{5}$. $\mathrm{Ag}_{2} \mathrm{O}$ generally behaves as a network modifier but can change its role to that of a network former [256]. This usually occurs with high concentrations, or if metallic silver particles form during glass synthesis. Both cases of silver behaving as a modifier or as a former will be examined. 
A Rapidly-Dissolving Silica-Silver Bioactive Glass For Cariostatic Applications, Saad Arshad, MASc, Ryerson University, 2017

$$
\text { Network Connectivity }=\frac{\text { Bridging Oxygens-Nonbridging oxygens }}{\text { Total bridging species }}
$$

\subsection{Glass Characterization}

\subsubsection{Particle Size Analysis (PSA)}

The dried glass was placed inside a $50 \mathrm{~mL}$ grinding jar for use in the Retsch PM100 Planetary Ball Mill (Retsch GmbH,Haan, Germany). 25mL of distilled water was added to the grinding jar along with eight $10 \mathrm{~mm} \varnothing$ grinding balls. The remainder of the volume was filled with glass. The jar was placed inside of the mill and allowed to grind at 550 RPM for 15 minutes.

The solution was then removed and placed in a Buchner funnel with a \#1 size $9 \mathrm{~cm} \varnothing$ filter paper and a vacuum pressure of about $300-350 \mathrm{mmHg}$ was maintained overnight until the powder was dry. The powder was then scraped off the filter paper and sieved through a $20 \mu \mathrm{m}$ sieve using a sieving brush.

A Microtrac S3500 Particle Size Analyzer (Microtrac Inc., USA) was used in order to collect particle size information about the glass powders.

\subsubsection{X-Ray Diffraction (XRD)}

Ground glass samples were placed on a glass slide and inserted into an X'Pert PRO PANanlytical XRD machine (PANanlytic Inc., St Laurent, QC, Canada). Samples were adhered to glass slides and placed inside the machine. The scan was run from a start position of $10^{\circ}$ to $80^{\circ} 2 \theta$ with a step size of $0.0500^{\circ}$ and a step time of $1.0000 \mathrm{~s}$. The generator was set to $40 \mathrm{~mA}$, $45 \mathrm{kV}$. 
A Rapidly-Dissolving Silica-Silver Bioactive Glass For Cariostatic Applications, Saad Arshad, MASc, Ryerson University, 2017

\subsubsection{Fourier Transform Infrared Spectroscopy (FTIR)}

FTIR was performed was on a PerkinElmer Spectrum One IR (PerkinElmer, Waltham, MA, USA). Ground glass $(\leq 20 \mu \mathrm{m})$ was placed inside the machine measuring from $450 \mathrm{~cm}^{-1}$ to 4000 $\mathrm{cm}^{-1}$ with a spectral resolution of $4 \mathrm{~cm}^{-1}$.

\subsubsection{Differential Scanning Calorimetry (DSC)}

DSC was performed on a NETZSCH STA 449F3 Jupiter (NETZSCH-Geratebau GmbH, Germany) using sapphire crucibles. The analysis was performed from $20^{\circ} \mathrm{C}$ to $1000^{\circ} \mathrm{C}$ with a step size of $20^{\circ} \mathrm{C} / \mathrm{min}$.

\subsubsection{Scanning Electron Microscope-Energy Dispersive Xray Spectroscopy (SEM-EDX)}

Ground glass samples were placed on a stage using two sided tape to hold the powder while excess powder was shaken off. The stage was then placed inside of a JEOL JSM-6380LV scanning electron microscope (JEOL Ltd., Tokyo, Japan) and examined using a beam energy of $20 \mathrm{kV}$. EDX spectra were also collected in order to determine the elements present in the glass. Three different sites were examined and averaged in order to limit the impact of localized testing. Multiple representative particles were measured in order to collect particle size information at different sites in a sample.

\subsection{Solubility Studies}

A buffer solution was prepared by mixing $15.09 \mathrm{~g}$ of tris (hydroxymethyl) aminomethane in approximately $800 \mathrm{~mL}$ of deionized water and adding $44.2 \mathrm{~mL}$ of $1 \mathrm{M}$ hydrochloric acid. The volume was then filled to $2 \mathrm{~L}$ using deionized water and maintaining a $\mathrm{pH}$ of 7.30 by adding hydrochloric acid and testing with a $\mathrm{pH}$ meter. The solution was then left at $37^{\circ} \mathrm{C}$ overnight. 
A Rapidly-Dissolving Silica-Silver Bioactive Glass For Cariostatic Applications, Saad Arshad, MASc, Ryerson University, 2017

$75 \mathrm{mg}$ of each glass powder was added along with $50 \mathrm{~mL}$ of tris solution in Nalgene plastic bottles. The bottles were then placed in an incubator at $37^{\circ} \mathrm{C}$ for 6,12 and 24 hours. The bottles were removed and the solutions were run through a filter paper to remove undissolved glass. The fluid meanwhile was collected and tested for $\mathrm{pH}$ and ion release.

The collected fluid from the tris buffer solubility test was run through an AAS machine, PinAAcle 500 Flame Atomic Absorption Spectrometer (PerkinElmer, Waltham, MA, USA). Calibration standard solutions were prepared for each ion by mixing their corresponding AAS standard in deionized water. 1000ppm AAS standards were diluted to $0.1 \mathrm{ppm}, 0.5 \mathrm{ppm}, 1 \mathrm{ppm}$, 5ppm, 10ppm and 20ppm. Deionized water was also kept for testing as a blank. Each sample was tested three times.

\subsection{Antibacterial Studies}

Oral cavity bacteria were collected by swabbing the teeth, gums and tongues of three volunteers at Ryerson University (Toronto, ON, Canada). The swabs were then placed in nutrient broth and allowed to grow for 3 days, after which they were inoculated onto strep agar plates, and allowed to grow for another 3 days. Four colonies of interest, such as those exhibiting satellitism or micro colonies were then extracted and suspended in broth again for three days. These isolates were then streaked across agar plates with glass powder. The isolate streaked agar plates were divided into thirds and $0.5 \mathrm{~g}$ of each glass composition measured out in Eppendorf tubes were placed in each third. After six hours, the inhibition zone was measured for each composition by comparing the dark, inoculated spaces against the lighter, inhibited spaces and measuring using a caliper. The difference in the diameters of the inhibited zone and the glass deposit was measured. 
A Rapidly-Dissolving Silica-Silver Bioactive Glass For Cariostatic Applications, Saad Arshad, MASc, Ryerson University, 2017

\subsection{Toothpaste Remineralization Studies}

Fifteen lamb molars were obtained from a local butcher in Toronto and their buccal surfaces were ground with 600 grit sandpaper on a water-cooled disc grinder. They were then mounted three per puck in cold-curing resin, with the buccal surfaces facing upward. The resin was then grinded down with 400, 600 and 1200 grit sandpaper on a water-cooled bench disc grinder (Buehler Ltd., IL, USA). The teeth were tested for their Knoop micro hardness and SEM images were taken of each. All five pucks were then placed in a container of $1.0 \mathrm{M} \mathrm{HCl}$ acid until fully submerged overnight $(12 \mathrm{~h})$ at $37^{\circ} \mathrm{C}$. The pucks were then retested for their micro hardness and SEM images were captured after this period. Three of the pucks were selected for remineralization through brushing with a glass-embedded toothpaste while two pucks were selected for control. One control involved brushing with no glass embedded in the tooth paste while the other involved brushing with deionized water. After remineralization, micro hardness results and SEM images were taken again using a JSM-6380LV SEM (JEOL Ltd., Tokyo, Japan). The pucks are pictured below in Figure 27.

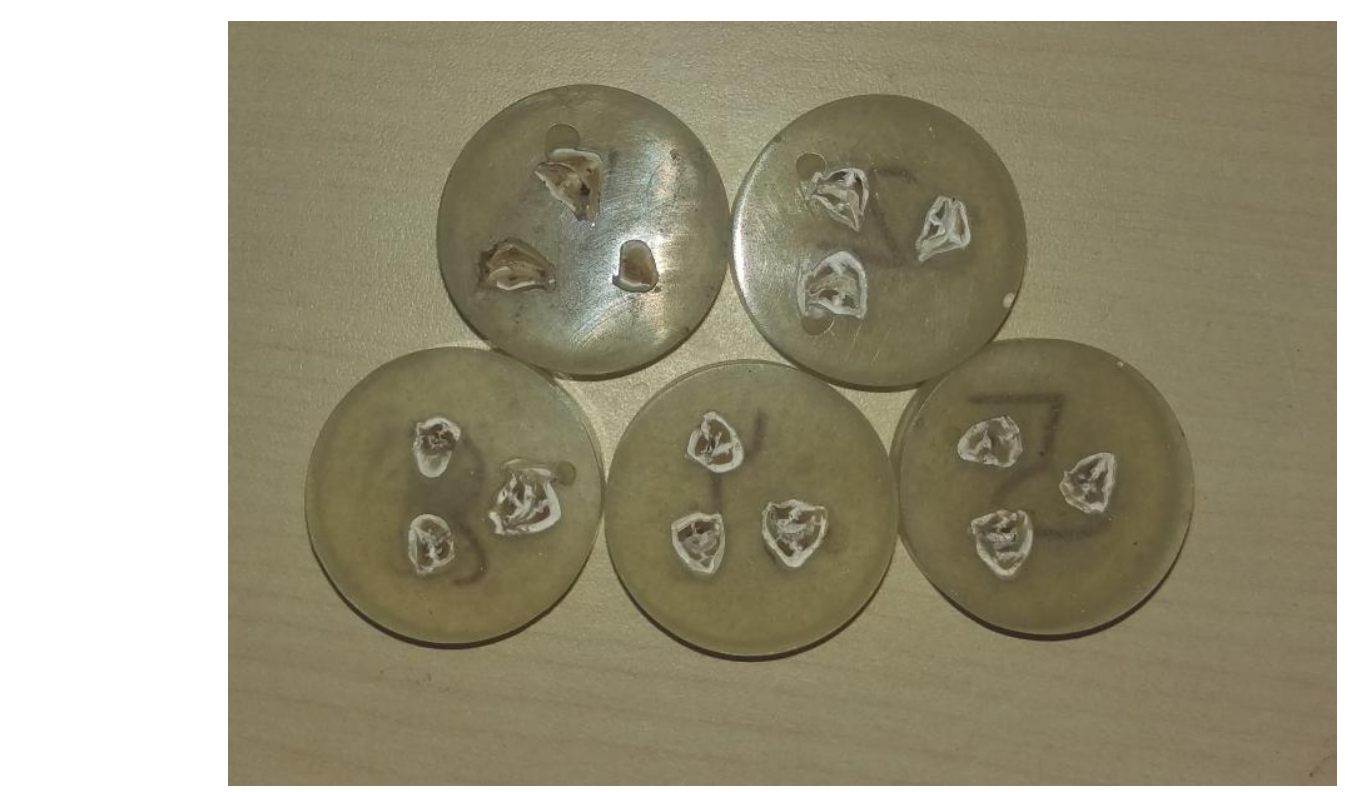

Figure 27: Dental Pucks mounted in resin and with their buccal surfaces exposed. Picture is taken after they were brushed 
A Rapidly-Dissolving Silica-Silver Bioactive Glass For Cariostatic Applications, Saad Arshad, MASc, Ryerson University, 2017

The degree of remineralization will be quantified by the percentage of surface hardness loss (\%SHL), a standard metric commonly used to describe mineral loss during dissolution as a function of microhardness [13], [167], [170]. A lower \%SHL is desirable as it indicates less mineral loss. \%SHL can be calculated using Error! Reference source not found. below.

$$
\% \text { SHL }=\frac{\text { Baseline Hardness-Treated Hardness }}{\text { Baseline Hardness }} * 100 \%
$$


A Rapidly-Dissolving Silica-Silver Bioactive Glass For Cariostatic Applications, Saad Arshad, MASc, Ryerson University, 2017

\section{Results}

\subsection{Network Connectivity}

Network connectivity of the different glasses were calculated using Equation 1. The network former is $\mathrm{SiO}_{2}$ contributing two bridging oxygens. The network modifiers are $\mathrm{P}_{2} \mathrm{O}_{5}, \mathrm{CaO}, \mathrm{Ag}_{2} \mathrm{O}$ and $\mathrm{Na}_{2} \mathrm{O} \cdot \mathrm{Ca}^{2+}$ provides two non-bridging oxygens and $\mathrm{Na}^{1+}$ provides one non-bridging oxygen per $\mathrm{Na}^{1+}$ ion. Recent work by Hill has shown that $\mathrm{P}_{2} \mathrm{O}_{5}$ functions as an orthophosphate $\left(\mathrm{Q}_{0}\right)$ modifier, contributing three non-bridging oxygens per $\mathrm{PO}_{4}{ }^{3-}$ ion [257], [258, p. 5]. Each $\mathrm{Ag}^{+}$ion provides a non-bridging oxygen [256], [259]. However, since $\mathrm{Ag}^{+}$ions can function as network formers under certain circumstances, network connectivity has been calculated for the case of $\mathrm{Ag}^{+}$as a network modifier and as a network former.

Table 20: Network connectivity for each composition assuming silver is either a network modifier (NM) or network former (NF).

\begin{tabular}{|c|c|c|c|c|c|c|c|}
\hline Glass & $\mathbf{S i O}_{2}$ & $\mathbf{C a O}$ & $\mathbf{P}_{2} \mathbf{O}_{\mathbf{5}}$ & $\mathbf{N a}_{2} \mathbf{O}$ & \multirow{2}{*}{$\mathbf{A g}_{\mathbf{2}} \mathbf{O}$} & \multicolumn{2}{|c|}{ Network Connectivity } \\
\hline Si-Control & 70 & 12 & 3 & 15 & 0 & 1.314 & 1.314 \\
\hline $\mathrm{Si}-02$ & 69.8 & 12 & 3 & 15 & 0.2 & 1.309 & 1.315 \\
\hline $\mathrm{Si}-05$ & 69.5 & 12 & 3 & 15 & 0.5 & 1.302 & 1.317 \\
\hline
\end{tabular}

\subsection{Glass Characterization}

\subsubsection{Particle Size Analysis (PSA)}

This is close to the $3 \mu \mathrm{m}$ particle size prescribed by Mneimne et al. so that the glass may enter the dentinal tubules [261]. Precipitation of apatite inside the tubules would occlude them and decrease sensitivity.

Table 21 contains the PSA results. Particle sizes were all required to be comparable to each other and below $20 \mu \mathrm{m}$ as smaller particle sizes promote faster dissolution due to their greater specific 
A Rapidly-Dissolving Silica-Silver Bioactive Glass For Cariostatic Applications, Saad Arshad, MASc, Ryerson University, 2017

surface area [249]. This allows for the particles to degrade faster and thereby release therapeutic ions more quickly [260]. The average particle size was found to be approximately $4-5 \mu \mathrm{m}$. This is close to the $3 \mu \mathrm{m}$ particle size prescribed by Mneimne et al. so that the glass may enter the dentinal tubules [261]. Precipitation of apatite inside the tubules would occlude them and decrease sensitivity.

Table 21: PSA Results. All measurements are in micrometers $(\mu \mathrm{m})$.

\begin{tabular}{|l|l|l|l|}
\hline Glass & D10 & D50 & D90 \\
\hline Si-Control & 2.29 & 4.22 & 9.31 \\
\hline Si-02 & 2.29 & 4.31 & 10.33 \\
\hline Si-05 & 2.38 & 5.11 & 12.73 \\
\hline
\end{tabular}

\subsubsection{Ray Diffraction (XRD)}

The XRD patterns were used to confirm whether the glasses were amorphous. From Figure 28, it was apparent that each of the glasses was amorphous. Despite the noise, each of the figures demonstrate the characteristic amorphous 'hump' near $25^{\circ} 2 \theta$. The amorphous hump occurs due to the non-periodicity of the crystal structure of amorphous materials. For crystalline materials, sharp Bragg peaks were observed at high intensities where the x-rays encounter and are scattered by the formed lattice planes. However, amorphous materials do not have a formed lattice plane and so they scatter the X-rays in many directions leading to a large distributed bump. 
A Rapidly-Dissolving Silica-Silver Bioactive Glass For Cariostatic Applications, Saad Arshad, MASc, Ryerson University, 2017

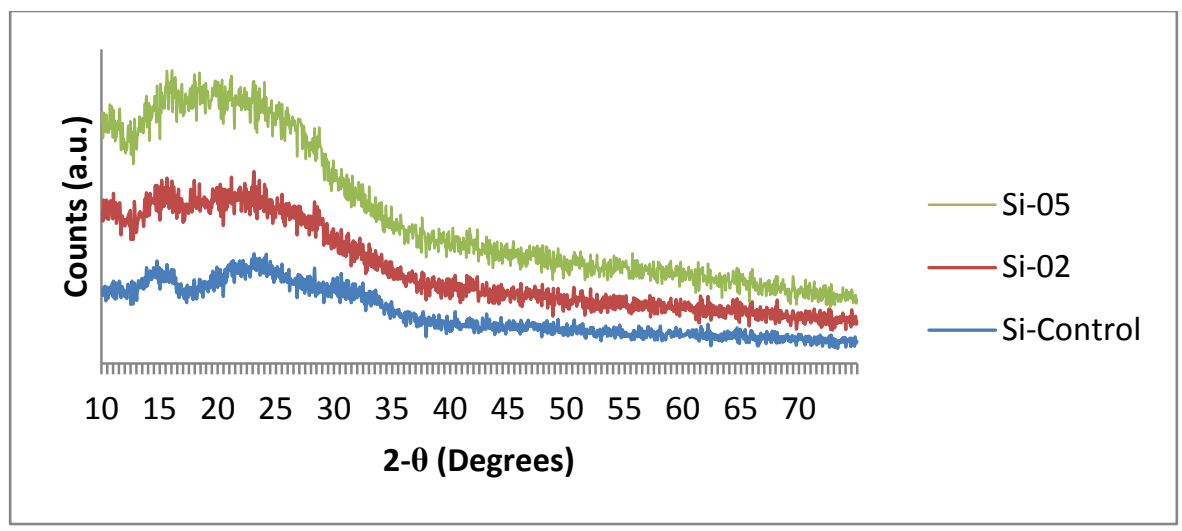

Figure 28: XRD patterns of glass compositions

\subsubsection{Fourier Transform Infrared Spectroscopy (FTIR)}

Figure 29 shows the FTIR spectra of all three glasses. As can be seen, there is the characteristic Si-O-Si (stretching) bonding band between 1000 and $1300 \mathrm{~cm}^{-1}$ [262], with an intense peak centered around 1024, 1022, and $1031 \mathrm{~cm}^{-1}$ for Si-Control, Si-02 and Si-05, respectively. There is also an Si-O (bending) bonding band between 700 and $800 \mathrm{~cm}^{-1}$ [262], with peaks centered around 777, 786 and $749 \mathrm{~cm}^{-1}$. Bands associated with $\mathrm{Si}-\mathrm{O}-\mathrm{NBO}$ per $\mathrm{SiO}_{4}$ tetrahedron were found at betwen 890 and $975 \mathrm{~cm}^{-1}$ [262], with peaks centered at 946,974 and $955 \mathrm{~cm}^{-1}$. The results are summarized in Error! Reference source not found.. 
A Rapidly-Dissolving Silica-Silver Bioactive Glass For Cariostatic Applications, Saad Arshad, MASc, Ryerson University, 2017

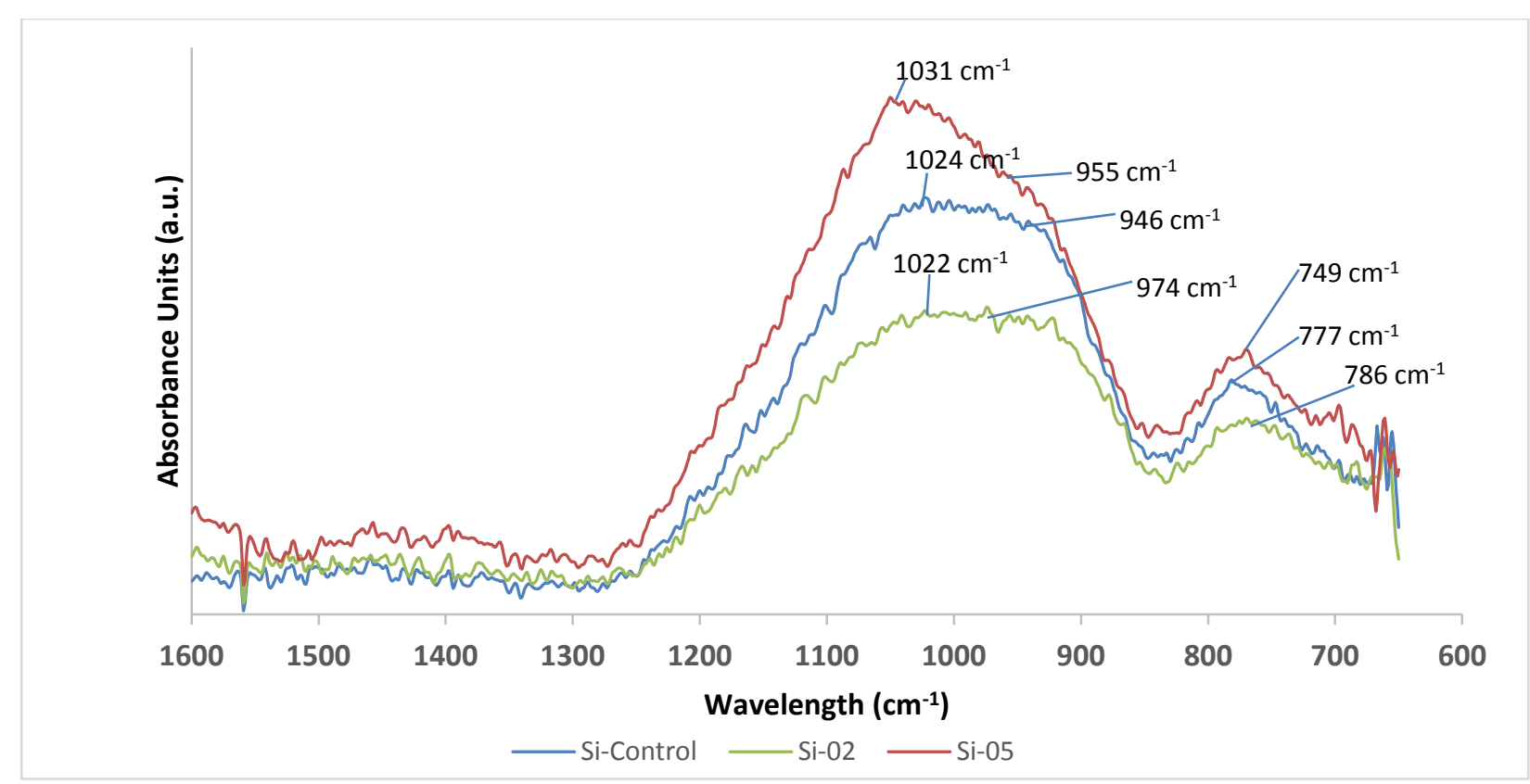

Figure 29: FTIR spectra of three glass compositions in absorbance units

As silver is added at the expense of silica, the intensity of each peak should decrease with increasing silver content as there is less network former available [262]. While this holds true from Si-Control to Si-02, Si-05 exhibits more intense peaks. Furthermore, peaks should be shifted towards lower wavelength numbers, and this trend holds the same with $\mathrm{Si}$-Control to $\mathrm{Si}$ 02 but not with $\mathrm{Si}-05$.

It is possible that this occurs due to the complex role of silver addition in the network. In Si-02, silver addition functions like a modifier, creating more NBO sites and introducing disconinuties in the network as the peaks are decreasing in intensity. However, in Si-05 spectra, the addition of silver behaves more like a network former, with peaks increasing in intensity as compared with Si-Control and Si-05. Generally, increasing intensity indicates a greater concentration of these types of bonds [263]. With the increasing intensity of peaks correlated with Si-O-Si bending and Si-O-Si stretching, it can be surmised that the quantity of bridging oxygen groups are increasing, indicating a reduction in NBO groups. Therefore, $\mathrm{Si}-05$ is behaving like a network former. 
A Rapidly-Dissolving Silica-Silver Bioactive Glass For Cariostatic Applications, Saad Arshad, MASc, Ryerson University, 2017

There is a precedent for the change in role from network modifier to network modifier; Baltzer and Copponnex report that quantities of silver greater than 3 mol\% transition their role from modifiers to formers due to the precipitation of spherical metallic silver nanoparticles [256]. Delben et al. found that bioactive glass samples containing 3\% and 5\% silver showed an increase of FTIR bands attributed to BO groups [264]. They found that increasing silver content was linked to higher Si-O-Si bond energies [264]. Furthermore, a study of Fe-doped borosilicate glasses by El-Damrawi et al. showed that quantities greater than $6 \mathrm{~mol} \%$ transitioned the role of Fe from modifier to former due to the reduction of NBO bonding sites [265]. Additional Fe removes $\mathrm{NBO}$ from the silicate network and consumes part of the modifier to form $\mathrm{FeO}_{4}$ groups. However, XRD traces of Si-05 showed amorphicity without the presence of metallic silver phases. The quantity of $\mathrm{Ag}$ ions is also significantly lower than the 3 mol\% suggested in the transitionary behaviour. However, since silver is added at the expense of silica, it is possible that some interactions are causing $\mathrm{Ag}$ addition to shield $\mathrm{BO}$ sites.

\subsubsection{Differential Scanning Calorimetry (DSC)}

Table 22 below summarizes the glass transition $\left(\mathrm{T}_{\mathrm{g}}\right)$ and crystallization temperatures $\left(\mathrm{T}_{\mathrm{x}}\right)$ of the three glasses. It is apparent that as more silver is added into the network structure, both the $T_{g}$ and $\mathrm{T}_{\mathrm{x}}$ increases.

Table 22: Crystallization and Glass Transition Temperatures of glass compositions

\begin{tabular}{|c|c|c|}
\hline Glass & $\mathbf{T}_{\mathbf{g}}\left({ }^{\circ} \mathbf{C}\right)$ & $\mathbf{T}_{\mathbf{x}}\left({ }^{\circ} \mathbf{C}\right)$ \\
\hline Si-Control & 609.5 & 825.6 \\
\hline Si-02 & 617.4 & 837.9 \\
\hline Si-05 & 619.6 & 848.1 \\
\hline
\end{tabular}

\subsubsection{SEM-EDX}


A Rapidly-Dissolving Silica-Silver Bioactive Glass For Cariostatic Applications, Saad Arshad, MASc, Ryerson University, 2017

SEM photos are exhibited below in Figure 30, with (a) as Si-Control, (b) as Si-02 and (c) as Si05. The photos confirm that the compositions are mostly homogenous in their particle sizes. However, Si-05 appears to be more granular and has sharper edges in its particles.
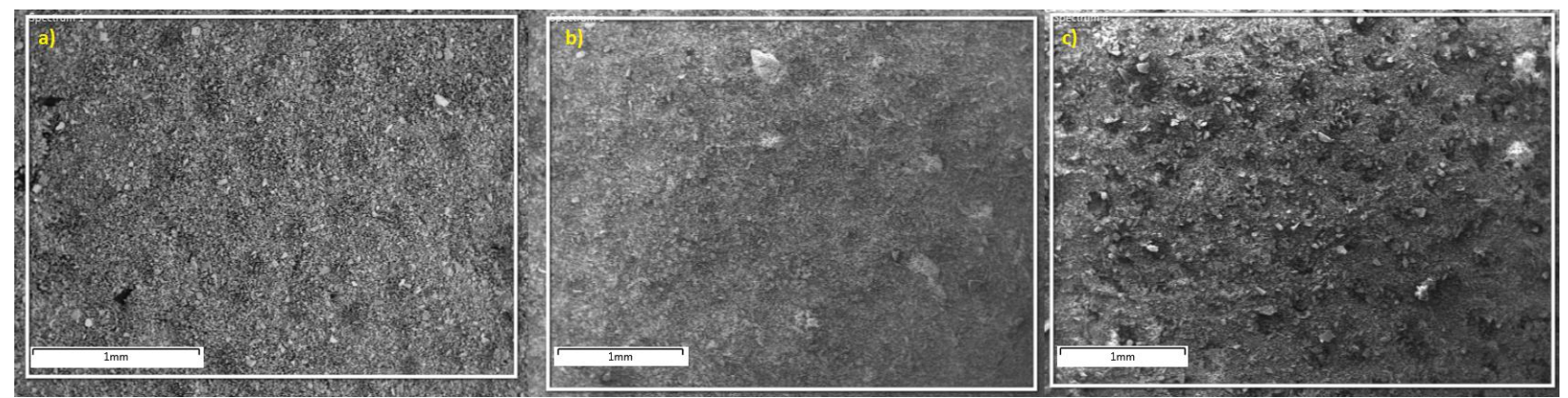

Figure 30: SEM photos of compositions: a) Si-Control b) Si-02 c) Si-05

EDX images were taken at multiple sites to determine the composition of the glasses and minimize the localization effects experienced. As can be seen in

Table 23, the glass compositions were close to the reagent amounts fired in the crucible. This confirms that the glass thoroughly melted during the firing process.

Table 23: Average of wt $\%$ in compositions for each composition

\begin{tabular}{|l|l|l|l|}
\hline Element & Si-Control & Si-02 & Si-05 \\
\hline $\mathrm{O}$ & 50.6 & 54.8 & 54.7 \\
\hline $\mathrm{Si}$ & 29.0 & 25.9 & 24.9 \\
\hline $\mathrm{Na}$ & 10.3 & 10.3 & 10.6 \\
\hline $\mathrm{Ca}$ & 7.60 & 6.60 & 6.77 \\
\hline $\mathrm{P}$ & 2.50 & 2.03 & 2.03 \\
\hline $\mathrm{Ag}$ & 0 & 0.3 & 0.97 \\
\hline
\end{tabular}


A Rapidly-Dissolving Silica-Silver Bioactive Glass For Cariostatic Applications, Saad Arshad, MASc, Ryerson University, 2017

\subsection{Solubility Results}

Figure 31 below summarizes the $\mathrm{pH}$ values found for each of the tests.

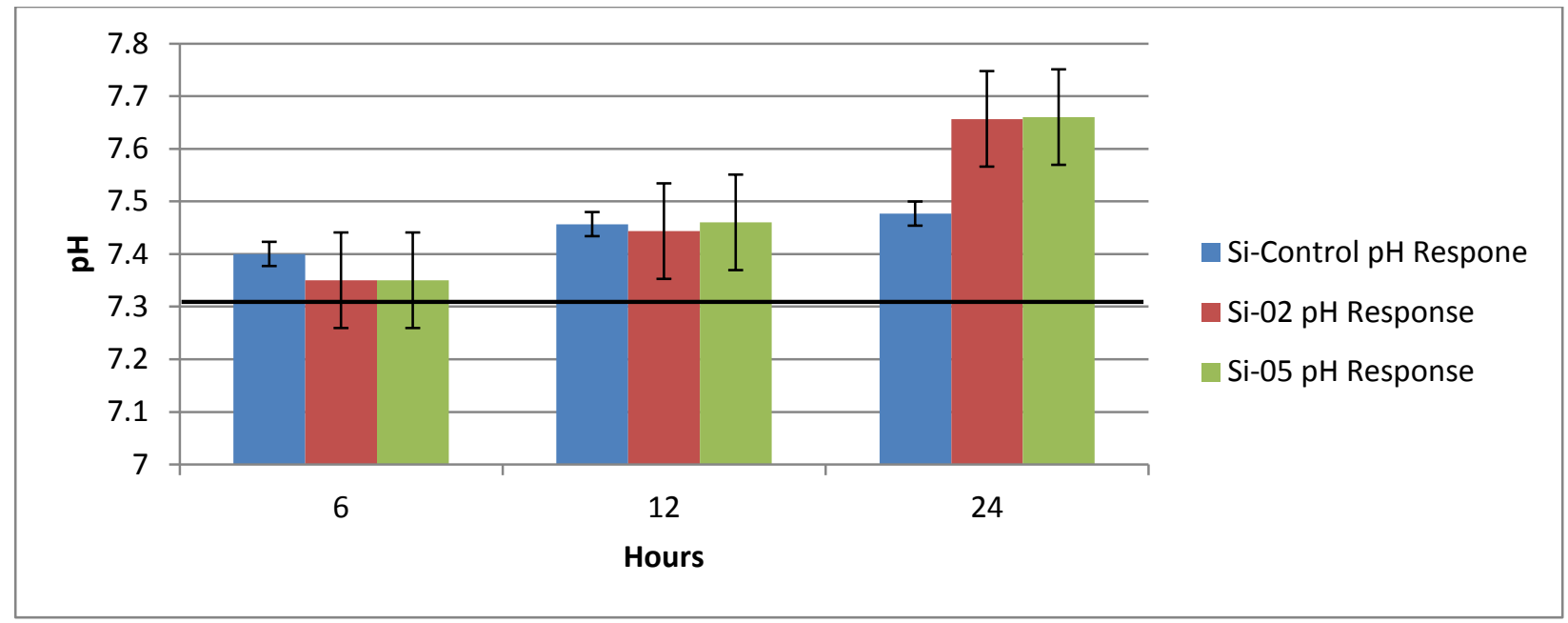

Figure 31: pH response of tris buffer solution upon glass dissolution after six, twelve and twenty-four hours. Black horizontal bar represents the initial pH value of the Tris buffer solution before dissolution.

It is apparent from the figure above that the $\mathrm{pH}$ of the tris buffer solution increases over time as the glass degrades. The $\mathrm{pH}$ of the tris solution is highest for Si-Control at six hours but does not reach the higher $\mathrm{pH}$ values of tris containing $\mathrm{Si}-02$ and $\mathrm{Si}-05$ over the longer time periods of twelve hours and twenty-four hours. It appears that the cations are not as readily exchanged during the early stages of $\mathrm{Si}-02$ and $\mathrm{Si}-05$ dissolution.

Figure 32 (a-d) below summarizes the ion release data. 
A Rapidly-Dissolving Silica-Silver Bioactive Glass For Cariostatic Applications, Saad Arshad, MASc, Ryerson University, 2017
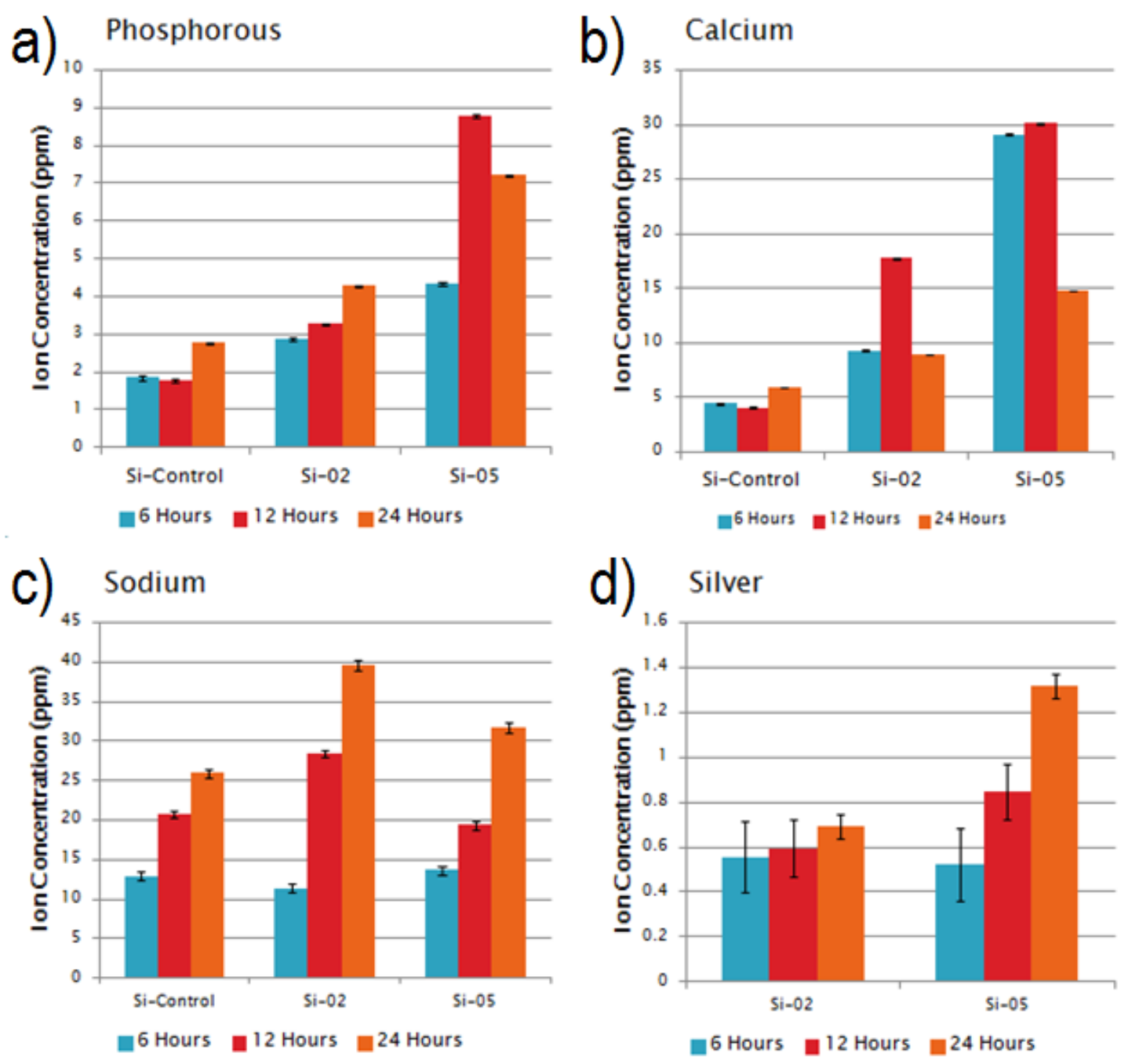

Figure 32 (a-d): Ion release profiles for (a) Phosphorous, (b) Calcium, (c) Sodium and (d) Silver. Si-Control silver release has been omitted from (d) as no silver was present in the composition.

While Si-05 releases more silver than $\mathrm{Si}-02, \mathrm{Si}-02$ releases a greater concentration of calcium, sodium and phosphorous. Si-05 releases a smaller concentration of calcium, sodium and phosphorous ions when compared with $\mathrm{Si}-02$ and Si-Control after 24 hours. While all ion amounts increase over time, they do not increase linearly. Si-02, for example, exhibits a marked spike in concentration from 12 hours to 24 hours for its phosphorous release, overtaking the phosphorous ion release from Si-Control and Si-05. Si-02 also experiences an increase at 12 hours in its calcium release, while Si-Control undergoes a similar spike after 24 hours in calcium 
A Rapidly-Dissolving Silica-Silver Bioactive Glass For Cariostatic Applications, Saad Arshad, MASc, Ryerson University, 2017

release. Sodium ion release exhibits more constant ion release rates for all compositions across all time spans.

To measure the ion release kinetics of an alkali-silicate glass, the heterogenous model was used [121], [266]. To confirm dissolution behaves under the heterogenous model, the total silver ion concentration was graphed against the square root of the time and a linear regression was employed. The correlation coefficient $\left(\mathrm{R}^{2}\right)$ was above 0.95 for both $\mathrm{Si}-02$ and $\mathrm{Si}-05$ compositions, confirming the model. The network is predicted to be very complex, formed by a backbone of $\mathrm{SiO}_{4}$ tetrahedra connected at the oxygen atoms to form a 3D network. However, the presence of alkali species breaks up the network continuity, as the oxygen atoms no longer bridge to the next tetrahedra but instead to an alkali ion. This should increase dissolution rates as these non-bridging oxygen bonds are easier to break than bridging oxygen bonds. However silver ions were added at the expense of silica ions, which should reduce the network connectivity as network formers were replaced with network modifiers. This leaves less silica ions available to form the backbone, as well as further disrupting the network. Ion release rates should be seen to be higher in $\mathrm{Si}-05$ than $\mathrm{Si}-02$, as well as being higher in $\mathrm{Si}-02$ than $\mathrm{Si}-\mathrm{Control}$. While this is observed over short time periods, with the exception of silver release, longer dissolution time periods favour Si-02.

\subsection{Antibacterial Studies}

Error! Reference source not found.Figure 33 describes the inhibition zones. The inhibition zone is useful for measuring how antibacterial these glasses are. As expected, $\mathrm{Si}-05$ consistently exhibited a larger inhibition zone against all tested bacteria and therefore a stronger antibacterial response. Additionally, the inhibition zone increases over time for all bacteria except strain D4, which experiences a dip in the inhibition zone before climbing again. However, one-way 
A Rapidly-Dissolving Silica-Silver Bioactive Glass For Cariostatic Applications, Saad Arshad, MASc, Ryerson University, 2017

ANOVA analysis showed this difference is not significant. Furthermore, since the control glasses did not experience any inhibition zone at any time period, the effects of $\mathrm{pH}$ rise can be eliminated as a potential bactericidal effect. As silver is the only ion species not present in SiControl, it is the most likely bactericidal agent responsible here. Silver has a known wideranging antibacterial effect and the increase of silver release over time is consistent with the growing inhibition zone.
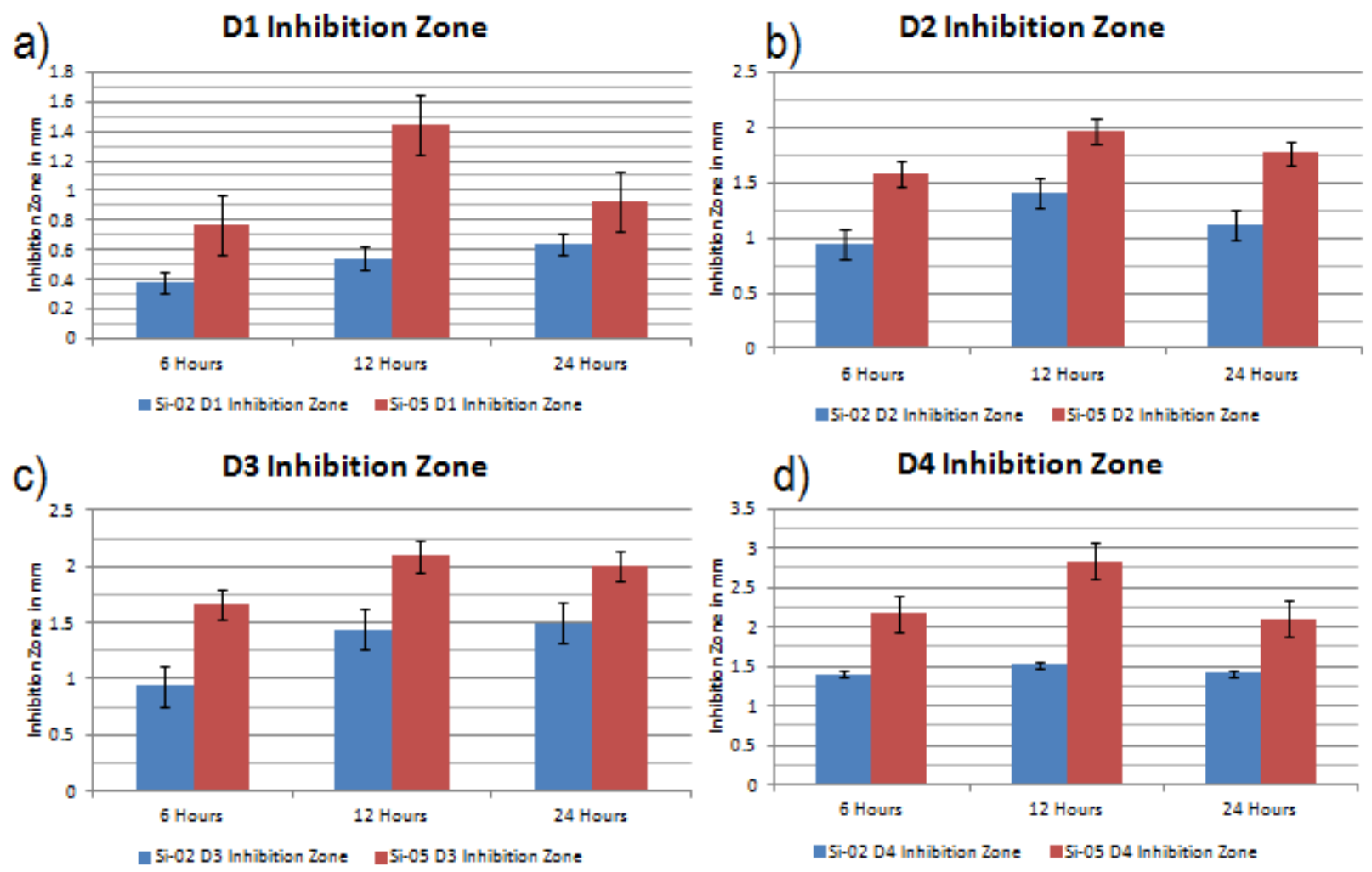

Figure 33: (a) Inhibition Zone against bacterial strain D1 (b) Inhibition Zone against bacterial strain D2 (c) Inhibition Zone against bacterial strain D3 (d) Inhibition Zone against bacterial strain D4. The inhibition zone produced by glass powders against four bacterial isolate strains. Si-Control was excluded as it produced no inhibition zone throughout the time period measured.

\subsection{Toothpaste Remineralization Studies}

Figure 34 shows the demineralization and remineralization of the dentin molars embedded in resin pucks. The degree of mineralization was quantified through Knoop microhardness and 
A Rapidly-Dissolving Silica-Silver Bioactive Glass For Cariostatic Applications, Saad Arshad, MASc, Ryerson University, 2017

control measurements were taken after the pucks were prepared and before they were subjected to an acid challenge, as well as before and after their dentifrice remineralization treatments.

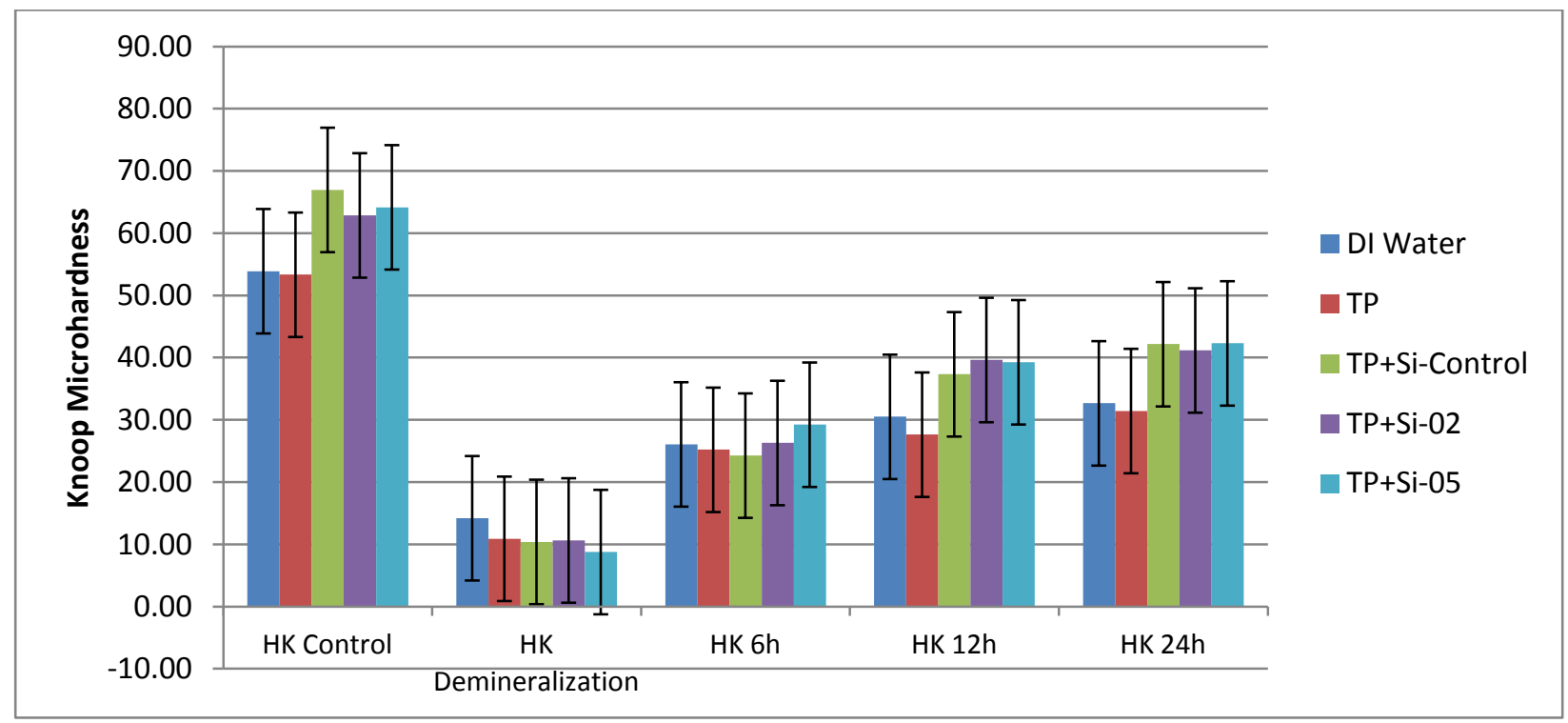

Figure 34: Knoop Microhardness Remineralization and Demineralization on lamb molar dentin samples. All measurements are Knoop Hardness (HK). DI is deionized water, TP is toothpaste.

The percentage of remineralization and demineralization are quantified through percentage hardness loss (\%SHL) in Table 24.

Table 24: Percent Surface Hardness Loss (\%SHL) for each stage of treatment as compared with baseline Knoop values

\begin{tabular}{|l|l|l|l|l|}
\hline \multicolumn{1}{|c|}{ Treatment } & \%Demin & $\begin{array}{c}\text { \%Remin after 6 } \\
\text { hours }\end{array}$ & $\begin{array}{c}\text { \%Remin after 12 } \\
\text { hours }\end{array}$ & $\begin{array}{c}\text { \% Remin after 24 } \\
\text { hours }\end{array}$ \\
\hline DI Water & $74 \%$ & $52 \%$ & $43 \%$ & $39 \%$ \\
\hline TP & $80 \%$ & $53 \%$ & $48 \%$ & $41 \%$ \\
\hline TP+Si-Control & $84 \%$ & $64 \%$ & $44 \%$ & $37 \%$ \\
\hline $\mathrm{TP}+\mathrm{Si}-02$ & $83 \%$ & $58 \%$ & $37 \%$ & $35 \%$ \\
\hline $\mathrm{TP}+\mathrm{Si}-05$ & $86 \%$ & $54 \%$ & $39 \%$ & $34 \%$ \\
\hline
\end{tabular}

It is apparent through these results that the glass compositions were more effective than the controls, with the highest microhardness after twenty four hours belonging to TP+Si-02 followed by TP+Si-Control, TP, TP+Si-05 and finally DI water. However, when taking into account the initial demineralization effects, $\mathrm{TP}+\mathrm{Si}-\mathrm{Control}, \mathrm{TP}+\mathrm{Si}-02$ and $\mathrm{TP}+\mathrm{Si}-05$ had similar remineralization percentages, as per Table 24. Additionally, the response was higher than just the 
A Rapidly-Dissolving Silica-Silver Bioactive Glass For Cariostatic Applications, Saad Arshad, MASc, Ryerson University, 2017

dentifrice treatment alone, indicating that the glass had a positive contribution to the mineralization treatments.

\subsection{Discussion}

Bioactive glasses cause $\mathrm{pH}$ rises upon dissolution in aqueous solutions, such as tris buffer. This facilitates apatite formation but can also cause a $\mathrm{pH}$ rise too great for the oral environment; an oral pH greater than 7.5 can irritate the oral mucous membranes [261], [267]. As per Figure 31, the tris buffers containing the $\mathrm{Si}-02$ and $\mathrm{Si}-05$ compositions exhibit a $\mathrm{pH}$ of 7.35 at six hours while the Si-Control solution shows a higher $\mathrm{pH}$ rise at 7.4. These values were not determined to be significantly different at $\mathrm{p}<0.05$. After twelve hours, the $\mathrm{pH}$ responses of the solutions are 7.46, 7.44 and 7.46 for $\mathrm{Si}-\mathrm{Control}, \mathrm{Si}-02$ and $\mathrm{Si}-05$ respectively indicating that the advantage gained by the control glass' early $\mathrm{pH}$ rise is lost over longer time frames. Indeed, by 24 hours, solutions containing $\mathrm{Si}-02$ and $\mathrm{Si}-05$ both show a $\mathrm{pH}$ of 7.66 while the solution containing SiControl shows a $\mathrm{pH}$ of 7.48 .

This compares favourably with other bioactive glasses in aqueuous solution. Brauer et al. found the $\mathrm{pH}$ response of an SBF solution containing fluoridated bioactive glass can reach 7.6 after 24 hours but to plateau at 7.8 shortly afterwards from day 3 to the end of the experiment [267]. Tris buffer solutions containing $\mathrm{Si}-02$ and $\mathrm{Si}-05$ both reached the same $\mathrm{pH}$ level after 24 hours while the solution containing $\mathrm{Si}-\mathrm{Control}$ did not show a significant $\mathrm{pH}$ rise after 12 hours. Time frames greater than 24 hours were not examined as they were not deemed relevant to the application of toothpaste in the oral environment; it is highly unlikely that the ions deposited from the degrading glass powders would remain in the mouth after a days consumption of liquids diluting the contents of the mouth [261]. 
A Rapidly-Dissolving Silica-Silver Bioactive Glass For Cariostatic Applications, Saad Arshad, MASc, Ryerson University, 2017

These glasses were designed with rapid ion release in mind and it was observed that, after twelve hours, the release rate accelerates. As per Figure 32 (d), Si-02 releases silver, on average, 2.5 times faster after 12 hours while $\mathrm{Si}-05$ releases silver on average 1.5 times faster after 12 hours. The incorporation of silver into the network structure changes the more linear response of the control composition into an accelerating one, albeit with a slower initial response time. This is due to the complex nature of the network structure when silver is incorporated, as shown by the apparent change of its role from network modifier in Si-02 to a network former in SI-05 in the FTIR spectra, as can be seen in Figure 29. As silver is added at the expense of silica, a network modifier is added at the expense of a network former, which should increase bioactivity and solubility of the glass as bridging oxygens are being lost and replaced with non-bridging oxygens, which should facilitate a greater release of cations, specifically sodium and calcium ions, which are basic [261], [268], and will produce a greater $\mathrm{pH}$ rise. The $\mathrm{pH}$ rise should disrupt the dissolution mechanism and promote remineralization. However, the initial lag before the 12hour acceleration indicates that the cations are not exchanged as readily during the early stages of dissolution. It may be that the complex network structure takes longer to degrade and favors dissolution of its formers more than its modifiers. This trend holds up when compared with the ion release profiles. The larger silver content yields higher initial release volumes but smaller release rates over time, leading to lower cumulative final release volumes. Interestingly, the $\mathrm{Si}$ Control composition generally displays ion release volumes either between the two silvercontaining compositions or closer to Si-02 ion profiles, as seen in Figure 32 (a-c). Si-05 releases less silver ions initially but greater quantities of all other ions when compared with $\mathrm{Si}-02$ after six hours, with the exception of phosphorous. However, over time, silver ion release rates increase rapidly with $\mathrm{Si}-05$ while $\mathrm{Si}-02$ releases silver ions at a constant rate. $\mathrm{Si}-02$ also generally 
A Rapidly-Dissolving Silica-Silver Bioactive Glass For Cariostatic Applications, Saad Arshad, MASc, Ryerson University, 2017

exhibits higher ion release volumes than $\mathrm{Si}-05$ after 24 hours for sodium, calcium and phosphorous. Generally, the more silver ions released, the less of every other ionic species is released. Silica release was not measured but it may be useful in further explaining how the network degradation functioned as silica was the backbone of the network.

Phosphorous ion release behaves differently to the sodium, calcium and silver release as it reaches a peak around 12 hours and then diminishes, as can be seen in Figure 32 (a). The decrease of phosphorous over longer time periods is associated with re-precipitation of $\mathrm{Ca}$ phosphate species, such as apatite and octacalcium phosphate, a sort of precursor mineral for apatite formation [269], [270]. However, the deposits would have to be examined under FTIR and XRD analysis in order to determine if any apatite has in fact precipitated, or if a different mineral has formed. Conventionally, the bioactivity of glasses has been defined as the apatiteforming ability of glasses after immersion in SBF [261], but immersion in tris buffer represents a more conservative test as it does not supply $\mathrm{Ca}^{2+}$ or phosphate species. This is a better model of the oral environment as saliva can be diluted when taking in liquids and become depleted of $\mathrm{Ca}^{2+}$ and phosphate species [261]. Phosphorous ions are also known to diminish the $\mathrm{pH}$ rise from dissolution due to their acidity. This effect can help moderate the $\mathrm{pH}$ rise associated with the other cations released from the glass dissolution and prevent $\mathrm{pH}$ spikes from local concentrations of cations, as well as promote bioactivity since a pH of approximately 7.3 is considered ideal for apatite precipitation [268].

Cell culture studies were singularly affected by $\mathrm{Ag}^{+}$release as all agar discs were kept under similar conditions and Si-Control exhibited no antibacterial response. It is therefore possible to eliminate $\mathrm{pH}$ as a bactericidal factor, since all compositions are known to cause similar $\mathrm{pH}$ rises, as per Figure 31. Referring to Figure 33 (a-d), across all time frames and all bacterial strains, Si- 
A Rapidly-Dissolving Silica-Silver Bioactive Glass For Cariostatic Applications, Saad Arshad, MASc, Ryerson University, 2017

05 outperformed $\mathrm{Si}-02$ in its bactericidal efficacy, which further suggests that silver is the lone bactericidal agent. However, at six hours, less silver was reported as having leached out in Si-05 as compared to $\mathrm{Si}-02$, although the difference was not statistically significant at $\mathrm{p}<0.05$. Silver is known to have wide ranging antibacterial properties; it is believed that DNA stops being able to replicate and proteins become inactive after contact with $\mathrm{Ag}^{+}$[266]. It has also been suggested silver ions interfere with the metabolism of the bacteria, which ultimately inhibits their growth [22].

Referring to Figure 34, all three glassses significantly remineralized enamel after 24 hours. As $\mathrm{Si}-02$ released the greatest amount of calcium and phosphorous after 12 hours $(17.7 \mathrm{ppm}$ and $8.79 \mathrm{ppm}$ respectively), it should have exhibited the greatest degree of remineralization at that time frame, which is consistent with the results, and indeed does not remineralize much more; from 12 hours to 24 hours, the teeth treated with the toothpaste embedded with $\mathrm{Si}-02$ only remineralize from $37 \%$ to $35 \%$. There is an upper limit to the amount of restoration which is possible after demineralization, which is approximately $35 \%$ surface hardness loss (\%SHL). To compare, a toothpaste containing $1100 \mathrm{ppm}$ F exhibited a maximum of 38\% SHL after four 7day phases of demineralization/remineralization cycles [271]. Percentage hardness losses for enamel treated with over the counter bleaching agents and then stored in artificial saliva range from 12-40\% according to Zantner et al. (2007), while a study by Chen et al. (2008) found an 18-32\% SHL for enamel treated with fluoridated bleaching agents followed by buffer saline solution [272], [273]. The upper limit can be explained by calcium and phosphorous uptake into the enamel being limited by the concentration of the ions available. Therefore, there may simply not be enough calcium or phosphorous to repair the lesions and form HA. It is also possible that apatite crystals precipitated over the surface level of the pucks, preventing the penetration of 
A Rapidly-Dissolving Silica-Silver Bioactive Glass For Cariostatic Applications, Saad Arshad, MASc, Ryerson University, 2017

glass deeper into the lesions and remineralizing the bulk of the material. However, it is also possible that the reason the teeth did not fully remineralize is damage to the underlying dentin and cementum, as well as the resin holding the teeth. Since all compositions had the same amount of calcium and phosphorous, all pucks restored with the glass-loaded dentifrices are expected to reach a similar remineralizing point. While the dentifrice alone was effective at remineralizing the dentin $(41 \% \mathrm{SHL})$, the glass loading did increase the remineralization slightly, with a percent difference of $15.4 \%$ between the average glass remineralization and the toothpaste surface hardness loss. However, the difference was not statistically significant at the $p<0.05$ level. 
A Rapidly-Dissolving Silica-Silver Bioactive Glass For Cariostatic Applications, Saad Arshad, MASc, Ryerson University, 2017

\subsection{Conclusion}

The goal of this project was to develop a silver-doped bioactive glass that could be incorporated into a dentifrice to remineralize dental tissues. Three glass compositions were synthesized and examined to determine effectiveness as an anticaries treatment. The glasses were characterized and tested for their antibacterial properties as well as their enamel remineralization capability.

- The addition of $0.2 \%$ and $0.5 \%$ silver to a $\mathrm{SiO}_{2}-\mathrm{CaO}-\mathrm{P}_{2} \mathrm{O}_{5}-\mathrm{Na}_{2} \mathrm{O}-\mathrm{Ag}_{2} \mathrm{O}$ glass composition at the expense of silica did not cause the glasses to crystallize when fired through the melt-quench method.

- The glasses caused a $\mathrm{pH}$ response in tris buffer solution, raising the $\mathrm{pH}$ from 7.3 to approximately 7.6. This is invaluable as remineralization and demineralization are $\mathrm{pH}$ dependent processes. An acidic environment will promote demineralization while a more alkaline environment will be more conducive to remineralization. However too great a change in the oral $\mathrm{pH}$ can cause irritation.

- Ion release profiles were found to be dependent on time and silver content. The network structure of the glass is complex and glass dissolution follows the heterogenous model, meaning the release of silver occurs in two phases. The first phase involves alkali ions being replaced with hydronium ions which varies with the square root of time while the second phase is the dissolution of the network which varies linearly with time

- The Si-05 glass exhibits a stronger antibacterial response than the Si-02 glass, while SiControl exhibits no antibacterial effect. This stronger antibacterial response is due to the silver content in each composition; while $\mathrm{pH}$ changes are caused by all glasses, SiControl contains no silver. It can be said then that $\mathrm{Ag}^{+}$is the sole bactericidal factor in the glasses. 
A Rapidly-Dissolving Silica-Silver Bioactive Glass For Cariostatic Applications, Saad Arshad, MASc, Ryerson University, 2017

- All glasses remineralize lamb dental enamel when incorporated into a toothpaste. This remineralization effect is more potent than the toothpaste alone, which is more effective than deionized water. All compositions contain the same amount of calcium and phosphorous. As these are the constituent ingredients in $\mathrm{HA}$, it is believed that $\mathrm{Ca}^{2+}$ and $\mathrm{P}^{3-}$ cause the remineralization effect. 
A Rapidly-Dissolving Silica-Silver Bioactive Glass For Cariostatic Applications, Saad Arshad, MASc, Ryerson University, 2017

\subsection{Future Work}

Further work on these glasses would involve tailoring their ion release profiles to release the majority of their ions during the early stages of dissolution, rather than accelerate after small releases. This is useful for the purposes of maximising the therapeutic effect of the glasses by allowing most of the ions to do their work before they can be leeched out of the mouth through daily liquid intake. This can be accomplished by increasing the bioactivity further, by decreasing the network connectivity or by shock quenching faster when firing the glasses. This can also be accomplished by further reducing particle size, or introducing a bimodal distribution of 'coarse' and 'fine' particles. Fine, or smaller particles would degrade faster, providing quick initial relief from dentinal sensitivity while ions released would promote immediate remineralization. The $\mathrm{pH}$ response provided would facilitate the coarser, or larger particles to provide a sustained release over time and reduce the daily enamel and dentin demineralization.

Furthermore, human enamel and dentin samples should be tested against these glasses to further confirm the remineralization treatments on human subjects as well as pre-existing teeth restorations, both in vivo and in vitro. Microfluidic techniques can also be employed to model the effects of the glass on biofilm formation and the ability of the glass to penetrate into cavities and cracks, including microcracks which occur in teeth restorations. 
A Rapidly-Dissolving Silica-Silver Bioactive Glass For Cariostatic Applications, Saad Arshad, MASc, Ryerson University, 2017

\section{Appendix}

List of tested products from Kleverlaan 2005 study, as summarized in Table 6.

\begin{tabular}{|l|l|}
\hline Product & Manufacturer \\
\hline HelioMolar & Ivoclar Vivadent \\
\hline Filtek A110 & $3 \mathrm{M}$ ESPE \\
\hline Filtek Z250 & $3 \mathrm{M}$ ESPE \\
\hline Filtek P60 & $3 \mathrm{M}$ ESPE \\
\hline Filtek Supreme & $3 \mathrm{M}$ ESPE \\
\hline Filtek Z100 & $3 \mathrm{M}$ ESPE \\
\hline Prodigy Condensable & Kerr \\
\hline Tetric Cream & Ivoclar Vivadent \\
\hline Herculite XRV & Kerr \\
\hline Spectrum TPH & Densply deTrey \\
\hline Point4 & Kerr \\
\hline Aelite Flo & Bisco \\
\hline Revolution Formula 2 & Kerr \\
\hline Flow-It & Jeneric/Pentron \\
\hline UltraSeal XT Plus & Ultradent \\
\hline
\end{tabular}


A Rapidly-Dissolving Silica-Silver Bioactive Glass For Cariostatic Applications, Saad Arshad, MASc, Ryerson University, 2017

Products tested in Table 5, including their classification and manufacturer [91], [92].

\begin{tabular}{|l|l|l|}
\hline Product Brand (Manufacturer) & Material Class & Source \\
\hline Filtek Z250 (3M ESPE, USA) & Adhesive Composite & \multirow{2}{*}{ Aghazadeh et al. (2007) [92] } \\
Letric Ceram (Ivoclar Vivadent, & Adhesive Composite & \\
Heliomolar (Ivoclar Vivadent, & Adhesive Composite & \\
Liechtenstein) & & \\
\hline Gradia Indirect (GC Gradia, Japan) & Traditional Composite & \\
\hline Gradia Direct (GC Gradia, Japan) & Traditional Composite & \multirow{2}{*}{ Berry and Powers (1994) [91] } \\
\cline { 1 - 2 } Geristore (DenMat, USA) & Adhesive Composite & \\
\cline { 1 - 2 } Tenure (DenMat, USA) & Bonding Agent & \\
\hline Marathon (DenMat, USA) & Traditional Composite & \\
\hline
\end{tabular}


A Rapidly-Dissolving Silica-Silver Bioactive Glass For Cariostatic Applications, Saad Arshad, MASc, Ryerson University, 2017

\section{References}

[1] Dogan Ozdemir, "Dental Caries: The Most Common Disease Worldwide and Preventive Strategies," Int. J. Biol., vol. 5, no. 4, p. 55, 2013.

[2] National Health and Nutrition Examination Survey, "Dental Caries (Tooth Decay) in Adults (Age 20 to 64)," National Institute of Health, National Institute of Dental and Craniofacial Research, 2008.

[3] V. C. C. Marinho, H. V. Worthington, T. Walsh, and J. E. Clarkson, "Fluoride varnishes for preventing dental caries in children and adolescents.," Cochrane Database Syst. Rev., vol. 7, p. CD002279, 2013.

[4] P. Axelsson, B. Nyström, and J. Lindhe, "The long-term effect of a plaque control program on tooth mortality, caries and periodontal disease in adults," J. Clin. Periodontol., vol. 31, no. 9, pp. 749-757, Sep. 2004.

[5] R. H. Selwitz, A. I. Ismail, and N. B. Pitts, “Dental caries," Lancet, vol. 369, no. 9555, pp. 51-59, 2007.

[6] J. M. Meyer, "Compomers: between glass-ionomer cements and composites," Biomaterials, vol. 19, no. 6, pp. 529-539, 1998.

[7] N. D. Ruse, “What is a 'compomer'?," J. Can. Dent. Assoc., vol. 65, no. 9, p. 500, 1999.

[8] C. L. Davidson, "Polymerization shrinkage and polymerization shrinkage stress in polymer-based restoratives," J. Dent., vol. 25, no. 6, pp. 435-440, 1997.

[9] P. A. Gronka, Bobkoski.Rl, G. J. Tomchick, F. Bach, and A. B. Rakow, "Mercury Vapor Exposures in Dental Offices," J. Am. Dent. Assoc., vol. 81, no. 4, p. 923-, 1970.

[10] J. Hyson J. M., “Amalgam: Its history and perils," J. Calif. Dent. Assoc., vol. 34, no. 3, p. $215,2006$.

[11] L. L. Hench, "Chronology of Bioactive Glass Development and Clinical Applications," New J. Glass Ceram., vol. 03, no. 02, pp. 67-73, 2013.

[12] L. L. Hench, R. J. Splinter, W. C. Allen, and T. K. Greenlee, "Bonding mechanisms at the interface of ceramic prosthetic materials," J. Biomed. Mater. Res., vol. 5, no. 6, pp. 117141, Nov. 1971.

[13] I. Diamanti, H. Koletsi-Kounari, E. Mamai-Homata, and G. Vougiouklakis, "Effect of fluoride and of calcium sodium phosphosilicate toothpastes on pre-softened dentin demineralization and remineralization in vitro," J. Dent., vol. 38, no. 8, pp. 671-677, Aug. 2010.

[14] T. Saito, H. Toyooka, S. Ito, and M. A. Crenshaw, "In vitro Study of Remineralization of Dentin: Effects of Ions on Mineral Induction by Decalcified Dentin Matrix," Caries Res., vol. 37, no. 6, pp. 445-449, 2003.

[15] A. Prabhakar and S. Kumar, "Antibacterial effect of bioactive glass in combination with powdered enamel and dentin," Indian J. Dent. Res., vol. 21, no. 1, p. 30, 2010.

[16] M. Zehnder, E. Söderling, J. Salonen, and T. Waltimo, "Preliminary Evaluation of Bioactive Glass S53P4 as an Endodontic Medication In Vitro,” J. Endod., vol. 30, no. 4, pp. 220-224, Apr. 2004.

[17] D. G. Gillam, Dentine Hypersensitivity: Advances in Diagnosis, Management, and Treatment. Springer, 2015.

[18] M. E. J. Curzon, "The Relation Between Caries Prevalence and Strontium Concentrations in Drinking Water, Plaque, and Surface Enamel," J. Dent. Res., vol. 64, no. 12, pp. 13861388, Dec. 1985. 
A Rapidly-Dissolving Silica-Silver Bioactive Glass For Cariostatic Applications, Saad Arshad, MASc, Ryerson University, 2017

[19] M. E. Curzon, P. C. Spector, and H. P. Iker, "An association between strontium in drinking water supplies and low caries prevalence in man," Arch. Oral Biol., vol. 23, no. 4, pp. 317-321, 1978.

[20] T. T. Thuy et al., "Effect of strontium in combination with fluoride on enamel remineralisation in vitro," Arch. Oral Biol., vol. 53, no. 11, pp. 1017-1022, 2008.

[21] T. MAVROGORDATO, "The preventive role of fluorine against caries," J. Dent. Res., vol. 30, no. 2, pp. 225-228, 1951.

[22] J. S. Kim et al., "Antimicrobial effects of silver nanoparticles (vol 1, pg 95, 2007)," Nanomedicine-Nanotechnol. Biol. Med., vol. 10, no. 5, pp. 1119-1119, 2014.

[23] A. Besinis, "The antibacterial effects of silver, titanium dioxide and silica dioxide nanoparticles compared to the dental disinfectant chlorhexidine on Streptococcus mutans using a suite of bioassays," Nanotoxicology, vol. 8, no. 1, pp. 1-16, Feb. 2014.

[24] D. Cummins, "Delivery of Antiplaque Agents from Dentifrices, Gels, and Mouthwashes," J. Dent. Res., vol. 71, no. 7, pp. 1439-1449, Jul. 1992.

[25] A. Young, G. Jonski, and G. Rölla, "Inhibition of orally produced volatile sulfur compounds by zinc, chlorhexidine or cetylpyridinium chloride - effect of concentration," Eur. J. Oral Sci., vol. 111, no. 5, pp. 400-404, Oct. 2003.

[26] N. R. Mohammed, "Physical chemical effects of zinc on in vitro enamel demineralization," vol. 42, no. 9, pp. 1096-1104, 2014.

[27] A. K. Burwell, "Calcium Sodium Phosphosilicate (NovaMin $\left.{ }^{\circledR}\right)$ : Remineralization Potential," Adv. Dent. Res., vol. 21, no. 1, pp. 35-39, Aug. 2009.

[28] B. F. A. Karim and D. G. Gillam, "The efficacy of strontium and potassium toothpastes in treating dentine hypersensitivity: a systematic review," Int. J. Dent., 2013.

[29] K. W. Stephen, "A 3-year oral health dose-response study of sodium monofluoro-phosphate dentifrices with and without zinc citrate: anti-caries results," vol. 16, no. 6, pp. 321-325, 1988.

[30] D. Zaytsev and P. Panfilov, "Deformation behavior of human enamel and dentin-enamel junction under compression," Mater. Sci. Eng. Mater. Biol. Appl., vol. 34, no. Journal Article, pp. 15-21, 2014.

[31] B. R. MacPherson and J. G. Tieman, "Oral Histology: A Digital Laboratory and Atlas.," Univ. Ky., no. Computer Program, 2003.

[32] S. Hillson, Teeth. 2005.

[33] M. Pasero, A. R. Kampf, C. Ferraris, I. V. Pekov, J. Rakovan, and T. J. White, "Nomenclature of the apatite supergroup minerals," Eur. J. Mineral., vol. 22, no. 2, pp. 163-179, Apr. 2010.

[34] S. Myoung, J. Lee, P. Constantino, P. Lucas, H. Chai, and B. Lawn, "Morphology and fracture of enamel," J. Biomech., vol. 42, no. 12, pp. 1947-1951, 2009.

[35] J. P. Simmer and A. G. Fincham, "Molecular mechanisms of dental enamel formation," Crit. Rev. Oral Biol. Med. Off. Publ. Am. Assoc. Oral Biol., vol. 6, no. 2, pp. 84-108, 1995.

[36] R. A. Young, "Implications of Atomic Substitutions and Other Structural Details in Apatites," J. Dent. Res., vol. 53, no. 2, pp. 193-203, 1974.

[37] S. Habelitz, S. J. Marshall, G. W. Marshall, and M. Balooch, "Mechanical properties of human dental enamel on the nanometre scale," Arch. Oral Biol., vol. 46, no. 2, pp. 173$183,2001$. 
A Rapidly-Dissolving Silica-Silver Bioactive Glass For Cariostatic Applications, Saad Arshad, MASc, Ryerson University, 2017

[38] A. V. Zavgorodniy, R. Rohanizadeh, and M. V. Swain, "Ultrastructure of dentine carious lesions," Arch. Oral Biol., vol. 53, no. 2, pp. 124-132, 2008.

[39] A. R. Ten Cate and A. C. Dale, Oral histology: development, structure, and function. St. Louis: Mosby, 1980.

[40] A. Maerten, P. Fratzl, O. Paris, and P. Zaslansky, "On the mineral in collagen of human crown dentine," Biomaterials, vol. 31, no. 20, pp. 5479-5490, 2010.

[41] V. Srot, B. Bussmann, U. Salzberger, C. Koch, G. Ci̊ $3 / 4 m e k$, and P. van Aken, "Characterization of Dentine, Dentinal Tubules and Dentine-Enamel Junction in Human Teeth by Advanced Analytical TEM," Microsc. Microanal., vol. 17, no. S2, pp. 286-287, 2011.

[42] G. Eliades, D. C. Watts, and T. Eliades, Dental hard tissues and bonding: interfacial phenomena and related properties. 2005.

[43] M. Ferrari, "Resistance of cementum in class II and V cavities to penetration by an adhesive system," Dent. Mater., vol. 13, no. 3, pp. 157-162, May 1997.

[44] Y. Açil, A. E. Mobasseri, P. H. Warnke, H. Terheyden, J. Wiltfang, and I. Springer, "Detection of mature collagen in human dental enamel," Calcif. Tissue Int., vol. 76, no. 2, pp. 121-126, 2005.

[45] A. Mandal, "Collagen - What is Collagen?," 2014.

[46] E. J. Kelly, "Collagen: Ubiquitous, Unsung Protein,” 2009.

[47] H. Flemming and J. Wingender, "The biofilm matrix," Nat. Rev. Microbiol., vol. 8, no. 9, pp. 623-33, Sep. 2010.

[48] H.-C. Flemming, J. Wingender, and T. R. Neu, Eds., Microbial extracellular polymeric substances: characterization, structure, and function. Berlin; New York: Springer, 1999.

[49] J. Kim, H.-D. Park, and S. Chung, "Microfluidic Approaches to Bacterial Biofilm Formation," Molecules, vol. 17, no. 8, pp. 9818-9834, Aug. 2012.

[50] B. Rosan and R. J. Lamont, "Dental plaque formation," Microbes Infect., vol. 2, no. 13, pp. 1599-1607, 2000.

[51] B. G. Bibby and M. Van Kesteren, "The Effect of Fluorine on Mouth Bacteria," J. Dent. Res., vol. 19, no. 4, pp. 391-402, 1940.

[52] D. Nguyen and J. Martin, "Common dental infections in the primary care setting," Am. Fam. Physician HWWilson - GS, vol. 77, no. 6, pp. 797-802, 2008.

[53] National Health Service, "Dental Abcess," 2014.

[54] M. J. Larsen, "Chemical Events during Tooth Dissolution," J. Dent. Res., vol. 69, no. Sup, pp. 575-580, Feb. 1990.

[55] R. Z. LeGeros, "Chemical and Crystallographic Events in the Caries Process," J. Dent. Res., vol. 69, no. Sup, pp. 567-574, Feb. 1990.

[56] R. Z. LeGeros, "In vitro Caries-like Lesion Formation in F-containing Tooth Enamel," $J$. Dent. Res., vol. 62, no. 2, pp. 138-144, Feb. 1983.

[57] C. Ganss, "Retention of $\mathrm{KOH}$-soluble fluoride on enamel and dentine under erosive conditions-A comparison of in vitro and in situ results," Arch. Oral Biol., vol. 52, no. 1, pp. 9-14, 2007.

[58] N. R. Mohammed, N. W. Kent, R. J. M. Lynch, N. Karpukhina, and R. Hill, "Effects of Fluoride on in vitro Enamel Demineralization Analyzed by F MAS-NMR - ProQuest," $2013 . \quad$ [Online].

Available: http://search.proquest.com/docview/1506469142?accountid=13631. [Accessed: 31-Aug$2015]$. 
A Rapidly-Dissolving Silica-Silver Bioactive Glass For Cariostatic Applications, Saad Arshad, MASc, Ryerson University, 2017

[59] M. E. Curzon, B. L. Adkins, B. G. Bibby, and F. L. Losee, "Combined effect of trace elements and fluorine on caries," J. Dent. Res., vol. 49, no. 3, pp. 526-528, 1970.

[60] G. N. JENKINS, "Theories on the mode of action of fluoride in reducing dental decay," Proc. Nutr. Soc., vol. 22, no. 1, pp. 97-104, 1963.

[61] Y. Li and W. Wang, "Predicting Caries in Permanent Teeth from Caries in Primary Teeth: An Eight-year Cohort Study,” J. Dent. Res., vol. 81, no. 8, pp. 561-566, Aug. 2002.

[62] A. Alm, L. K. Wendt, G. Koch, and D. Birkhed, "Prevalence of Approximal Caries in Posterior Teeth in 15-Year-Old Swedish Teenagers in Relation to Their Caries Experience at 3 Years of Age," Caries Res., vol. 41, no. 5, pp. 392-398, Aug. 2007.

[63] M. S. Skeie, M. Raadal, G. V. Strand, and I. Espelid, "The relationship between caries in the primary dentition at 5 years of age and permanent dentition at 10 years of age - a longitudinal study," Int. J. Paediatr. Dent., vol. 16, no. 3, pp. 152-160, May 2006.

[64] L. V. Powell, "Caries prediction: a review of the literature," Community Dent. Oral Epidemiol., vol. 26, no. 6, pp. 361-371, Dec. 1998.

[65] A. V. Ritter, "Dental amalgam," J. Esthet. Restor. Dent. Off. Publ. Am. Acad. Esthet. Dent. Al, vol. 15 , no. 5, p. 319, 2003.

[66] R. Bharti, K. K. Wadhwani, A. P. Tikku, and A. Chandra, "Dental amalgam: An update," J. Conserv. Dent. JCD, vol. 13, no. 4, pp. 204-208, 2010.

[67] C. Guthrow, L. Johnson, and K. Lawless, "Corrosion of Dental Amalgam and its Component Phases," J. Dent. Res., vol. 46, no. 6, pp. 1372-1381, 1967.

[68] M. M. Joselow, L. Goldwater, A. Alvarez, and J. Herndon, "Absorption and Excretion of Mercury in Man .15. Occupational Exposure among Dentists," Arch. Environ. Health, vol. 17, no. 1, p. 39-, 1968.

[69] J. M. A. Lenihan, H. Smith, and W. Harvey, "Mercury Hazards in Dental Practice Assessment and Control by Activation-Analysis," Br. Dent. J., vol. 135, no. 8, pp. 365369, 1973.

[70] Y. Uçar and W. A. Brantley, "Biocompatibility of dental amalgams," Int. J. Dent., vol. 2011, no. Journal Article, p. 981595, 2011.

[71] Health Canada, "The Safety of Dental Amalgam," 1996.

[72] A. Shenoy, "Is it the end of the road for dental amalgam? A critical review," J. Conserv. Dent. JCD, vol. 11, no. 3, pp. 99-107, 2008.

[73] S. Rojas, G. Frigo, M. Bernardi, A. S. Rastelli, A. Hernandes, and V. Bagnato, "Thermal and structural properties of commercial dental resins light-cured with blue emitting diodes (LEDs)," J. Therm. Anal. Calorim., vol. 99, no. 1, pp. 263-268, 2010.

[74] K. S. Anseth, C. N. Bowman, and N. A. Peppas, "Polymerization kinetics and volume relaxation behavior of photopolymerized multifunctional monomers producing highly crosslinked networks," J. Polym. Sci. Part Polym. Chem., vol. 32, no. 1, pp. 139-147, 1994.

[75] Y. Liu and Y. Wang, "Effect of proanthocyanidins and photo-initiators on photopolymerization of a dental adhesive," J. Dent., vol. 41, no. 1, pp. 71-79, 2013.

[76] D. C. Watts, "Reaction kinetics and mechanics in photo-polymerised networks," Dent. Mater., vol. 21, no. 1, pp. 27-35, Jan. 2005.

[77] J. R. Condon and J. L. Ferracane, "In vitro Wear of Composite with Varied Cure, Filler Level, and Filler Treatment," J. Dent. Res., vol. 76, no. 7, pp. 1405-1411, Jul. 1997.

[78] S. Klapdohr and N. Moszner, "New Inorganic Components for Dental Filling Composites," Monatshefte F Ãl/4r Chem. - Chem. Mon., vol. 136, no. 1, pp. 21-45, 2005. 
A Rapidly-Dissolving Silica-Silver Bioactive Glass For Cariostatic Applications, Saad Arshad, MASc, Ryerson University, 2017

[79] W. Geurtsen, "Substances released from dental resin composites and glass ionomer cements," Eur. J. Oral Sci., vol. 106, no. 2 Pt 2, pp. 687-695, 1998.

[80] N. Beyth, S. Farah, A. J. Domb, and E. I. Weiss, "Antibacterial dental resin composites," React. Funct. Polym., vol. 75, pp. 81-88, Feb. 2014.

[81] W. M. Palin, G. J. P. Fleming, F. J. T. Burke, P. M. Marquis, and R. C. Randall, "The influence of short and medium-term water immersion on the hydrolytic stability of novel low-shrink dental composites," Dent. Mater., vol. 21, no. 9, pp. 852-863, Sep. 2005.

[82] D. C. Sarrett, "Clinical challenges and the relevance of materials testing for posterior composite restorations," Dent. Mater., vol. 21, no. 1, pp. 9-20, Jan. 2005.

[83] M. J. Tyas, "Correlation between fracture properties and clinical performance of composite resins in Class IV cavities," Aust. Dent. J., vol. 35, no. 1, pp. 46-49, 1990.

[84] J. L. Ferracane, "Elution of Leachable Components from Composites," J. Oral Rehabil., vol. 21, no. 4, pp. 441-452, 1994.

[85] M. N. Aboushelib, A. J. Feilzer, and C. J. Kleverlaan, "Bridging the gap between clinical failure and laboratory fracture strength tests using a fractographic approach," Dent. Mater., vol. 25, no. 3, pp. 383-391, Mar. 2009.

[86] H. H. K. Xu, J. B. Quinn, D. T. Smith, A. A. Giuseppetti, and F. C. Eichmiller, "Effects of different whiskers on the reinforcement of dental resin composites," Dent. Mater., vol. 19, no. 5, pp. 359-367, Jul. 2003.

[87] A. J. Feilzer, "Increased Wall-to-Wall Curing Contraction in Thin Bonded Resin Layers," J. Dent. Res., vol. 68, no. 1, pp. 48-50, Jan. 1989.

[88] R. L. Bowen and W. A. Marjenhoff, "Dental Composites/Glass Ionomers: the Materials," Adv. Dent. Res., vol. 6, no. 1, pp. 44-49, Sep. 1992.

[89] C. L. Davidson, "The Competition between the Composite-Dentin Bond Strength and the Polymerization Contraction Stress," J. Dent. Res., vol. 63, no. 12, pp. 1396-1399, Dec. 1984.

[90] R. Hickel and J. Manhart, "Longevity of restorations in posterior teeth and reasons for failure.," J. Adhes. Dent., vol. 3, no. 1, pp. 45-64, 2001.

[91] E. A. Berry and J. M. Powers, "Bond strength of adhesive composites to dental substrates," J. Prosthodont. Off. J. Am. Coll. Prosthodont., vol. 3, no. 3, pp. 126-129, 1994.

[92] J. AGHAZADEH MOHANDESI, M. A. RAFIEE, V. BARZEGARAN, and F. SHAFIEI, "Compressive Fatigue Behavior of Dental Restorative Composites," Dent. Mater. J., vol. 26, no. 6, pp. 827-837, 2007.

[93] A. Htang, M. Ohsawa, and H. Matsumoto, "Fatigue resistance of composite restorations: Effect of filler content," Dent. Mater., vol. 11, no. 1, pp. 7-13, Jan. 1995.

[94] C. J. Kleverlaan, "Polymerization shrinkage and contraction stress of dental resin composites," Dent. Mater., vol. 21, no. 12, pp. 1150-1157, 2005.

[95] A. Versluis, W. H. Douglas, M. Cross, and R. L. Sakaguchi, "Does an Incremental Filling Technique Reduce Polymerization Shrinkage Stresses?," J. Dent. Res., vol. 75, no. 3, pp. 871-878, Mar. 1996.

[96] C. L. Davidson, "Destructive Stresses in Adhesive Luting Cements," J. Dent. Res., vol. 70, no. 5, pp. 880-882, May 1991.

[97] G. J. Pearson and C. M. Longman, "Water Sorption and Solubility of Resin-Based Materials Following Inadequate Polymerization by a Visible-Light Curing System," J. Oral Rehabil., vol. 16, no. 1, pp. 57-61, 1989. 
A Rapidly-Dissolving Silica-Silver Bioactive Glass For Cariostatic Applications, Saad Arshad, MASc, Ryerson University, 2017

[98] K. Tanaka, M. Taira, H. Shintani, K. Wakasa, and M. Yamaki, "Residual Monomers (Tegdma and Bis-Gma) of a Set Visible-Light-Cured Dental Composite Resin when Immersed in Water," J. Oral Rehabil., vol. 18, no. 4, pp. 353-362, 1991.

[99] S. Y. Lee, E. H. Greener, and D. L. Menis, "Detection of leached moieties from dental composites in fluids simulating food and saliva," Dent. Mater., vol. 11, no. 5-6, pp. 348353, 1995.

[100] K. J. M. Soderholm, "Filler Leachability during Water Storage of 6 Composite-Materials," Scand. J. Dent. Res., vol. 98, no. 1, pp. 82-88, 1990.

[101] H. Oysaed and I. E. Ruyter, "Water sorption and filler characteristics of composites for use in posterior teeth," J. Dent. Res., vol. 65, no. 11, pp. 1315-1318, 1986.

[102] J. Emmler, M. Seiss, H. Kreppel, F. X. Reichl, R. Hickel, and K. Kehe, "Cytotoxicity of the dental composite component TEGDMA and selected metabolic by-products in human pulmonary cells," Dent. Mater., vol. 24, no. 12, pp. 1670-1675, 2008.

[103] K. M. Galler, "TEGDMA Reduces Mineralization in Dental Pulp Cells," J. Dent. Res., vol. 90, no. 2, pp. 257-262, Feb. 2011.

[104] J. E. Shelby, Introduction to glass science and technology, 2nd ed. Cambridge: Royal Society of Chemistry, 2005.

[105] A. M. F. Alhalawani and M. R. Towler, "The effect of $\mathrm{ZnO} \leftrightarrow$ Ta2O5 substitution on the structural and thermal properties of $\mathrm{SiO} 2-\mathrm{ZnO}-\mathrm{SrO}-\mathrm{CaO}-\mathrm{P} 2 \mathrm{O} 5$ glasses," Mater. Charact., vol. 114, pp. 218-224, Apr. 2016.

[106] M. N. Rahaman et al., "Bioactive glass in tissue engineering," Acta Biomater., vol. 7, no. 6, pp. 2355-2373, 2011.

[107] B. Kent, B. Lewis, and A. Wilson, "Properties of a Glass Ionomer Cement," Br. Dent. J., vol. 135, no. 7, pp. 322-326, 1973.

[108] B. Kościelska and A. Winiarski, "Structural investigations of nitrided Nb2O5 and Nb2O5SiO2 sol-gel derived films," J. Non-Cryst. Solids, vol. 354, no. 35-39, pp. 4349-4353, Oct. 2008.

[109] I. Elgayar, A. E. Aliev, A. R. Boccaccini, and R. G. Hill, "Structural analysis of bioactive glasses," J. Non-Cryst. Solids, vol. 351, no. 2, pp. 173-183, Jan. 2005.

[110] A. Hoppe, N. S. Güldal, and A. R. Boccaccini, "A review of the biological response to ionic dissolution products from bioactive glasses and glass-ceramics," Biomaterials, vol. 32, no. 11, pp. 2757-2774, Apr. 2011.

[111] N. Gargiulo, A. Cusano, F. Causa, D. Caputo, and P. Netti, "Silver-containing mesoporous bioactive glass with improved antibacterial properties," J. Mater. Sci. Mater. Med., vol. 24, no. 9, pp. 2129-2135, 2013.

[112] R. Payami, M. Ghorbanpour, and A. P. Jadid, "Antibacterial silver-doped bioactive silica gel production using molten salt method," J. Nanostructure Chem., vol. 6, no. 3, pp. 215221, Sep. 2016.

[113] W. Bragg, "CHAPTER 2 - THE GLASSY STATE A2 - Rao, K.J.," in Structural Chemistry of Glasses, Oxford: Elsevier Science Ltd, 2002, pp. 13-76.

[114] W. H. Zachariasen, "THE ATOMIC ARRANGEMENT IN GLASS," J. Am. Chem. Soc., vol. 54, no. 10, pp. 3841-3851, Oct. 1932.

[115] S. Grabowsky, M. F. Hesse, C. Paulmann, P. Luger, and J. Beckmann, "How to Make the Ionic $\mathrm{Si}-\mathrm{O}$ Bond More Covalent and the $\mathrm{Si}-\mathrm{O}-\mathrm{Si}$ Linkage a Better Acceptor for Hydrogen Bonding," Inorg. Chem., vol. 48, no. 10, pp. 4384-4393, May 2009. 
A Rapidly-Dissolving Silica-Silver Bioactive Glass For Cariostatic Applications, Saad Arshad, MASc, Ryerson University, 2017

[116] M. Eigen, "CHAPTER 12 - OXIDE GLASSES A2 - Rao, K.J.," in Structural Chemistry of Glasses, Oxford: Elsevier Science Ltd, 2002, pp. 463-511.

[117] R. T. Sanderson, "An Interpretation of Bond Lengths and a Classification of Bonds," Science, vol. 114, no. 2973, pp. 670-672, 1951.

[118] G. Calas, L. Cormier, L. Galoisy, and P. Jollivet, "Structure-property relationships in multicomponent oxide glasses," Comptes Rendus Chim., vol. 5, no. 12, pp. 831-843, 2002.

[119] J. Haber, M. Witko, and R. Tokarz, "Vanadium pentoxide I. Structures and properties," Appl. Catal. Gen., vol. 157, no. 1, pp. 3-22, Sep. 1997.

[120] J. Livage, "Vanadium pentoxide gels," Chem. Mater., vol. 3, no. 4, pp. 578-593, Jul. 1991.

[121] M. G. Cerruti, D. Greenspan, and K. Powers, "An analytical model for the dissolution of different particle size samples of Bioglass $®$ in TRIS-buffered solution," Biomaterials, vol. 26, no. 24, pp. 4903-4911, 2005.

[122] B. C. Bunker, "Molecular mechanisms for corrosion of silica and silicate glasses," J. NonCryst. Solids, vol. 179, pp. 300-308, Nov. 1994.

[123] B. C. Bunker, G. W. Arnold, E. K. Beauchamp, and D. E. Day, "Mechanisms for alkali leaching in mized-Na $\square$ K silicate glasses," J. Non-Cryst. Solids, vol. 58, no. 2, pp. 295322, Nov. 1983.

[124] S. Cho and A. C. Cheng, "A Review of Glass Ionomer Restorations in the Primary Dentition," 1999.

[125] S. K. Sidhu and J. W. Nicholson, "A Review of Glass-Ionomer Cements for Clinical Dentistry," J. Funct. Biomater., vol. 7, no. 3, p. 16, Jun. 2016.

[126] J. W. McLean, J. W. Nicholson, and A. D. Wilson, "Proposed nomenclature for glassionomer dental cements and related materials," Quintessence Int. Berl. Ger. 1985, vol. 25, no. 9, pp. 587-589, Sep. 1994.

[127] J. W. Nicholson, “Chemistry of glass-ionomer cements: a review," Biomaterials, vol. 19, no. 6, pp. 485-494, Apr. 1998.

[128] M. Khoroushi and F. Keshani, "A review of glass-ionomers: From conventional glassionomer to bioactive glass-ionomer.," Dent. Res. J., vol. 10, no. 4, pp. 411-20, 2013.

[129] L. Shen, A. Coughlan, M. Towler, and M. Hall, "Degradable borate glass polyalkenoate cements," J. Mater. Sci. Mater. Med., vol. 25, no. 4, pp. 965-973, 2014.

[130] M.-A. Cattani-Lorente, C. Godin, and J.-M. Meyer, "Mechanical behavior of glass ionomer cements affected by long-term storage in water," Dent. Mater., vol. 10, no. 1, pp. 37-44, Jan. 1994.

[131] M. S. Bapna, C. M. Gadia, and J. L. Drummond, "Effects of aging and cyclic loading on the mechanical properties of glass ionomer cements," Eur. J. Oral Sci., vol. 110, no. 4, pp. 330-334, 2002.

[132] M. M. Barakat and J. M. Powers, "In vitro bond strength of cements to treated teeth," Aust. Dent. J., vol. 31, no. 6, pp. 415-419, 1986.

[133] D. Xie, W. A. Brantley, B. M. Culbertson, and G. Wang, "Mechanical properties and microstructures of glass-ionomer cements," Dent. Mater., vol. 16, no. 2, pp. 129-138, 2000.

[134] A. Mallmann, J. C. O. AtaÃ-de, R. Amoedo, P. V. Rocha, and L. B. Jacques, "Compressive strength of glass ionomer cements using different specimen dimensions," Braz. Oral Res., vol. 21, no. 3, p. 204, 2007. 
A Rapidly-Dissolving Silica-Silver Bioactive Glass For Cariostatic Applications, Saad Arshad, MASc, Ryerson University, 2017

[135] K. J. Anusavice, "Reducing the failure potential of ceramic-based restorations. Part 1: Metal-ceramic crowns and bridges.," Gen. Dent., vol. 44, no. 6, pp. 492-4, 1996.

[136] J. Ellis and A. Wilson, "Polyphosphonate cements: a new class of dental materials," $J$. Mater. Sci. Lett., vol. 9, no. 9, pp. 1058-1060, 1990.

[137] M. A. Fareed and A. Stamboulis, "Nanoclay addition to a conventional glass ionomer cements: Influence on physical properties," Eur. J. Dent., vol. 8, no. 4, pp. 456-463, 2014.

[138] Y. E. Aboush and H. Torabzadeh, "Fluoride release from tooth-colored restorative materials: a 12-month report.," J. Can. Dent. Assoc., vol. 64, no. 8, pp. 561-568, 1998.

[139] E. M. Benelli, M. C. Serra, A. L. Rodrigues, and J. A. Cury, "In-Situ Anticariogenic Potential of Glass-Ionomer Cement," Caries Res., vol. 27, no. 4, pp. 280-284, 1993.

[140] N. K. Ersin, U. Candan, A. Aykut, O. Oncag, C. Eronat, and T. Kose, "A clinical evaluation of resin-based. composite and glass ionomer cement restorations placed in primary teeth using the ART approach - Results at 24 months," J. Am. Dent. Assoc., vol. 137, no. 11, pp. 1529-1536, 2006.

[141] S. M. Levy and M. E. Jensen, "A clinical evaluation of the restoration of root surface caries.," Spec. Care Dent. Off. Publ. Am. Assoc. Hosp. Dent. Acad. Dent. Handicap. Am. Soc. Geriatr. Dent., vol. 10, no. 5, pp. 156-60, 1990.

[142] S. Mickenautsch, V. Yengopal, S. C. Leal, L. B. Oliveira, A. C. Bezerra, and M. Bonecker, "Absence of carious lesions at margins of glass-ionomer and amalgam restorations: a meta-analysis," Eur. J. Paediatr. Dent., vol. 10, no. 1, pp. 41-46, 2009.

[143] J. W. Nicholson and E. J. Swift, “Compomers," J. Esthet. Restor. Dent., vol. 20, no. 1, pp. 3-4, Feb. 2008.

[144] T. Attin, "Fluoride release/uptake of polyacid-modified resin composites (compomers) in neutral and acidic buffer solutions," J. Oral Rehabil., vol. 26, no. 5, pp. 388-393, 1999.

[145] A. J. Preston, "Fluoride recharge of aesthetic dental materials," J. Oral Rehabil., vol. 26, no. 12, pp. 936-940, 1999.

[146] A. J. Preston, "The recharge of esthetic dental restorative materials with fluoride in vitrotwo years' results," Dent. Mater., vol. 19, no. 1, pp. 32-37, 2003.

[147] E. Asmussen, "Long-term fluoride release from a glass ionomer cement, a compomer, and from experimental resin composites," Acta Odontol., vol. 60, no. 2, pp. 93-97, Jan. 2002.

[148] S. M. Mousavinasab and I. Meyers, "Fluoride Release by Glass Ionomer Cements, Compomer and Giomer," Dent. Res. J., vol. 6, no. 2, Apr. 2010.

[149] A. U. Yap, S. H. Teoh, G. W. Hastings, and C. S. Lu, "Comparative wear ranking of dental restorative materials utilizing different wear simulation modes," J. Oral Rehabil., vol. 24, no. 8, pp. 574-580, Aug. 1997.

[150] A. Peutzfeldt, F. García-Godoy, and E. Asmussen, "Surface hardness and wear of glass ionomers and compomers," Am. J. Dent., vol. 10, no. 1, pp. 15-17, Feb. 1997.

[151] A. Peutzfeldt, "Compomers and glass ionomers: bond strength to dentin and mechanical properties," Am. J. Dent., vol. 9, no. 6, pp. 259-263, Dec. 1996.

[152] F. P. Bowden, J. B. P. Williamson, and P. G. Laing, "The Significance of Metallic Transfer in Orthopaedic Surgery," J. Bone Joint Surg. Br., vol. 37-B, no. 4, pp. 676-690, Nov. 1955.

[153] T. K. Greenlee, C. A. Beckham, A. R. Crebo, and J. C. Malmorg, "Glass ceramic bone implants. A light microscopic study," J. Biomed. Mater. Res., vol. 6, no. 3, pp. 235-244, May 1972. 
A Rapidly-Dissolving Silica-Silver Bioactive Glass For Cariostatic Applications, Saad Arshad, MASc, Ryerson University, 2017

[154] M. Plewinski, "The effect of crystallization of bioactive bioglass 45S5 on apatite formation and degradation," vol. 29, no. 12, pp. 1256-1264, 2013.

[155] C. A. Beckham, T. K. G. Jr, and A. R. Crebo, "Bone formation at a ceramic implant interface," Calcif. Tissue Res., vol. 8, no. 1, pp. 165-171, Dec. 1971.

[156] A. E. Clark, L. L. Hench, and H. A. Paschall, "The influence of surface chemistry on implant interface histology: A theoretical basis for implant materials selection," J. Biomed. Mater. Res., vol. 10, no. 2, pp. 161-174, Mar. 1976.

[157] P. Griss et al., "Evaluation of a bioglass-coated A12O3 total hip prosthesis in sheep," $J$. Biomed. Mater. Res., vol. 10, no. 4, pp. 511-518, Jul. 1976.

[158] L. L. Hench, "The story of Bioglass®," J. Mater. Sci. Mater. Med., vol. 17, no. 11, pp. 967-978, 2006.

[159] M. Lombardini, M. Ceci, M. Colombo, S. Bianchi, and C. Poggio, "Preventive effect of different toothpastes on enamel erosion: AFM and SEM studies," Scanning, vol. 36, no. 4, pp. 401-410, Jul. 2014.

[160] A. S. Bakry, "The effect of a bioglass paste on enamel exposed to erosive challenge," vol. 42, no. 11, pp. 1458-1463, 2014.

[161] British Dental Journal, "Tooth reparative particles win prize,” Br. Dent. J., vol. 215, no. 2, pp. 61-61, Jul. 2013.

[162] B. C. Bunker, D. R. Tallant, T. J. Headley, G. L. Turner, and R. J. Kirkpatrick, "STRUCTURE OF LEACHED SODIUM BOROSILICATE GLASS.," Phys. Chem. Glas., vol. 29, no. 3, pp. 106-120, 1988.

[163] A. S. Bakry, H. Takahashi, M. Otsuki, A. Sadr, K. Yamashita, and J. Tagami, "CO2 Laser Improves 45S5 Bioglass Interaction with Dentin,” J. Dent. Res., vol. 90, no. 2, pp. 246250, Feb. 2011.

[164] Y. Qi et al., "Remineralization of artificial dentinal caries lesions by biomimetically modified mineral trioxide aggregate," Acta Biomater., vol. 8, no. 2, pp. 836-842, Feb. 2012.

[165] P. N. R. Nair, "Pathogenesis of Apical Periodontitis and the Causes of Endodontic Failures," Crit. Rev. Oral Biol. Med., vol. 15, no. 6, pp. 348-381, Nov. 2004.

[166] T. Waltimo, T. J. Brunner, M. Vollenweider, W. J. Stark, and M. Zehnder, "Antimicrobial Effect of Nanometric Bioactive Glass 45S5," J. Dent. Res., vol. 86, no. 8, pp. 754-757, Aug. 2007.

[167] I. Diamanti, H. Koletsi-Kounari, E. Mamai-Homata, and G. Vougiouklakis, "In vitro evaluation of fluoride and calcium sodium phosphosilicate toothpastes, on root dentine caries lesions," J. Dent., vol. 39, no. 9, pp. 619-628, Sep. 2011.

[168] E. C. Reynolds et al., "Fluoride and Casein Phosphopeptide-Amorphous Calcium Phosphate," J. Dent. Res., vol. 87, no. 4, pp. 344-348, Apr. 2008.

[169] J. S. Wefel, "NovaMin ®: Likely Clinical Success," Adv. Dent. Res., vol. 21, no. 1, pp. 40-43, Aug. 2009.

[170] M. Deng et al., "Effects of 45S5 bioglass on surface properties of dental enamel subjected to 35\% hydrogen peroxide," Int. J. Oral Sci., vol. 5, no. 2, pp. 103-110, Jun. 2013.

[171] S. Hooper et al., "A randomised in situ trial, measuring the anti-erosive properties of a stannous-containing sodium fluoride dentifrice compared with a sodium fluoride/potassium nitrate dentifrice," Int. Dent. J., vol. 64, pp. 35-42, Mar. 2014. 
A Rapidly-Dissolving Silica-Silver Bioactive Glass For Cariostatic Applications, Saad Arshad, MASc, Ryerson University, 2017

[172] C. Valkenburg, D. E. Slot, E. W. P. Bakker, and F. A. Van der Weijden, "Does dentifrice use help to remove plaque? A systematic review," J. Clin. Periodontol, p. n/a-n/a, Oct. 2016.

[173] Z. Wang et al., "The dentine remineralization activity of a desensitizing bioactive glasscontaining toothpaste: an in vitro study," Aust. Dent. J., vol. 56, no. 4, pp. 372-381, Dec. 2011.

[174] F. D. Babcock, J. C. King, and T. H. Jordan, "The Reaction of Stannous Fluoride and Hydroxyapatite," J. Dent. Res., vol. 57, no. 9, pp. 933-938, Sep. 1978.

[175] N. Schlueter, A. Duran, J. Klimek, and C. Ganss, "Investigation of the Effect of Various Fluoride Compounds and Preparations Thereof on Erosive Tissue Loss in Enamel in vitro," Caries Res., vol. 43, no. 1, pp. 10-6, Mar. 2009.

[176] N. Schlueter, L. Neutard, J. von Hinckeldey, J. Klimek, and C. Ganss, "Tin and fluoride as anti-erosive agents in enamel and dentine in vitro," Acta Odontol. Scand., vol. 68, no. 3, pp. 180-184, May 2010.

[177] C. Ganss, L. Neutard, J. von Hinckeldey, J. Klimek, and N. Schlueter, "Efficacy of a Tin/Fluoride Rinse a Randomized in situ Trial on Erosion," J. Dent. Res., vol. 89, no. 11, pp. 1214-1218, Nov. 2010.

[178] S. M. Hooper, R. G. Newcombe, R. Faller, S. Eversole, M. Addy, and N. X. West, "The protective effects of toothpaste against erosion by orange juice: Studies in situ and in vitro," J. Dent., vol. 35, no. 6, pp. 476-481, Jun. 2007.

[179] R. J. M. Lynch et al., "Effects of Zinc and Fluoride on the Remineralisation of Artificial Carious Lesions under Simulated Plaque Fluid Conditions," Caries Res., vol. 45, no. 3, pp. 313-22, Jul. 2011.

[180] D. R et al., "Desensitizing efficacy of a new toothpaste containing 5.5\% potassium citrate: a 4-week clinical study.," Am. J. Dent., vol. 20, no. 4, pp. 209-211, 20072007.

[181] E. S. Gjorgievska, "Remineralization of Demineralized Enamel by Toothpastes: A Scanning Electron Microscopy, Energy Dispersive X-Ray Analysis, and ThreeDimensional Stereo-Micrographic Study," vol. 19, no. 3, pp. 587-595, Jun. 2013.

[182] F. Van Der Weijden and D. E. Slot, "Oral hygiene in the prevention of periodontal diseases: the evidence," Periodontol. 2000, vol. 55, no. 1, pp. 104-123, Feb. 2011.

[183] S. Paraskevas, M. f. Timmerman, U. van der Velden, and G. a. van der Weijden, "Additional Effect of Dentifrices on the Instant Efficacy of Toothbrushing," $J$. Periodontol., vol. 77, no. 9, pp. 1522-1527, Aug. 2006.

[184] S. Mankodi, H. Berkowitz, K. Durbin, and B. Nelson, "Evaluation of the effects of brushing on the removal of dental plaque," J. Clin. Dent., vol. 9, no. 3, pp. 57-60, 1998.

[185] C. F. Vallotton, "An Acquired Pigmented Pellicle of the Enamel Surface II. Clinical and Histologic Studies," J. Dent. Res., vol. 24, no. 3, pp. 171-181, Jun. 1945.

[186] W. B. Davis, "Cleaning and polishing of teeth by brushing," Community Dent. Oral Epidemiol., vol. 8, no. 5, pp. 237-243, 1980.

[187] G. Sapra, Y. K. Vyas, R. Agarwal, A. Aggarwal, K. T. Chandrashekar, and K. Sharma, "Effect of an herb root extract, herbal dentifrice and synthetic dentifrice on human salivary amylase," Dent. Res. J., vol. 10, no. 4, pp. 493-498, 2013.

[188] F. A. Scannapieco, G. I. Torres, and M. J. Levine, "Salivary amylase promotes adhesion of oral streptococci to hydroxyapatite," J. Dent. Res., vol. 74, no. 7, pp. 1360-1366, Jul. 1995. 
A Rapidly-Dissolving Silica-Silver Bioactive Glass For Cariostatic Applications, Saad Arshad, MASc, Ryerson University, 2017

[189] D. de Araújo, L. Silva, E. Campos, and R. Correia de Araújo, "In vitro study on tooth enamel lesions related to whitening dentifrice," Indian J. Dent. Res., vol. 22, no. 6, pp. 770-6, Nov. 2011.

[190] K. Kawamoto and Y. Tsujimoto, "Effects of the Hydroxyl Radical and Hydrogen Peroxide on Tooth Bleaching," J. Endod., vol. 30, no. 1, pp. 45-50, 2004.

[191] D.-H. Goo, T.-Y. Kwon, S.-H. Nam, H.-J. Kim, K.-H. Kim, and Y.-J. Kim, “The Efficiency of 10\% Carbamide Peroxide Gel on Dental Enamel," Dent. Mater. J., vol. 23, no. 4, pp. 522-527, 2004.

[192] M. de Menezes, C. P. Turssi, J. J. Faraoni-Romano, and M. C. Serra, "Susceptibility of bleached enamel and root dentin to artificially formed caries-like lesions," Am. J. Dent., vol. 20, no. 3, pp. 173-176, Jun. 2007.

[193] Y.-F. Ren, A. Amin, and H. Malmstrom, "Effects of tooth whitening and orange juice on surface properties of dental enamel," J. Dent., vol. 37, no. 6, pp. 424-431, Jun. 2009.

[194] C. C. Worschech, J. A. Rodrigues, L. R. M. Martins, and G. M. B. Ambrosano, "In vitro evaluation of human dental enamel surface roughness bleached with $35 \%$ carbamide peroxide and submitted to abrasive dentifrice brushing," Pesqui. Odontológica Bras., vol. 17, no. 4, pp. 342-348, Dec. 2003.

[195] C. F. Pinto, R. de Oliveira, V. Cavalli, and M. Giannini, "Peroxide bleaching agent effects on enamel surface microhardness, roughness and morphology," Braz. Oral Res., vol. 18, no. 4, pp. 306-311, Dec. 2004.

[196] K. Roopa, N. Basappa, O. Raju, and G. Lamba, "Effect of Whitening Dentifrice on Micro Hardness, Colour Stability and Surface Roughness of Aesthetic Restorative Materials," J. Clin. Diagn. Res., vol. 10, no. 3, Mar. 2016.

[197] T. Debner, D. P. Warren, and J. M. Powers, "Effects of Fluoride Varnish on Color of Esthetic Restorative Material," J. Esthet. Restor. Dent., vol. 12, no. 3, pp. 160-163, May 2000.

[198] E. C. n. Teixeira, J. L. Thompson, J. R. Piascik, and J. Y. Thompson, "In Vitro Toothbrush-Dentifrice Abrasion of Two Restorative Composites," J. Esthet. Restor. Dent., vol. 17, no. 3, pp. 172-181, May 2005.

[199] K. Magyari, R. Stefan, D. C. Vodnar, A. Vulpoi, and L. Baia, "The silver influence on the structure and antibacterial properties of the bioactive 10B2O3-30Na2O-60P2O2 glass," J. Non-Cryst. Solids, vol. 402, no. Journal Article, pp. 182-186, 2014.

[200] J. M. Schierholz, C. Fleck, J. Beuth, and G. Pulverer, "The antimicrobial efficacy of a new central venous catheter with long-term broad-spectrum activity," J. Antimicrob. Chemother., vol. 46, no. 1, pp. 45-50, Jul. 2000.

[201] D. S. Brauer et al., "Bactericidal strontium-releasing injectable bone cements based on bioactive glasses," J. R. Soc. Interface, vol. 10, no. 78, Jan. 2013.

[202] M. Bellantone, H. D. Williams, and L. L. Hench, "Broad-Spectrum Bactericidal Activity of Ag2O-Doped Bioactive Glass," Antimicrob. Agents Chemother., vol. 46, no. 6, pp. 1940-1945, Jun. 2002.

[203] L. Baia, M. Baia, W. Kiefer, J. Popp, and S. Simon, "Structural and morphological properties of silver nanoparticles-phosphate glass composites," Chem. Phys., vol. 327, no. 1, pp. 63-69, Aug. 2006.

[204] B. Kwakye-Awuah, C. Williams, M. A. Kenward, and I. Radecka, "Antimicrobial action and efficiency of silver-loaded zeolite X," J. Appl. Microbiol., vol. 104, no. 5, pp. 15161524, May 2008. 
A Rapidly-Dissolving Silica-Silver Bioactive Glass For Cariostatic Applications, Saad Arshad, MASc, Ryerson University, 2017

[205] S. P. Valappil et al., "Role of gallium and silver from phosphate-based glasses on in vitro dual species oral biofilm models of Porphyromonas gingivalis and Streptococcus gordonii," Acta Biomater., vol. 8, no. 5, pp. 1957-1965, 2012.

[206] S. P. Valappil, J. C. Knowles, and M. Wilson, "Effect of Silver-Doped Phosphate-Based Glasses on Bacterial Biofilm Growth," Appl. Environ. Microbiol., vol. 74, no. 16, pp. 5228-5230, Aug. 2008.

[207] S. P. Valappil et al., "Effect of Silver Content on the Structure and Antibacterial Activity of Silver-Doped Phosphate-Based Glasses," Antimicrob. Agents Chemother., vol. 51, no. 12, pp. 4453-4461, Dec. 2007.

[208] S. P. Valappil et al., "Antimicrobial Gallium-Doped Phosphate-Based Glasses," Adv. Funct. Mater., vol. 18, no. 5, pp. 732-741, Mar. 2008.

[209] S. P. Valappil et al., "Controlled delivery of antimicrobial gallium ions from phosphatebased glasses," Acta Biomater., vol. 5, no. 4, pp. 1198-1210, May 2009.

[210] D. L. Williams, K. D. Sinclair, S. Jeyapalina, and R. D. Bloebaum, "Characterization of a novel active release coating to prevent biofilm implant-related infections," J. Biomed. Mater. Res. B Appl. Biomater., vol. 101B, no. 6, pp. 1078-1089, Aug. 2013.

[211] S. P. Nielsen, "The biological role of strontium," Bone, vol. 35, no. 3, pp. 583-588, 2004.

[212] P. J. Marie, P. Ammann, G. Boivin, and C. Rey, "Mechanisms of action and therapeutic potential of strontium in bone," Calcif. Tissue Int., vol. 69, no. 3, pp. 121-129, Sep. 2001.

[213] D. Boyd, "Preliminary investigation of novel bone graft substitutes based on strontiumcalcium-zinc-silicate glasses," J. Mater. Sci. Mater. Med., vol. 20, no. 1, pp. 413-420, Jan. 2009.

[214] A. Guida, M. R. Towler, J. G. Wall, R. G. Hill, and S. Eramo, "Preliminary work on the antibacterial effect of strontium in glass ionomer cements," J. Mater. Sci. Lett., vol. 22, no. 20, pp. 1401-1403, Oct. 2003.

[215] Y. Lin, "Synthesis, characterization and antibacterial property of strontium half and totally substituted hydroxyapatite nanoparticles," J. Wuhan Univ. Technol.-Mater Sci Ed, vol. 23, no. 4, pp. 475-479, Aug. 2008.

[216] L. Liu, S. Pushalkar, D. Saxena, R. Z. LeGeros, and Y. Zhang, "Antibacterial property expressed by a novel calcium phosphate glass," J. Biomed. Mater. Res. B Appl. Biomater., vol. 102, no. 3, pp. 423-429, Apr. 2014.

[217] F. Dabsie, G. Gregoire, M. Sixou, and P. Sharrock, "Does strontium play a role in the cariostatic activity of glass ionomer? Strontium diffusion and antibacterial activity," $J$. Dent., vol. 37, no. 7, pp. 554-559, 2009.

[218] Z. Geng, "Strontium incorporation to optimize the antibacterial and biological characteristics of silver-substituted hydroxyapatite coating," vol. 58, no. Complete, pp. 467-477, 2015.

[219] J. W. Alexander, "History of the medical use of silver," Surg. Infect., vol. 10, no. 3, p. 289+, Jun. 2009.

[220] O. Gordon et al., "Silver Coordination Polymers for Prevention of Implant Infection: Thiol Interaction, Impact on Respiratory Chain Enzymes, and Hydroxyl Radical Induction," Antimicrob. Agents Chemother., vol. 54, no. 10, pp. 4208-4218, Oct. 2010.

[221] K. Mijnendonckx, N. Leys, J. Mahillon, S. Silver, and R. Van Houdt, "Antimicrobial silver: uses, toxicity and potential for resistance," Biometals, vol. 26, no. 4, pp. 609-621, 2013. 
A Rapidly-Dissolving Silica-Silver Bioactive Glass For Cariostatic Applications, Saad Arshad, MASc, Ryerson University, 2017

[222] G. H. Yassen, F. Lippert, G. Eckert, J. Eder, and A. F. Zandona, "The effect of strontium and combinations of strontium and fluoride on the remineralization of artificial caries lesions in vitro," Quintessence Int., vol. 43, no. 7, pp. E95-E103, 2012.

[223] H. Koletsi-Kounari, E. Mamai-Homata, and I. Diamanti, "An in vitro study of the effect of aluminum and the combined effect of strontium, aluminum, and fluoride elements on early enamel carious lesions," Biol. Trace Elem. Res., vol. 147, no. 1-3, pp. 418-427, 2012.

[224] P. L. Drake and K. J. Hazelwood, "Exposure-related health effects of silver and silver compounds: A review," Ann. Occup. Hyg., vol. 49, no. 7, pp. 575-585, 2005.

[225] A. B. G. Lansdown, "A pharmacological and toxicological profile of silver as an antimicrobial agent in medical devices.," Adv. Pharmacol. Sci., vol. 2010, no. Journal Article, pp. 910686-910686, 2010.

[226] World Health Organization, "Silver in drinking water: background document for the development of WHO Guidelines for drinking water quality.," no. Journal Article, 1996.

[227] J. Santos Valdeci Elias dos et al., "A new 'silver-bullet' to treat caries in children--nano silver fluoride: a randomised clinical trial," J. Dent., vol. 42, no. 8, p. 945, 2014.

[228] Q. H. Zhi, E. C. M. Lo, and H. C. Lin, "Randomized clinical trial on effectiveness of silver diamine fluoride and glass ionomer in arresting dentine caries in preschool children," J. Dent., vol. 40, no. 11, pp. 962-967, 2012.

[229] Q. L. Feng, J. Wu, G. Q. Chen, F. Z. Cui, T. N. Kim, and J. O. Kim, “A mechanistic study of the antibacterial effect of silver ions on Escherichia coli and Staphylococcus aureus," $J$. Biomed. Mater. Res., vol. 52, no. 4, pp. 662-668, 2000.

[230] T. N. KIM et al., "Antimicrobial effects of metal ions (Ag+, $\mathrm{Cu} 2+, \mathrm{Zn} 2+)$ in hydroxyapatite,” J. Mater. Sci. Mater. Med., vol. 9, no. 3, pp. 129-134, 1998.

[231] K. B. Holt and A. J. Bard, "Interaction of Silver(I) Ions with the Respiratory Chain of Escherichia coli: An Electrochemical and Scanning Electrochemical Microscopy Study of the Antimicrobial Mechanism of Micromolar Ag+," Biochemistry (Mosc.), vol. 44, no. 39, pp. 13214-13223, Oct. 2005.

[232] C.-N. Lok et al., "Proteomic Analysis of the Mode of Antibacterial Action of Silver Nanoparticles," J. Proteome Res., vol. 5, no. 4, Apr. 2006.

[233] W. J. Schreurs and H. Rosenberg, "Effect of silver ions on transport and retention of phosphate by Escherichia coli.," J. Bacteriol., vol. 152, no. 1, pp. 7-13, Oct. 1982.

[234] R. J. M. Lynch, "Zinc in the mouth, its interactions with dental enamel and possible effects on caries; a review of the literature," vol. 61, pp. 46-54, 2011.

[235] I. Kleinberg and D. m. Codipilly, "Cysteine challenge testing: a powerful tool for examining oral malodour processes and treatments in vivo," Int. Dent. J., vol. 52, no. S5P1, pp. 221-228, Jun. 2002.

[236] E. Giertsen, W. H. Bowen, and S. K. Pearson, "Combined effects of Zn2+-chlorhexidine and $\mathrm{Zn} 2+$-cetylpyridinium chloride on caries incidence in partially desalivated rats," Eur. J. Oral Sci., vol. 99, no. 4, pp. 301-309, Aug. 1991.

[237] F. Brudevold, L. T. Steadman, M. A. Spinelli, B. H. Amdur, and P. Grøn, "A study of zinc in human teeth," Arch. Oral Biol., vol. 8, no. 2, pp. 135-144, Mar. 1963.

[238] R. Oppermann and G. Rolla, "Effect of Some Polyvalent Cations on the Acidogenicity of Dental Plaque Invivo," Caries Res., vol. 14, no. 6, pp. 422-427, 1980.

[239] I. H. C. Gallagher and T. W. Cutress, "The effect of trace elements on the growth and fermentation by oral Streptococci and Actinomyces," Arch. Oral Biol., vol. 22, no. 10-11, pp. 555-562, 1977. 
A Rapidly-Dissolving Silica-Silver Bioactive Glass For Cariostatic Applications, Saad Arshad, MASc, Ryerson University, 2017

[240] G. He, E. I. F. Pearce, and C. H. Sissons, "Inhibitory effect of ZnCl2 on glycolysis in human oral microbes," Arch. Oral Biol., vol. 47, no. 2, pp. 117-129, Feb. 2002.

[241] R. J. Gilbert and G. S. Ingram, "The Oral Disposition of Zinc Following the Use of an Anticalculus Toothpaste Containing 0.5\% Zinc Citrate," J. Pharm. Pharmacol., vol. 40, no. 6, pp. 399-402, Jun. 1988.

[242] R. M. Duckworth, S. N. Morgan, and A. M. Murray, "Fluoride in Saliva and Plaque Following Use of Fluoride-containing Mouthwashes," J. Dent. Res., vol. 66, no. 12, pp. 1730-1734, Dec. 1987.

[243] P. j. Hall et al., "Plaque antibacterial levels following controlled food intake and use of a toothpaste containing 2\% zinc citrate and 0.3\% Triclosan," Int. Dent. J., vol. 53, no. S6P1, pp. 379-384, Dec. 2003.

[244] R. Hill, P. Wadke, and E. Redahan, "Fighting tooth decay with glass," Mater. World, vol. 21, no. 8, p. 14, Aug. 2013.

[245] J. Serra et al., "Influence of the non-bridging oxygen groups on the bioactivity of silicate glasses," J. Mater. Sci. Mater. Med., vol. 13, no. 12, pp. 1221-1225, Dec. 2002.

[246] E. Redahan, R. Hill, and P. Wadke, "Fighting tooth decay with glass," Mater. World, vol. 21, no. 8, pp. 14-14, Aug. 2013.

[247] I. Shuman, "Tooth Sensitivity," Dent. Econ., vol. 95, no. 2, p. 136A, 136B,136C,136D,136E,136F, Feb. 2005.

[248] A. Pantchev, "Endodontic surgery with and without inserts of bioactive glass PerioGlas®—a clinical and radiographic follow-up," Oral Maxillofac. Surg., vol. 13, no. 1, pp. 21-26, Mar. 2009.

[249] M. Vollenweider, "Remineralization of human dentin using ultrafine bioactive glass particles," Acta Biomater., vol. 3, no. 6, pp. 936-943, 2007.

[250] P. Sepulveda, J. R. Jones, and L. L. Hench, "In vitro dissolution of melt-derived 45S5 and sol-gel derived 58S bioactive glasses," J. Biomed. Mater. Res., vol. 61, no. 2, pp. 301-311, Aug. 2002.

[251] I. Allan, "Antibacterial activity of particulate Bioglass ${ }^{\circledR}$ against supra- and subgingival bacteria," Biomaterials, vol. 22, no. 12, pp. 1683-1687, 2001.

[252] R. G. Hill, "The ability of a nano hydroxyapatite toothpaste and oral rinse containing fluoride to protect enamel during an acid challenge using 19F solid state NMR spectroscopy," vol. 156, no. Complete, pp. 69-71, 2015.

[253] J. M. Griffin, J. R. Yates, A. J. Berry, S. Wimperis, and S. E. Ashbrook, "High-Resolution 19F MAS NMR Spectroscopy: Structural Disorder and Unusual J Couplings in a Fluorinated Hydroxy-Silicate," J. Am. Chem. Soc., vol. 132, no. 44, pp. 15651-15660, Nov. 2010.

[254] H. B. Porcelli, F. A. Maeda, B. R. Silva, W. G. J. Miranda, and P. E. Cardoso, "Remineralizing agents: effects on acid-softened enamel.," Gen. Dent., vol. 63, no. 4, pp. 73-6, 2015.

[255] M. Danelon, "Effect of toothpaste with nano-sized trimetaphosphate on dental caries: In situ study," vol. 43, no. 7, pp. 806-813, 2015.

[256] N. Baltzer and T. Copponnex, Precious Metals for Biomedical Applications. Elsevier, 2014.

[257] R. G. Hill and D. S. Brauer, "Predicting the bioactivity of glasses using the network connectivity or split network models," J. Non-Cryst. Solids, vol. 357, no. 24, pp. 38843887, Dec. 2011. 
A Rapidly-Dissolving Silica-Silver Bioactive Glass For Cariostatic Applications, Saad Arshad, MASc, Ryerson University, 2017

[258] M. D. O’Donnell, S. J. Watts, R. V. Law, and R. G. Hill, "Effect of P2O5 content in two series of soda lime phosphosilicate glasses on structure and properties - Part II: Physical properties," J. Non-Cryst. Solids, vol. 354, no. 30, pp. 3561-3566, Jul. 2008.

[259] M. A. García et al., "Photoluminescence of silver in glassy matrices," J. Appl. Phys., vol. 96, no. 7, pp. 3737-3741, Oct. 2004.

[260] A. M. Deliormanl1, "Size-dependent degradation and bioactivity of borate bioactive glass," Ceram. Int., vol. 39, no. 7, pp. 8087-8095, 2013.

[261] M. Mneimne, R. G. Hill, A. J. Bushby, and D. S. Brauer, "High phosphate content significantly increases apatite formation of fluoride-containing bioactive glasses," Acta Biomater., vol. 7, no. 4, pp. 1827-1834, Apr. 2011.

[262] J. Serra et al., "FTIR and XPS studies of bioactive silica based glasses," J. Non-Cryst. Solids, vol. 332, no. 1-3, pp. 20-27, Dec. 2003.

[263] M. S. Gaafar, N. S. A. El-Aal, O. W. Gerges, and G. El-Amir, "Elastic properties and structural studies on some zinc-borate glasses derived from ultrasonic, FT-IR and X-ray techniques," J. Alloys Compd., vol. 475, no. 1-2, pp. 535-542, May 2009.

[264] J. Delben et al., "Synthesis and thermal properties of nanoparticles of bioactive glasses containing silver," J. Therm. Anal. Calorim., vol. 97, no. 2, pp. 433-436, 2009.

[265] G. El-Damrawi, A. M. Hassan, R. Ramadan, and S. El-Jadal, "Nuclear Magnetic Resonance and FTIR Structural Studies on Borosilicate Glasses Containing Iron Oxide," New J. Glass Ceram., vol. 06, no. 04, pp. 47-56, 2016.

[266] A. M. El-Kady, A. F. Ali, R. A. Rizk, and M. M. Ahmed, "Synthesis, characterization and microbiological response of silver doped bioactive glass nanoparticles," Ceram. Int., vol. 38, no. 1, pp. 177-188, 2012.

[267] D. S. Brauer, M. Mneimne, and R. G. Hill, "Fluoride-containing bioactive glasses: Fluoride loss during melting and ion release in tris buffer solution," J. Non-Cryst. Solids, vol. 357, no. 18, pp. 3328-3333, Sep. 2011.

[268] M. O’Donnell, S. Watts, R. Hill, and R. Law, "The effect of phosphate content on the bioactivity of soda-lime-phosphosilicate glasses," J. Mater. Sci. Mater. Med., vol. 20, no. 8, pp. 1611-1618, 2009.

[269] V. Aina, G. Malavasi, A. Fiorio Pla, L. Munaron, and C. Morterra, "Zinc-containing bioactive glasses: Surface reactivity and behaviour towards endothelial cells," Acta Biomater., vol. 5, no. 4, pp. 1211-1222, May 2009.

[270] D. Sriranganathan, N. Kanwal, K. A. Hing, and R. G. Hill, "Strontium substituted bioactive glasses for tissue engineered scaffolds: the importance of octacalcium phosphate," J. Mater. Sci. Mater. Med., vol. 27, no. 2, p. 39, Dec. 2015.

[271] G. C. Vale, C. P. M. Tabchoury, A. A. Del Bel Cury, L. M. A. Tenuta, J. M. ten Cate, and J. A. Cury, "APF and Dentifrice Effect on Root Dentin Demineralization and Biofilm," J. Dent. Res., vol. 90, no. 1, pp. 77-81, 2011.

[272] C. Zantner, N. Beheim-Schwarzbach, K. Neumann, and A. M. Kielbassa, "Surface microhardness of enamel after different home bleaching procedures," Dent. Mater., vol. 23, no. 2, pp. 243-250, 2007.

[273] H.-P. Chen, C.-H. Chang, J.-K. Liu, S.-F. Chuang, and J.-Y. Yang, "Effect of fluoride containing bleaching agents on enamel surface properties," J. Dent., vol. 36, no. 9, pp. 718-725, 2008. 